\title{
A Catalytic Asymmetric Bioorganic Route to Enantioenriched Tetrahydro- and Dihydropyranones
}

\author{
Charles Baker-Glenn ${ }^{\mathrm{a}, \mathrm{b}}$, Neil Hodnett ${ }^{\mathrm{a}, \mathrm{b}}$, Maud Reiter ${ }^{\mathrm{a}}$, Sandrine Ropp ${ }^{\mathrm{a}}$, Rachael Ancliff ${ }^{\mathrm{c}}$ \\ and Veronique Gouverneur ${ }^{\mathrm{a} *}$ \\ ${ }^{a}$ Chemistry Research Laboratory, University of Oxford, Mansfield Road, Oxford, OX1 3TA \\ (UK); ${ }^{\mathrm{b}}$ These two authors have contributed equally to this paper; ${ }^{\mathrm{c}}$ GlaxoSmithKline Medicines \\ Research Centre, Gunnels Wood Road, SG1 2NY, Stevenage (UK)
}

\section{SUPPORTING INFORMATION}

General: Melting points were determined in a capillary and are uncorrected. NMR spectra were recorded on a Bruker DPX-400, a Bruker AVANCE AV400, a Bruker DPX-500 or a Bruker AMX-500 spectrometer. The experiments were performed at $400 \mathrm{MHz}$ for ${ }^{1} \mathrm{H}$ and $100 \mathrm{MHz}$ for ${ }^{13} \mathrm{C}$, except where otherwise specified. Chemical shifts $(\delta)$ are reported in parts per million (ppm) from tetramethylsilane with the undeuterated solvent resonance as the internal standard. IR spectra were recorded on a Perkin-Elmer Paragon 1000 FT-IR spectrometer. Selected absorption bands are reported in wavenumbers $\left(\mathrm{cm}^{-1}\right)$. Mass spectra $(\mathrm{m} / \mathrm{z})$ and HRMS were recorded on a Micromass GCT in Chemical Ionization $\left(\mathrm{NH}_{3}, \mathrm{CI}\right)$, Electron Impact $\left(\mathrm{EI}^{+}\right)$or Field Ionization (FI) mode or on a Micromass AutoSpec $\left(\mathrm{CI}^{+}\right)$. Optical rotations were determined on a Perkin-Elmer 241 polarimeter in a $1 \mathrm{dm}$ cell. Concentrations are given in $\mathrm{g} / 100 \mathrm{ml}$. Microanalyses were performed by 'Elemental Microanalysis Limited', Devon. Thin layer chromatography (TLC) was performed using Merck aluminium foil backed sheets pre-coated with Kieselgel $60 \mathrm{~F}_{254}$. Column chromatography refers to chromatography on Merck Silica gel C60 $(40-60 \mu \mathrm{m})$. Biphasic antibody-catalyzed reactions were carried out in Oak Ridge Teflon ${ }^{\circledR}$ centrifuge tubes $(10$ or $30 \mathrm{ml}$ ) and agitated in a Nickel Electro NE5-28 shaking bath at room temperature.

\section{Preparation of $\beta$-hydroxyenones $( \pm)-1 a-l$}

General procedure: To a solution of lithium di-isopropylamide [prepared by dropwise addition of $n$-butyllithium $(5.6 \mathrm{ml}, 11.2 \mathrm{mmol})$ to a solution of di-isopropylamine $(1.65 \mathrm{ml}, 11.3 \mathrm{mmol})$ in $\operatorname{dry} \operatorname{THF}(15 \mathrm{ml})$ at $\left.0{ }^{\circ} \mathrm{C}\right]$ at $-78{ }^{\circ} \mathrm{C}$ was added the enone $(1.32 \mathrm{ml}, 11.3 \mathrm{mmol})$ in dry THF $(7.5 \mathrm{ml})$ via cannula. The reaction was allowed to stir at $-78{ }^{\circ} \mathrm{C}$ for $30 \mathrm{~min}$ for aldols $\mathbf{1 a}, 20 \mathrm{~min}$ for aldols $\mathbf{1 f}, \mathbf{g}$ and $\mathbf{j}$ or $15 \mathrm{~min}$ for aldol 
1b, 1c, 1e, 1i and 1l. The aldehyde (1.22 g, $7.5 \mathrm{mmol})$ in dry THF $(7.5 \mathrm{ml})$ was then added via cannula, and the mixture allowed to stir at $-78{ }^{\circ} \mathrm{C}$ for $15 \mathrm{~min}$ for aldols $1 \mathrm{a}$ 11. The reaction was quenched by the addition of saturated aqueous ammonium chloride $(50 \mathrm{ml})$ and allowed to warm to room temperature. The aqueous layer was extracted with ethyl acetate $(3 \times 50 \mathrm{ml})$. The combined organic fractions were dried $\left(\mathrm{MgSO}_{4}\right)$, filtered under suction and the solvent removed in vacuo. The residue was then purified by column chromatography to yield the desired $\beta$-hydroxyenone.

\section{(E)-1-Hydroxy-1-(4-methoxyphenyl)-hex-4-en-3-one 1a}<smiles>C/C=C/C(=O)CC(O)c1ccc(OC)cc1</smiles>

Prepared from 3-penten-2-one (2.80 g, $33.2 \mathrm{mmol})$ and anisaldehyde (3.02 g, 22.2 mmol) according to the general procedure. The crude product was purified by column chromatography on silica (hexane:ethyl acetate $9: 1$ to $2: 1)$ to yield $\mathbf{1 a}(3.22 \mathrm{~g}, 66 \%)$ as a pale yellow solid $\left(\mathrm{mp} 35.5-36.5^{\circ} \mathrm{C}\right) ; \mathrm{R}_{\mathrm{f}}$ (hexane:ethyl acetate, $\left.1: 1\right)=0.34 ; \delta 1_{\mathrm{H}}$ $\left(\mathrm{CDCl}_{3}\right) 1.92(3 \mathrm{H}, \mathrm{dd}, J=6.9,1.6 \mathrm{~Hz}), 2.91(1 \mathrm{H}, \mathrm{dd}, J=16.0,4.4 \mathrm{~Hz}), 2.95(1 \mathrm{H}, \mathrm{dd}$, $J=16.0,8.0 \mathrm{~Hz}), 3.52(1 \mathrm{H}$, br d, $J=2.7 \mathrm{~Hz}), 3.81(3 \mathrm{H}, \mathrm{s}), 5.08-5.21(1 \mathrm{H}, \mathrm{m}), 6.14$ $(1 \mathrm{H}, \mathrm{dq}, J=15.8,1.6 \mathrm{~Hz}), 6.84-6.94(3 \mathrm{H}, \mathrm{m}), 7.31(2 \mathrm{H}, \mathrm{d}, J=8.7 \mathrm{~Hz}, \mathrm{~m}) ; \delta_{13 \mathrm{C}}$ $\left(\mathrm{CDCl}_{3}\right)$ 18.4, 48.0, 55.3, 69.7, 113.9 (2C), 126.9 (2C), 132.1, 135.2, 144.4, 159.0, $200.3 ; v_{\max }\left(\mathrm{CHCl}_{3}\right) 3513,3019,2400,1686,1662,1628,1614,1515,1442,1250$, 1222 and 1036; $\mathrm{m} / \mathrm{z}\left(\mathrm{HRMS}, \mathrm{ESI}^{-}\right)$found $219.1024\left([\mathrm{M}-\mathrm{H}]^{-}\right), \mathrm{C}_{13} \mathrm{H}_{15} \mathrm{O}_{3}$ requires 219.1021 .

\section{(E)-1-Hydroxy-1-(4-methoxyphenyl)-hept-4-en-3-one 1b}<smiles>CCC=CC(=O)CC(O)c1ccc(OC)cc1</smiles>

Prepared from anisaldehyde $(0.19 \mathrm{ml}, 1.53 \mathrm{mmol})$ and hex-3-en-2-one $(0.21 \mathrm{~g}, 2.14$ $\mathrm{mmol}$ ) according to the general procedure. The crude product was purified by column chromatography on silica (hexane:ethyl acetate $3: 1)$ to yield $\mathbf{1 b}(0.2 \mathrm{~g}, 0.86 \mathrm{mmol}$, $56 \%)$ as a colourless oil. $\mathrm{R}_{\mathrm{f}}$ (hexane:ethyl acetate, $\left.1: 1\right)=0.35 ; \delta_{1_{\mathrm{H}}}\left(\mathrm{CDCl}_{3}\right) 1.02(3 \mathrm{H}$, $\mathrm{t}, J=7.3 \mathrm{~Hz}), 2.27(2 \mathrm{H}, \mathrm{q}, J=7.3 \mathrm{~Hz}), 2.94(1 \mathrm{H}, \mathrm{s}), 2.96(1 \mathrm{H}, \mathrm{d}, J=2.5 \mathrm{~Hz}), 3.53$ $\left(1 \mathrm{H}, \mathrm{d},{ }^{3} J=2.8 \mathrm{~Hz}\right), 3.82(3 \mathrm{H}, \mathrm{s}), 5.13-5.18(1 \mathrm{H}, \mathrm{m}), 6.11\left(1 \mathrm{H}, \mathrm{dt},{ }^{3} J=15.9,1.8 \mathrm{~Hz}\right)$, 6.88-6.91 (2H, m), $6.94\left(1 \mathrm{H}, \mathrm{dt},{ }^{3} J=15.9,7.1 \mathrm{~Hz}\right), 7.31-7.34(2 \mathrm{H}, \mathrm{m}) ; \delta_{13 \mathrm{C}}\left(\mathrm{CDCl}_{3}\right) \delta$ $12.1,25.6,48.0,55.3,69.7,113.8,127.0,130.6,138.0,150.6,159.0,200.7 ; v_{\max }$ (neat) $3451,2968,2837,1614,1514,1462,1303,1249,1176,1110,1034 ; \mathrm{m} / z$ (HRMS, FI) found $234.1244\left(\left[\mathrm{M}^{\circ}\right]\right), \mathrm{C}_{14} \mathrm{H}_{18} \mathrm{O}_{3}$ requires 234.1256.

\section{(E)-1-Hydroxy-1-(4-methoxyphenyl)-oct-4-en-3-one 1c}<smiles>CCC/C=C/C(=O)CC(O)c1ccc(OC)cc1</smiles> 
Prepared from anisaldehyde $(0.45 \mathrm{ml}, 3.73 \mathrm{mmol})$ and 3-hepten-2-one $(0.73 \mathrm{ml}, 5.6$ $\mathrm{mmol}$ ) according to the general procedure. The crude product was purified by column chromatography on silica (hexane:ethyl acetate 3:1) to yield 1c $(0.65 \mathrm{~g}, 2.62 \mathrm{mmol}$, $71 \%)$ as a colourless oil. $\mathrm{R}_{\mathrm{f}}$ (hexane:ethyl acetate, $\left.1: 1\right)=0.43 ; \delta_{1_{\mathrm{H}}}\left(\mathrm{CDCl}_{3}\right) 0.92(3 \mathrm{H}$, $\left.\mathrm{t},{ }^{3} \mathrm{~J}=7.6 \mathrm{~Hz}\right), 1.50\left(2 \mathrm{H}, \mathrm{h},{ }^{3} J=7.6 \mathrm{~Hz}\right), 2.20\left(2 \mathrm{H}, \mathrm{q},{ }^{3} J=7.1 \mathrm{~Hz}\right), 2.92(1 \mathrm{H}, \mathrm{s}), 2.96$ $\left(1 \mathrm{H}, \mathrm{d},{ }^{3} J=3.0 \mathrm{~Hz}\right), 3.54(1 \mathrm{H}, \mathrm{bs}), 3.81(3 \mathrm{H}, \mathrm{s}), 5.13-5.18(1 \mathrm{H}, \mathrm{m}), 6.11\left(1 \mathrm{H}, \mathrm{dt},{ }^{3} J=\right.$ $15.9,1.5 \mathrm{~Hz}), 6.87\left(1 \mathrm{H}, \mathrm{dt},{ }^{3} J=15.9,7.1 \mathrm{~Hz}\right), 6.89\left(2 \mathrm{H}, \mathrm{d},{ }^{3} J=8.4 \mathrm{~Hz}\right), 7.34(2 \mathrm{H}, \mathrm{d}$, $\left.{ }^{3} J=8.4 \mathrm{~Hz}\right) ; \delta_{13 \mathrm{C}}\left(\mathrm{CDCl}_{3}\right) 13.7,21.2,34.5,48.1,55.3,69.7,113.8,127.0,130.6$, 135.1, 149.1, 159.0, 200.6; $v_{\max }$ (neat) 3456, 2961, 2934, 1662, 1615, 1514, 1464, $1303,1249,1176,1036 ; \mathrm{m} / z$ (HRMS, FI) found $248.1412\left(\left(\left[\mathrm{M}^{*}\right]\right), \mathrm{C}_{15} \mathrm{H}_{20} \mathrm{O}_{3}\right.$ 248.1412 .

\section{(E)-1-Hydroxy-1-(4-methoxyphenyl)-pentadec-4-en-3-one 1d}<smiles>COc1ccc(C(O)CC(=O)/C=C/C(C)C)cc1</smiles>

To a Schlenk tube containing a solution of $\mathbf{1 a}(200 \mathrm{mg}, 0.91 \mathrm{mmol})$ and 1-dodecene $(600 \mu \mathrm{l}, 2.72 \mathrm{mmol})$ in anhydrous dichloromethane $(3 \mathrm{ml}$, EtOH free) was added Hoveyda-Grubbs catalyst $(30 \mathrm{mg}, 0.048 \mathrm{mmol}$ ) at room temperature. The reaction was stirred under an argon atmosphere for $16 \mathrm{~h}$ and then concentrated under reduced pressure to afford a dark brown oil. The reaction mixture was purified by column chromatography (hexane:ethyl acetate, $2: 1)$ to yield $\mathbf{1 d ~}(240 \mathrm{mg}, 77 \%)$ as a brown oil; $\mathrm{R}_{\mathrm{f}}$ (hexane:ethyl acetate, $\left.1: 1\right)=0.59 ; \delta_{\mathrm{H}_{\mathrm{H}}}\left(\mathrm{CDCl}_{3}\right) 0.89(3 \mathrm{H}, \mathrm{dd}, J=7.1,6.5 \mathrm{~Hz})$, 1.23-1.35 (14H, m), 1.38-1.51 (2H, m), 2.18-2.26 (2H, m), 2.90-3.01 (2H, m), 3.54 $(1 \mathrm{H}, \mathrm{d}, J 2.8), 3.81(3 \mathrm{H}, \mathrm{s}), 5.12-5.18(1 \mathrm{H}, \mathrm{m}), 6.10(1 \mathrm{H}, \mathrm{dt}, J=16.0,1.4 \mathrm{~Hz}), 6.85$ $(1 \mathrm{H}, \mathrm{dt}, J=16.0,7.0 \mathrm{~Hz}), 6.90(2 \mathrm{H}, \mathrm{d}, J=8.6), 7.32(2 \mathrm{H}, \mathrm{d}, J 8.6) ; \delta_{13 \mathrm{C}}\left(\mathrm{CDCl}_{3}\right) 14.1$, 22.7, 28.0, 29.2, 29.3, 29.3, 29.5, 29.5, 31.9, 32.6, 48.0, 55.3, 69.7, 113.8 (2C), 126.9 (2C), 130.5, 135.1, 149.5, 159.0; $v_{\max }$ (neat) 3454, 2926, 2854, 1660, 1514, 1465, $1248,1175,1037$.

\section{(E)-8-Furan-2-yl-6-hydroxy-2-methyl-octa-2,7-dien-4-one 1e}<smiles>CC(C)=CC(=O)CC(O)C=Cc1ccco1</smiles>

Synthesized from 3-furan-2-yl-propionaldehyde (1.22 g, $10 \mathrm{mmol})$ and mesityl oxide $(1.75 \mathrm{ml}, 15 \mathrm{mmol})$ according to the general procedure. Purification by column chromatography (hexane:ethyl acetate, $5: 1)$ afforded $1 \mathrm{e}(1.62 \mathrm{~g}, 74 \%)$ as an unstable oil; $\mathrm{R}_{\mathrm{f}}$ (hexane:ethyl acetate, $\left.1: 1\right)=0.39 ; \delta_{1 \mathrm{H}}\left(\mathrm{CDCl}_{3}\right) 1.85(3 \mathrm{H}, \mathrm{d}, J=1.2 \mathrm{~Hz}), 2.12$ $(3 \mathrm{H}, \mathrm{d}, J=1.2 \mathrm{~Hz}), 2.63(1 \mathrm{H}, \mathrm{dd}, J=17.1,8.0 \mathrm{~Hz}), 2.67(1 \mathrm{H}, \mathrm{dd}, J=17.1,4.4 \mathrm{~Hz})$, $3.69(1 \mathrm{H}, \mathrm{br} \mathrm{s}), 4.66-4.73(1 \mathrm{H}, \mathrm{m}), 6.02(1 \mathrm{H}, \mathrm{m}), 6.11(1 \mathrm{H}, \mathrm{dd}, J=15.8,5.8 \mathrm{~Hz}), 6.17$ $(1 \mathrm{H}, \mathrm{d}, J=3.2 \mathrm{~Hz}), 6.30(1 \mathrm{H}, \mathrm{dd}, J=3.4,2.0 \mathrm{~Hz}), 6.43(1 \mathrm{H}, \mathrm{d}, J=15.6 \mathrm{~Hz}), 7.28$ $(1 \mathrm{H}, \mathrm{d}, J=2.0 \mathrm{~Hz}) ; \delta_{13 \mathrm{C}}\left(\mathrm{CDCl}_{3}\right) 21.0,27.7,50.1,68.2,108.0,111.2,118.1,123.8$, 129.3, 141.8, 152.3, 157.3, 200.2; $v_{\max }\left(\mathrm{CHCl}_{3}\right) 3428.4,1681.8,1614.0 ; \mathrm{m} / \mathrm{z}$ (HRMS, GCT, FI) found $220.1099\left(\mathrm{M}^{+}\right), \mathrm{C}_{13} \mathrm{H}_{16} \mathrm{O}_{3}$ requires 220.1099 .

\section{6-Hydroxy-7-(4-methoxyphenyl)-2-methyl-hept-2-en-4-one 1f}


$\mathrm{MeO}$<smiles>CC(C)=CC(=O)CC(O)Cc1ccc(C)cc1</smiles>

Synthesized from mesityl oxide $(0.35 \mathrm{ml}, 3 \mathrm{mmol})$ and 4-methoxyphenylacetaldehyde ${ }^{\dagger}$ (300 mg, $2 \mathrm{mmol}$ ) using the procedure described above. Purification by column chromatography (hexane:ethyl acetate, 4:1) yielded the product (298 mg, $60 \%)$ as an oil; $\mathrm{R}_{\mathrm{f}}$ (hexane:ethyl acetate, $\left.4: 1\right)=0.28 ; \delta_{1_{\mathrm{H}}}\left(\mathrm{CDCl}_{3}\right) 1.89(3 \mathrm{H}, \mathrm{s}), 2.15$ $(3 \mathrm{H}, \mathrm{s}), 2.51(1 \mathrm{H}, \mathrm{dd}, J=17.3,8.8 \mathrm{~Hz}), 2.60(1 \mathrm{H}, \mathrm{dd}, J=17.3,2.8 \mathrm{~Hz}), 2.68(1 \mathrm{H}, \mathrm{dd}$, $J=13.7,6.8 \mathrm{~Hz}), 2.82(1 \mathrm{H}, \mathrm{dd}, J=13.7 \mathrm{~Hz}), 3.34(1 \mathrm{H}, \mathrm{br} \mathrm{s}) 3.80(3 \mathrm{H}, \mathrm{s}), 4.22-4.31$ $(1 \mathrm{H}, \mathrm{m}), 6.02(1 \mathrm{H}, \mathrm{s}), 6.85(2 \mathrm{H}, \mathrm{d}, J=8.6 \mathrm{~Hz}), 7.14(2 \mathrm{H}, \mathrm{d}, J=8.6 \mathrm{~Hz}) ; \delta_{13 \mathrm{C}}\left(\mathrm{CDCl}_{3}\right)$ 20.9, 27.7, 42.09, 49.1, 55.1, 69.2, 113.8 (2C), 123.8, 130.1, 130.4 (2C), 156.7, 158.2, $200.9 ; v_{\max }$ (neat) $3465,1681,1613 ; \mathrm{m} / z$ (HRMS, GCT, FI) found 248.1405 ([M]), $\mathrm{C}_{15} \mathrm{H}_{20} \mathrm{O}_{3}$ requires 248.1412 .

\section{6-Hydroxy-2-methyl-8-phenyl-oct-2-en-4-one $1 \mathrm{~g}$}<smiles>CC(C)=CC(=O)CC(O)CCc1ccccc1</smiles>

Synthesized from mesityl oxide $(4.4 \mathrm{ml}, 37.5 \mathrm{mmol})$ and 3-phenylpropionaldehyde ( $3.3 \mathrm{ml}, 25 \mathrm{mmol})$ using the procedure described above. Purification by column chromatography (hexane:ethyl acetate, 4:1) yielded the product $(5.07 \mathrm{~g}, 87 \%)$ as a colorless oil; $\mathrm{R}_{\mathrm{f}}$ (hexane:ethyl acetate, $\left.1: 1\right)=0.48 ; \delta_{1_{\mathrm{H}}}\left(\mathrm{CDCl}_{3}\right) 1.65-1.90(2 \mathrm{H}, \mathrm{m})$, $1.91(3 \mathrm{H}, \mathrm{d}, J=0.8 \mathrm{~Hz}), 2.17(3 \mathrm{H}, \mathrm{s}), 2.55(1 \mathrm{H}, \mathrm{d}, J=12.4,8.8 \mathrm{~Hz}), 2.62(1 \mathrm{H}, \mathrm{d}, J=$ $12.4,2.8 \mathrm{~Hz}), 2.71(1 \mathrm{H}, \mathrm{ddd}, J=6.8,13.8,9.6 \mathrm{~Hz}), 2.83(1 \mathrm{H}, \mathrm{ddd}, J=4.8,13.8,9.4$ $\mathrm{Hz}), 3.50(1 \mathrm{H}$, br s $), 4.04-4.13(1 \mathrm{H}, \mathrm{m}), 6.03-6.06(1 \mathrm{H}, \mathrm{m}), 7.16-7.32(5 \mathrm{H}, \mathrm{m}) ; \delta_{13 \mathrm{C}}$ $\left(\mathrm{CDCl}_{3}\right)$ 20.9, 27.8, 31.8, 38.1, 50.0, 67.2, 123.8, 125.8, 128.4 (2C), 128.5 (2C), 142.0, 157.1, 201.4; $v_{\max }$ (neat) 3344, 1674, 1614; m/z (HRMS, GCT, FI) found $232.1463\left(\left[\mathrm{M}^{\circ}\right]\right), \mathrm{C}_{15} \mathrm{H}_{20} \mathrm{O}_{2}$ requires 232.1463.

\section{6-Hydroxy-8-(4-methoxyphenyl)-2-methyl-octa-2,7-dien-4-one $1 \mathrm{~h}$}<smiles>COc1ccc(/C=C/C(O)CC(=O)C=C(C)C)cc1</smiles>

Synthesized from mesityl oxide $(1.32 \mathrm{ml}, 11.3 \mathrm{mmol})$ and 4-methoxycinnamaldehyde (1.22 g, 7.5mmol) using the procedure described above. Purification by column chromatography (hexane:ethyl acetate, $4: 1)$ yielded the product $(1.24 \mathrm{~g}, 64 \%)$ as a yellow oil; $\mathrm{R}_{\mathrm{f}}$ (hexane:ethyl acetate, $\left.1: 1\right)=0.49 ; \delta_{1_{\mathrm{H}}}\left(\mathrm{CDCl}_{3}\right) 1.92(3 \mathrm{H}, \mathrm{d}, J=1.2 \mathrm{~Hz})$, $2.19(3 \mathrm{H}, \mathrm{d}, J=0.8 \mathrm{~Hz}), 2.71(1 \mathrm{H}, \mathrm{dd}, J=17.2,8.4 \mathrm{~Hz}), 2.76(1 \mathrm{H}, \mathrm{dd}, J=17.2,4.0$ $\mathrm{Hz}), 3.48(1 \mathrm{H}, \mathrm{br} \mathrm{s}), 3.80(3 \mathrm{H}, \mathrm{s}), 4.72-4.78(1 \mathrm{H}, \mathrm{m}), 6.06-6.09(1 \mathrm{H}, \mathrm{m}), 6.09(1 \mathrm{H}$, $\mathrm{dd}, J=6.8,16.4 \mathrm{~Hz}), 6.58(1 \mathrm{H}, \mathrm{d}, J=16 \mathrm{~Hz}), 6.85(2 \mathrm{H}, \mathrm{d}, J=8.8 \mathrm{~Hz}), 7.32(2 \mathrm{H}, \mathrm{d}, J$ $=8.8 \mathrm{~Hz}) ; \delta_{13 \mathrm{C}}\left(\mathrm{CDCl}_{3}\right)$ 21.0, 27.9, 50.1, 55.3, 69.0, $113.9(2 \mathrm{C}), 123.8,127.6(2 \mathrm{C})$, $128.2,129.4,129.7,157.4,159.2,200.0 ; v_{\max }$ (neat) 3432, 1682, 1614; $\mathrm{m} / z$ (HRMS, FI) found $260.1417\left(\left[\mathrm{M}^{*}\right]\right), \mathrm{C}_{16} \mathrm{H}_{20} \mathrm{O}_{3}$ requires 260.1412 .

\section{(E)-1-Hydroxy-1-(6-methoxynaphthalen-2-yl)-hex-4-en-3-one 1i}

\footnotetext{
${ }^{\dagger}$ For the preparation of (4-methoxyphenyl)-acetaldehyde, see A. Harris, Chem. Ber. 1916, 1032.
} 
<smiles>C/C=C/C(=O)CC(O)c1ccc2cc(OC)ccc2c1</smiles>

Prepared from 3-penten-2-one (1.1 g, $11.2 \mathrm{mmol})$ and 6-methoxy-2-naphthaldehyde $(1.4 \mathrm{~g}, 7.5 \mathrm{mmol})$ according to the general procedure. The crude product was purified by column chromatography on silica (hexane:ethyl acetate, 5:1 to 2:1) to yield $\mathbf{1 i}$ $(1.32 \mathrm{~g}, 65 \%)$ as a colorless solid $\left(\mathrm{mp} 66.5-67.5^{\circ} \mathrm{C}\right) ; \mathrm{R}_{\mathrm{f}}$ (hexane:ethyl acetate, $\left.1: 1\right)=$ $0.35 ; \delta_{1_{\mathrm{H}}}\left(\mathrm{CDCl}_{3}\right) 1.88(3 \mathrm{H}, \mathrm{dd}, J=6.9,1.6 \mathrm{~Hz}), 2.98(1 \mathrm{H}, \mathrm{dd}, J=16.4,4.0 \mathrm{~Hz}), 3.02$ $(1 \mathrm{H}, \mathrm{dd}, J=16.4,8.4), 3.81(1 \mathrm{H}, \mathrm{br} \mathrm{s}), 3.90(3 \mathrm{H}, \mathrm{s}), 5.28-5.35(1 \mathrm{H}, \mathrm{m}), 6.13(1 \mathrm{H}, \mathrm{dq}$, $J=15.8,1.6), 6.87(1 \mathrm{H}, \mathrm{dq}, J=15.8,6.9), 7.12(1 \mathrm{H}, \mathrm{br} \mathrm{d}, J=2.5), 7.15(1 \mathrm{H}, \mathrm{dd}, J=$ 8.8, 2.5), $7.44(1 \mathrm{H}, \mathrm{dd}, J=8.5,1.7), 7.71(1 \mathrm{H}, \mathrm{d}, J=8.8), 7.72(1 \mathrm{H}, \mathrm{d}, J=8.5), 7.75$ $(1 \mathrm{H}$, br s$) ; \delta_{13 \mathrm{C}}\left(\mathrm{CDCl}_{3}\right) 18.4,48.0,55.3,70.1,105.6,118.9,124.3,124.5,127.1$, 128.7, 129.5, 132.1, 134.0, 138.2, 144.6, 157.6, 200.2; $\mathrm{m} / \mathrm{z}\left(\mathrm{HRMS}_{\mathrm{K}} \mathrm{ESI}^{+}\right)$found $293.1162\left([\mathrm{M}+\mathrm{Na}]^{+}\right), \mathrm{C}_{17} \mathrm{H}_{18} \mathrm{O}_{3}$ requires 293.1154 .

\section{(E,E)-6-Hydroxy-8-(4-methoxyphenyl)-octa-2,7-dien-4-one 1j}<smiles>C/C=C/C(=O)CC(O)/C=C/c1ccc(OC)cc1</smiles>

Synthesized from pent-3-en-2-one $(0.29 \mathrm{ml}, 3 \mathrm{mmol})$ and 4-methoxycinnamaldehyde (325 mg, $1.5 \mathrm{mmol}$ ) using the procedure described above. Purification by column chromatography (hexane:ethyl acetate, 1:1) yielded the product $(334 \mathrm{mg}, 68 \%$ ) as a yellow solid $\left(\mathrm{mp} 43-44^{\circ} \mathrm{C}\right) ; \mathrm{R}_{\mathrm{f}}$ (hexane:ethyl acetate, $\left.1: 1\right)=0.27 ; \delta_{1_{\mathrm{H}}}\left(\mathrm{CDCl}_{3}\right) 1.93$ $(3 \mathrm{H}, \mathrm{dd}, J=1.5,6.5 \mathrm{~Hz}, 2.84(1 \mathrm{H}, \mathrm{dd}, J=17.2,8.0 \mathrm{~Hz}), 2.87(1 \mathrm{H}, \mathrm{dd}, J=17.2,4.0$ $\mathrm{Hz}), 3.36(1 \mathrm{H}, \mathrm{d}, J=3.5 \mathrm{~Hz}), 3.81(3 \mathrm{H}, \mathrm{s}), 4.74-4.81(1 \mathrm{H}, \mathrm{m}), 6.10(1 \mathrm{H}, \mathrm{dd}, J=6.2$, $16.0 \mathrm{~Hz}), 6.15(1 \mathrm{H}, \mathrm{dqt}, J=1.5,16.0 \mathrm{~Hz}), 6.59(1 \mathrm{H}, \mathrm{d}, J=16.0 \mathrm{~Hz}), 6.85(2 \mathrm{H}, \mathrm{d}, J=$ $9.0 \mathrm{~Hz}), 6.92(1 \mathrm{H}, \mathrm{dq}, J=6.5,16.0 \mathrm{~Hz}), 7.32(2 \mathrm{H}, \mathrm{d}, J=9.0 \mathrm{~Hz}) ; \delta_{1_{3} \mathrm{C}}\left(\mathrm{CDCl}_{3}\right) 18.4$, 46.9, 55.2, 68.8, 113.9 (2C), 127.6 (2C), 128.0, 129.3, 129.8, 132.2, 144.3, 159.3, 200.2; $v_{\max }$ (neat) $3435,1659,1607 ; \mathrm{m} / \mathrm{z}$ (HRMS, FI) found 246.1254 ([Mं]), $\mathrm{C}_{15} \mathrm{H}_{18} \mathrm{O}_{3}$ requires 246.1256 .

\section{(E,E)-5-Hydroxy-1-methoxy-7-(4-methoxyphenyl)-hepta-1,6-dien-3-one 1k}<smiles>CO/C=C/C(=O)CC(O)/C=C/c1ccc(OC)cc1</smiles>

To di-isopropylamine $(0.95 \mathrm{ml}, 6.75 \mathrm{mmol})$ in dry THF $(15 \mathrm{ml})$ in an ice bath was added n-butyllithium $(3.2 \mathrm{ml}, 6.75 \mathrm{mmol})$ under argon. The mixture was allowed to stir in the ice bath for $30 \mathrm{~min}$. The reaction was then cooled to $-78^{\circ} \mathrm{C}$ and HMPA $(1.5$ $\mathrm{ml})$ followed by 4-methoxy-but-3-en-2-one $(0.87 \mathrm{ml}, 8.53 \mathrm{mmol})$ were then added. The reaction was allowed to stir at $-78{ }^{\circ} \mathrm{C}$ for $2 \mathrm{~h}$. To this was added paramethoxycinnamaldehyde $(811 \mathrm{mg}, 5 \mathrm{mmol})$ in dry THF $(15 \mathrm{ml})$ via cannula, and the mixture allowed to stir for $1 \mathrm{~h}$ at $-78{ }^{\circ} \mathrm{C}$. The reaction was then quenched with buffer (25 $\mathrm{ml}$ of buffer containing $2.5 \mathrm{~g}$ of $\mathrm{NaH}_{2} \mathrm{PO}_{4}$ and the $\mathrm{pH}$ adjusted to $\mathrm{pH} 7$ with $\mathrm{NaOH})$ and allowed to warm to room temperature. The aqueous layer was extracted with ethyl acetate $(3 \times 25 \mathrm{ml})$. The organic fractions were combined, dried $\left(\mathrm{MgSO}_{4}\right)$, filtered under suction and the solvent removed in vacuo. Purification by column 
chromatography (hexane:ethyl acetate, 1:1) to yield the product (807 $\mathrm{mg}, 63 \%)$ as a yellow solid (mp $\left.72-73{ }^{\circ} \mathrm{C}\right) ; \mathrm{R}_{\mathrm{f}}$ (hexane:ethyl acetate, 1:1) $=0.22 ; \delta_{1_{\mathrm{H}}}\left(\mathrm{CDCl}_{3}\right) 2.76$ $(1 \mathrm{H}, \mathrm{dd}, J=17.3,8.0 \mathrm{~Hz}), 2.80(1 \mathrm{H}, \mathrm{dd}, J=17.3,3.6 \mathrm{~Hz}), 3.51(1 \mathrm{H}, \mathrm{d}, J=2.8 \mathrm{~Hz})$, $3.74(3 \mathrm{H}, \mathrm{s}), 3.82(3 \mathrm{H}, \mathrm{s}), 4.73-4.81(1 \mathrm{H}, \mathrm{m}), 5.62(1 \mathrm{H}, \mathrm{d}, J=12.8 \mathrm{~Hz}), 6.10(1 \mathrm{H}, \mathrm{dd}$, $J=6.2,16 \mathrm{~Hz}), 6.60(1 \mathrm{H}, \mathrm{d}, J=16.0 \mathrm{~Hz}), 6.86(2 \mathrm{H}, \mathrm{d}, J=8.6 \mathrm{~Hz}), 7.32(2 \mathrm{H}, \mathrm{d}, J=$ $8.6 \mathrm{~Hz}), 7.66(1 \mathrm{H}, \mathrm{d}, J=12.8 \mathrm{~Hz}) ; \delta_{13 \mathrm{C}}\left(\mathrm{CDCl}_{3}\right) 47.0,55.2,57.7,105.9,113.9(2 \mathrm{C})$, 127.6 (2C), 128.2, 129.4, 129.8, 159.3, 163.6, 199.7; $v_{\max }$ (neat) 3480, 1621, 1589; $\mathrm{m} / z$ (HRMS, GCT, FI) $262.1168\left(\left[\mathrm{M}^{*}\right]\right), \mathrm{C}_{15} \mathrm{H}_{18} \mathrm{O}_{4}$ requires 262.1205.

\section{(E)-5-Hydroxy-7-(4-methoxyphenyl)-hepta-1,6-dien-3-one 11}<smiles>C=CC(=O)CC(O)/C=C/c1ccc(OC)cc1</smiles>

Synthesized from methyl vinyl ketone $(0.62 \mathrm{ml}, 7.5 \mathrm{mmol})$ and 4methoxycinnamaldehyde $(811 \mathrm{mg}, 5 \mathrm{mmol})$ according to the general procedure. Purification by column chromatography (hexane:ethyl acetate, 4:1) yielded the product (314 $\mathrm{mg}, 27 \%)$ as a yellow oil; $\mathrm{R}_{\mathrm{f}}$ (hexane:ethyl acetate, $\left.1: 1\right)=0.27 ; \delta_{1_{\mathrm{H}}}$ $\left(\mathrm{CDCl}_{3}\right) 2.92(2 \mathrm{H}, \mathrm{d}, J=6.4 \mathrm{~Hz}), 3.14(1 \mathrm{H}, \mathrm{br} \mathrm{s}), 3.81(3 \mathrm{H}, \mathrm{s}), 4.80(1 \mathrm{H}, \mathrm{dt}, J=6.4$, $6.0 \mathrm{~Hz}), 5.93(1 \mathrm{H}, \mathrm{dd}, J=0.8,10.0 \mathrm{~Hz}), 6.11(1 \mathrm{H}, \mathrm{dd}, J=15.8,6.0 \mathrm{~Hz}), 6.27(1 \mathrm{H}, \mathrm{dd}$, $J=0.8,17.4 \mathrm{~Hz}), 6.39(1 \mathrm{H}, \mathrm{dd}, J=17.4,10.2 \mathrm{~Hz}), 6.60(1 \mathrm{H}, \mathrm{d}, J=15.6 \mathrm{~Hz}), 6.85$ $(2 \mathrm{H}, \mathrm{d}, J=6.4 \mathrm{~Hz}), 7.32(2 \mathrm{H}, \mathrm{d}, J=6.4 \mathrm{~Hz}) ; \delta_{13 \mathrm{C}}\left(\mathrm{CDCl}_{3}\right) 45.9,55.2,68.7,114.5$ (2C), 127.7 (2C), 127.9, 129.2, 129.4, 130.0, 136.7, 159.3, 200.5; $v_{\max }$ (neat) 3438,

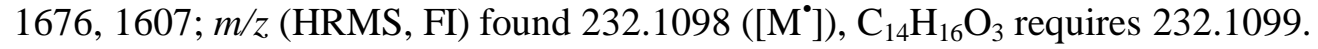




\section{Preparation of $( \pm)-2 f-h$ (racemic standards for chiral HPLC studies)}

\section{6-(4-Methoxybenzyl)-2,2-dimethyltetrahydropyran-4-one ( \pm )-2f}<smiles>COc1ccc(CC2CC(=O)CC(C)(C)O2)cc1</smiles>

To aldol ( \pm )-1f $(200 \mathrm{mg}, 0.81 \mathrm{mmol})$ in dichloromethane $(4 \mathrm{ml})$ at $-78{ }^{\circ} \mathrm{C}$ was added DIPEA $(0.02 \mathrm{ml}, 0.16 \mathrm{mmol})$ and TMSOTf $(0.04 \mathrm{ml}, 0.22 \mathrm{mmol})$. The reaction was allowed to stir at $-78^{\circ} \mathrm{C}$ for $2 \mathrm{~h}$ and then warmed to $-15^{\circ} \mathrm{C}$. The reaction was allowed to stir at $-15^{\circ} \mathrm{C}$ for $40 \mathrm{~h}$ and then quenched with $\mathrm{NaHCO}_{3(\mathrm{aq})}(5 \mathrm{ml})$. The mixture was extracted with dichloromethane $(3 \times 5 \mathrm{ml})$, the combined organic fractions dried over $\mathrm{MgSO}_{4}$, filtered under suction and the solvent removed in vacuo. Purification by column chromatography (hexane:ethyl acetate, 4:1) yielded the product (133 mg, $67 \%)$ as an oil; $\mathrm{R}_{\mathrm{f}}$ (hexane:ethyl acetate, $\left.1: 1\right)=0.55 ; \delta_{1_{\mathrm{H}}}\left(\mathrm{CDCl}_{3}\right) 1.16(3 \mathrm{H}, \mathrm{s}), 1.38$ $(3 \mathrm{H}, \mathrm{s}), 2.14-2.42(4 \mathrm{H}, \mathrm{m}), 2.73(1 \mathrm{H}, \mathrm{dd}, J=13.9,6.0 \mathrm{~Hz}), 2.95(1 \mathrm{H}, \mathrm{dd}, J=13.9,6.0$ $\mathrm{Hz}), 3.80(3 \mathrm{H}, \mathrm{s}), 3.96-4.06(1 \mathrm{H}, \mathrm{m}), 6.83(2 \mathrm{H}, \mathrm{d}, J=8.6 \mathrm{~Hz}), 7.13(2 \mathrm{H}, \mathrm{d}, J=8.6$ $\mathrm{Hz}) ; \delta_{{ }_{13 \mathrm{C}}}\left(\mathrm{CDCl}_{3}\right) 24.0,30.9,41.9,46.7,53.1,55.1,71.8,75.1,113.7$ (2C), 129.4, $130.4(2 \mathrm{C}), 161.2,208.2 ; v_{\max }$ (neat) 1717; $\mathrm{m} / z\left(\mathrm{GCT} \mathrm{CI}^{+}\right) 231\left([\mathrm{M}-\mathrm{OH}]^{+}, 29 \%\right), 249$ $\left([\mathrm{M}+\mathrm{H}]^{+}, 61 \%\right), 266\left(\left[\mathrm{M}+\mathrm{NH}_{4}\right]^{+}, 100 \%\right) ; \mathrm{m} / z\left(\mathrm{HRMS}, \mathrm{GCT}, \mathrm{CI}^{+}\right)$found 266.1760 $\left(\left[\mathrm{M}+\mathrm{NH}_{4}\right]^{+}\right), \mathrm{C}_{15} \mathrm{H}_{24} \mathrm{NO}_{3}$ requires 266.1756.

\section{2,2-Dimethyl-6-phenethyltetrahydropyran-4-one ( \pm )-2g}

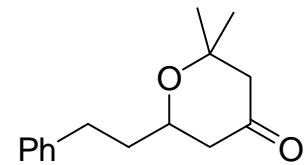

To aldol ( \pm )-19 (200 $\mathrm{mg}, 0.86 \mathrm{mmol})$ in dichloromethane $(4 \mathrm{ml})$ at $-78{ }^{\circ} \mathrm{C}$ was added DIPEA $(0.02 \mathrm{ml}, 0.16 \mathrm{mmol})$ and TMSOTf $(0.04 \mathrm{ml}, 0.22 \mathrm{mmol}){ }^{\dagger}{ }^{\dagger}$ The reaction was allowed to stir at $-78^{\circ} \mathrm{C}$ for $2 \mathrm{~h}$ and then warmed to $-20^{\circ} \mathrm{C}$. The reaction was allowed to stir at $-20{ }^{\circ} \mathrm{C}$ for $24 \mathrm{~h}$ and then quenched with saturated aqueous $\mathrm{NaHCO}_{3}(5 \mathrm{ml})$. The mixture was extracted with dichloromethane $(3 \times 5 \mathrm{ml})$, the combined organic fractions dried over $\mathrm{MgSO}_{4}$, filtered under suction and the solvent removed in vacuo. Purification by column chromatography (hexane:ethyl acetate, 4:1) yielded the product $(140 \mathrm{mg}, 70 \%)$ as an oil; $\mathrm{R}_{\mathrm{f}}$ (hexane:ethyl acetate, $\left.1: 1\right)=0.54 ; \delta_{1_{\mathrm{H}}}\left(\mathrm{CDCl}_{3}\right)$ $1.20(3 \mathrm{H}, \mathrm{s}), 1.44(3 \mathrm{H}, \mathrm{s}), 1.80-2.06(2 \mathrm{H}, \mathrm{m}), 2.20-2.48(4 \mathrm{H}, \mathrm{m}), 2.74(1 \mathrm{H}, \mathrm{ddd}, J=$ 7.6, 14.1, 8.2 Hz), $2.86(1 \mathrm{H}, \mathrm{ddd}, J=5.2,14.1,9.0 \mathrm{~Hz}), 3.81-3.89(1 \mathrm{H}, \mathrm{m}), 7.21-7.36$ $(5 \mathrm{H}, \mathrm{m}) ; \delta_{13 \mathrm{C}}\left(\mathrm{CDCl}_{3}\right) 24.0,31.0,31.5,38.2,47.5,53.2,69.6,75.0,125.9,128.4(2 \mathrm{C})$, $128.5(2 \mathrm{C}), 141.66,208.1 ; v_{\max }\left(\mathrm{CHCl}_{3}\right) 1721 ; \mathrm{m} / z\left(\mathrm{CGT}, \mathrm{CI}^{+}\right) 233\left([\mathrm{M}+\mathrm{H}]^{+}, 100 \%\right)$, $250\left(\left[\mathrm{M}+\mathrm{NH}_{4}\right]^{+}, 100 \%\right) ; \mathrm{m} / \mathrm{z}\left(\mathrm{HRMS}, \mathrm{GCT}, \mathrm{CI}^{+}\right)$found $250.1809\left(\left[\mathrm{M}+\mathrm{NH}_{4}\right]^{+}\right)$, $\mathrm{C}_{15} \mathrm{H}_{24} \mathrm{NO}_{2}$ requires 250.1807 .

\footnotetext{
${ }^{\dagger}$ Addition of trimethylsilyl triflate imparts a red color to the reaction. The reaction did not proceed when this red color was not observed and additional TMSOTf was added as necessary.
} 


\section{6-[2-(4-Methoxyphenyl)-ethyl]-2,2-dimethyltetrahydropyran-4-one ( \pm )-2h}<smiles>COc1ccc(CCC2CC(=O)CC(C)(C)O2)cc1</smiles>

Aldol ( \pm )-1h $(100 \mathrm{mg}, 0.35 \mathrm{mmol})$ in toluene $(10 \mathrm{ml})$ was added to $\mathrm{RhCl}\left(\mathrm{PPh}_{3}\right)_{3}(100$ mg, 1 mass eq). The mixture was degassed and placed under $\mathrm{H}_{2}$ (3-layer balloon) and allowed to stir for $18 \mathrm{~h}$. The solvent was removed in vacuo and the residue taken up in dichloromethane $(2 \mathrm{ml})$ and filtered through a plug of silica which was washed with dichloromethane. The solvent was removed in vacuo to yield a yellow oil. The residue was dissolved in dichloromethane $(2 \mathrm{ml})$ and cooled to $-78^{\circ} \mathrm{C}$. To this was added diisopropylethylamine $(0.01 \mathrm{ml}, 0.08 \mathrm{mmol})$ and TMSOTf $(0.02 \mathrm{ml}, 0.11 \mathrm{mmol})$ and the mixture allowed to stir for $1 \mathrm{~h}$. The mixture was then allowed to warm to $-20^{\circ} \mathrm{C}$, stirred for $3 \mathrm{~h}$ and then placed in the freezer overnight. The reaction was quenched by addition of saturated $\mathrm{NaHCO}_{3(\mathrm{aq})}(5 \mathrm{ml})$. The mixture was extracted with dichloromethane $(3 \times 5 \mathrm{ml})$, the combined organic fractions dried over $\mathrm{MgSO}_{4}$, filtered under suction and the solvent removed in vacuo. The residue was purified by column chromatography (cyclohexane:diethyl ether, 2:1) to yield the desired product (56 mg, $56 \%$ over 2 steps) as an oil; $\mathrm{R}_{\mathrm{f}}$ (cyclohexane:diethyl ether, $\left.1: 1\right)=0.36 ; \delta_{1_{\mathrm{H}}}\left(\mathrm{CDCl}_{3}\right)$ $1.15(3 \mathrm{H}, \mathrm{s}), 1.39(3 \mathrm{H}, \mathrm{s}), 1.72-1.98(2 \mathrm{H}, \mathrm{m}), 2.17-2.43(4 \mathrm{H}, \mathrm{m}), 2.64(1 \mathrm{H}, \mathrm{ddd}, J=$ 7.6, 14.1, $7.8 \mathrm{~Hz}), 2.75(1 \mathrm{H}, \mathrm{ddd}, J=5.2,14.1,9.2 \mathrm{~Hz}), 3.75-3.83(1 \mathrm{H}, \mathrm{m}) 3.79(3 \mathrm{H}$, s), $6.83(2 \mathrm{H}, \mathrm{d}, J=8.6 \mathrm{~Hz}), 7.11(2 \mathrm{H}, \mathrm{d}, J=8.6 \mathrm{~Hz}) ; \delta_{13 \mathrm{C}}\left(\mathrm{CDCl}_{3}\right) 24.16,30.6,30.9$, $38.5,47.5,53.2,55.2,69.6,74.9,113.8(2 \mathrm{C}), 129.3(2 \mathrm{C}), 141.7,157.8,208.2 ; v_{\max }$ (neat) $1718 ; \mathrm{m} / \mathrm{z}\left(\mathrm{GCT}, \mathrm{CI}^{+}\right) 263\left([\mathrm{M}+\mathrm{H}]^{+}, 100 \%\right), 280\left(\left[\mathrm{M}+\mathrm{NH}_{4}\right]^{+}, 87 \%\right) ; \mathrm{m} / \mathrm{z}$ (HRMS, GCT, $\left.\mathrm{CI}^{+}\right)$found $280.1905\left(\left[\mathrm{M}+\mathrm{NH}_{4}\right]^{+}\right), \mathrm{C}_{16} \mathrm{H}_{26} \mathrm{NO}_{3}$ requires 280.1913 . 


\section{2-(4-Methoxyphenyl)-6-methyl-2,3-dihydro-4H-pyran-4-one ( \pm )-3a}<smiles>COc1ccc(C2CC(=O)C=C(C)O2)cc1</smiles>

A $25 \mathrm{ml} \mathrm{Schlenk} \mathrm{tube} \mathrm{was} \mathrm{charged} \mathrm{with} \mathrm{palladium(II)} \mathrm{chloride}(55 \mathrm{mg}, 0.31 \mathrm{mmol})$ and copper(I) chloride (31 mg, $0.31 \mathrm{mmol}$ ) before evacuating and back-filling with oxygen (balloon). To this was added a solution of aldol $( \pm)-1 \mathrm{a}(345 \mathrm{mg}, 1.57 \mathrm{mmol})$ in toluene $(2.5 \mathrm{ml})$. The reaction was heated to $50{ }^{\circ} \mathrm{C}$ before adding phosphatebuffered saline $(2.5 \mathrm{ml}, \mathrm{pH}$ 7.4). The addition was accompanied by a gradual darkening of colour and the appearance of Pd black. The resulting biphasic mixture was stirred vigorously at $50{ }^{\circ} \mathrm{C}$ for $87 \mathrm{~h}$. The reaction was then cooled to room temperature and the toluene layer separated. The aqueous phase was extracted with ethyl acetate $(3 \times 10 \mathrm{ml})$ and the combined organic phases were filtered through a plug of silica gel and dried over anhydrous magnesium sulphate. The solvent was evaporated under reduced pressure to afford 3a (342 mg, quant.) as a yellow solid (mp $\left.56-58{ }^{\circ} \mathrm{C}\right) ; \mathrm{R}_{\mathrm{f}}$ (hexane:ethyl acetate, $\left.1: 1\right)=0.32 ; \delta_{1 \mathrm{H}}\left(\mathrm{CDCl}_{3}\right) 2.07(3 \mathrm{H}, \mathrm{s}), 2.56(1 \mathrm{H}$, ddd, $J=16.8,3.4,1.0 \mathrm{~Hz}), 2.84(1 \mathrm{H}, \mathrm{dd}, J=16.8,14.3 \mathrm{~Hz}), 3.84(3 \mathrm{H}, \mathrm{s}), 5.34(1 \mathrm{H}$, $\mathrm{dd}, J=14.3,3.4 \mathrm{~Hz}), 5.43(1 \mathrm{H}, \mathrm{s}), 6.95(2 \mathrm{H}, \mathrm{d}, J=8.7 \mathrm{~Hz}), 7.35(2 \mathrm{H}, \mathrm{d}, J=8.7 \mathrm{~Hz})$; $\delta_{13 \mathrm{C}}\left(\mathrm{CDCl}_{3}\right)$ 21.1, 42.1, 55.3, 80.6, 105.1, 114.1(2C), 127.8, 130.2 (2C), 160.0, 174.4, $192.3 ; v_{\max }\left(\mathrm{CHCl}_{3}\right) 3019,2400,1659,1609,1517 ; \mathrm{m} / z\left(\mathrm{GCT}, \mathrm{CI}^{+}\right)$found 219.1014 $\left([\mathrm{M}+\mathrm{H}]^{+}\right), \mathrm{C}_{13} \mathrm{H}_{15} \mathrm{O}_{3}$ requires 219.1021 . 


\section{Antibody-Catalyzed Reactions}

General: High performance liquid chromatography (HPLC): Analytical HPLC and semi-preparative HPLC were performed on a Waters HPLC system (626 Pump, 600S Controller, 996 Photodiode Array Detector, Millenium ${ }^{32}$ Software). Phosphatebuffered saline (PBS) was made up as $10 \mathrm{mM}$ phosphate, $16 \mathrm{mM} \mathrm{NaCl}, \mathrm{pH}$ 7.4. All antibody-catalyzed reactions were carried out using stock solutions of the antibodies. Abzyme $84 \mathrm{G} 3$ (RMM 150000) was available as a $32 \mu \mathrm{M}$ or a $66.7 \mu \mathrm{M}$ solution in PBS, abzyme 93F3 (RMM 150000) was available as an $82 \mu \mathrm{M}$ solution in PBS, abzyme 33F12 (RMM 150000) was available as a 66.7 $\mu \mathrm{M}$ in PBS and abzyme 38C2 (RMM 150000) was available as an $83.3 \mu \mathrm{M}$ solution in PBS. All reactions were carried out in PBS at pH 7.4 with $\mathrm{MeCN}$ as a co-solvent.

\section{Supplementary Material for the data reported in Table 1}

Aldol reactions were followed by analytical RP-HPLC on a Nova-pak Waters column,

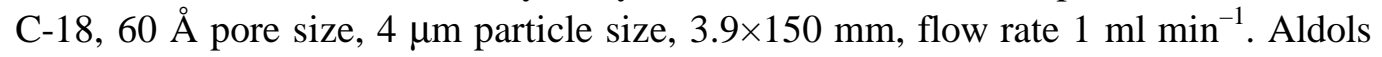
were isolated by semi-preparative reverse-phase HPLC, Hypersil ODS column, $5 \mu \mathrm{m}$ particle size, $7 \times 250 \mathrm{~mm}$, flow rate $2.0 \mathrm{ml} \mathrm{min}^{-1}$ or Phenomenex Luna $\mathrm{C} 18$ column, $8.8 \mu \mathrm{m}$ particle size, $15 \times 250 \mathrm{~mm}$, flow rate $8.0 \mathrm{ml} \mathrm{min}^{-1}$. Enantioselectivities were determined by normal phase HPLC using a Chiracel OD, Chiracel OJ, Chiracel OJ-H

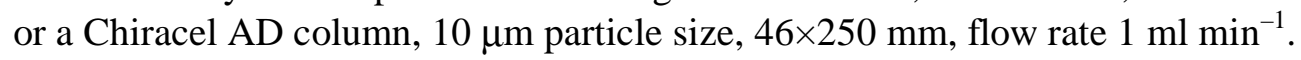

General procedure for screening of antibody-catalyzed retro-aldol reactions:

Antibody (6.4 nmol) was added to a stock solution of the racemic aldol ( $80 \mu \mathrm{l}$ of 800 $\mu \mathrm{M}$ in $10 \%$ acetonitrile, $90 \% \mathrm{PBS}, 64 \mathrm{nmol})$. The reactions were monitored by RPHPLC using a Nova-pak Waters column, C18, $60 \AA$ pore size, $4 \mu \mathrm{m}$ particle size,

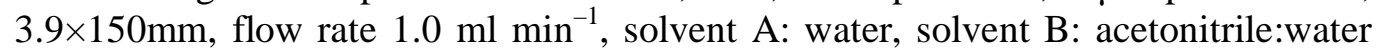
$(1: 1)$, solvent $\mathrm{C}$ : acetonitrile. A blank was made up as for the antibody-catalyzed reaction with the antibody replaced by PBS and was monitored using the same procedure.

Reference dehydrated product: 8-(4-Methoxyphenyl)-2-methylocta-2,5,7-trien-4-one<smiles>COc1ccc(/C=C/C=C/C(=O)C=C(C)C)cc1</smiles>

To aldol $( \pm)-\mathbf{1 g}(100 \mathrm{mg}, 0.38 \mathrm{mmol})$ in dichloromethane $(2 \mathrm{ml})$ at $0{ }^{\circ} \mathrm{C}$ was added two drops of trifluoroacetic acid. The mixture was allowed to stir for $5 \mathrm{~min}$ and the solvent removed in vacuo to yield essentially pure alkene (92 $\mathrm{mg}$, quant.) as a yellow solid $\left(\mathrm{mp} 82-83^{\circ} \mathrm{C}\right) ; \mathrm{R}_{\mathrm{f}}$ (hexane:ethyl acetate, $\left.1: 1\right)=0.63 ; \delta_{1_{\mathrm{H}}}\left(\mathrm{CDCl}_{3}\right) 1.94(3 \mathrm{H}, \mathrm{s})$, $2.20(3 \mathrm{H}, \mathrm{s}), 3.84(3 \mathrm{H}, \mathrm{s}), 6.26-6.28(1 \mathrm{H}, \mathrm{m}), 6.30(1 \mathrm{H}, \mathrm{d}, J=15.2 \mathrm{~Hz}), 6.79(1 \mathrm{H}, \mathrm{dd}$, $J=10.8,15.4 \mathrm{~Hz}), 6.90(1 \mathrm{H}, \mathrm{d}, J=15.2 \mathrm{~Hz}), 6.90(2 \mathrm{H}, \mathrm{d}, J=8.8 \mathrm{~Hz}), 7.36(1 \mathrm{H}, \mathrm{dd}, J$ $=15.2,10.8 \mathrm{~Hz}), 7.43(2 \mathrm{H}, \mathrm{d}, J=8.6 \mathrm{~Hz}) ; \delta_{13 \mathrm{C}}\left(\mathrm{CDCl}_{3}\right) 20.9,27.8,55.3,114.3(2 \mathrm{C})$, $123.6,125.0,128.6(2 \mathrm{C}), 129.1,130.8,140.4,142.5,155.3,160.4,190.3 ; v_{\max }$ (neat) 1623.7, 1602.0, 1577.1; $\mathrm{m} / \mathrm{z}\left(\mathrm{GCT}, \mathrm{CI}^{+}\right) 243\left([\mathrm{M}+\mathrm{H}]^{+}, 100 \%\right) ; \mathrm{m} / z(\mathrm{HRMS}, \mathrm{GCT}$, $\left.\mathrm{CI}^{+}\right)$found $243.1379\left([\mathrm{M}+\mathrm{H}]^{+}\right), \mathrm{C}_{16} \mathrm{H}_{19} \mathrm{O}_{2}$ requires 243.1385. 


\section{Screening results for selected antibody-catalyzed retro-aldolizations}

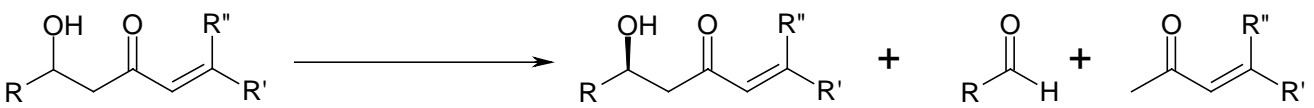

\begin{tabular}{|c|c|c|}
\hline Aldol & Conditions & Results \\
\hline$( \pm)-\mathbf{1 a}$ & $\begin{array}{l}10 \% \text { Ab84G3, } 0.5 \mathrm{~h} \\
10 \% \text { Ab93F3, } 0.5 \mathrm{~h} \\
\text { PBS, } 0.5 \mathrm{~h}\end{array}$ & $\begin{array}{l}51 \% \text { loss of aldol; } 41 \% \text { formation of aldehyde } \\
58 \% \text { loss of aldol; } 36 \% \text { formation of aldehyde } \\
\text { No reaction }\end{array}$ \\
\hline$( \pm)-1 b$ & $\begin{array}{l}10 \% \text { Ab84G3, } 6 \mathrm{~h} \\
10 \% \text { Ab93F3, } 9 \mathrm{~h} \\
\text { PBS, } 12 \mathrm{~h}\end{array}$ & $\begin{array}{l}58 \% \text { loss of aldol; } 20 \% \text { formation of aldehyde } \\
55 \% \text { loss of aldol; } 22 \% \text { formation of aldehyde } \\
\text { No reaction }\end{array}$ \\
\hline$( \pm)-\mathbf{1 f}$ & $\begin{array}{l}10 \% \text { Ab84G3, } 44 \mathrm{~h} \\
10 \% \text { Ab93F3, } 44 \mathrm{~h} \\
\quad \mathrm{PBS}, 44 \mathrm{~h}\end{array}$ & $\begin{array}{l}47 \% \text { loss of aldol } \\
49 \% \text { loss of aldol } \\
\text { No reaction }\end{array}$ \\
\hline$( \pm)-1 g$ & $\begin{array}{l}10 \% \text { Ab84G3, } 42 \mathrm{~h} \\
10 \% \text { Ab93F3, } 42 \mathrm{~h} \\
\text { PBS, } 42 \mathrm{~h}\end{array}$ & $\begin{array}{l}34 \% \text { loss of aldol } \\
46 \% \text { loss of aldol } \\
\text { No reaction }\end{array}$ \\
\hline$( \pm)-\mathbf{1 h}$ & $\begin{array}{l}10 \% \text { Ab84G3, } 1 \mathrm{~h} \\
10 \% \text { Ab93F3, } 1 \mathrm{~h} \\
\text { PBS, } 1 \mathrm{~h}\end{array}$ & $\begin{array}{l}55 \% \text { loss of aldol; } 39 \% \text { formation of aldehyde }{ }^{\dagger} \\
51 \% \text { loss of aldol; } 39 \% \text { formation of aldehyde } \\
\text { No reaction }\end{array}$ \\
\hline$( \pm)-\mathbf{1 i}$ & $\begin{array}{l}10 \% \text { Ab84G3, } 2 \mathrm{~h} \\
10 \% \text { Ab93F3, } 2 \mathrm{~h} \\
\text { PBS, } 2 \mathrm{~h}\end{array}$ & $\begin{array}{l}58 \% \text { loss of aldol; } 21 \% \text { formation of aldehyde } \\
55 \% \text { loss of aldol; } 22 \% \text { formation of aldehyde } \\
\text { No reaction }\end{array}$ \\
\hline$( \pm)-\mathbf{1} \mathbf{j}$ & $\begin{array}{l}10 \% \text { Ab84G } 3,40 \mathrm{~m} \\
10 \% \text { Ab93F3, } 40 \mathrm{~m} \\
\text { PBS, } 40 \mathrm{~m}\end{array}$ & $\begin{array}{l}49 \% \text { loss of aldol; } 43 \% \text { formation of aldehyde } \\
55 \% \text { loss of aldol; } 42 \% \text { formation of aldehyde } \\
\text { No reaction }\end{array}$ \\
\hline$( \pm)-1 k$ & $\begin{array}{l}10 \% \text { Ab84G } 3,48 \mathrm{~h} \\
\mathrm{PBS}, 48 \mathrm{~h}\end{array}$ & $\begin{array}{l}74 \% \text { loss of aldol; } 5 \% \text { formation of aldehyde } \\
54 \% \text { loss of aldol; No aldehyde observed }\end{array}$ \\
\hline$( \pm)-11$ & $\begin{array}{l}10 \% \text { Ab84G3, } 12 \mathrm{~h} \\
10 \% \text { Ab93F3, } 12 \mathrm{~h} \\
\text { PBS, } 12 \mathrm{~h}\end{array}$ & $\begin{array}{l}97 \% \text { loss of aldol; No aldehyde observed } \\
98 \% \text { loss of aldol; No aldehyde observed } \\
11 \% \text { loss of aldol; No aldehyde observed }\end{array}$ \\
\hline
\end{tabular}

\section{Reverse-phase retention times for the products in Figure 1:}

Reaction of 1a: Isocratic $65 \% \mathrm{~A}: 35 \% \mathrm{~B}, \mathrm{t}_{\mathrm{R}}$ ketone $=3.4 \mathrm{~min}$, $t_{R}$ anisaldehyde $=15.2 \mathrm{~min}, t_{R}$ aldol 1a $=22.7 \mathrm{~min}$.

Reaction of 1b: Isocratic $40 \% \mathrm{~A}: 60 \% \mathrm{~B}, \mathrm{t}_{\mathrm{R}}$ ketone $=3.8 \mathrm{~min}$, $t_{R}$ anisaldehyde $=5.6 \mathrm{~min}, t_{R}$ aldol $\mathbf{1 b}=10.1 \mathrm{~min}$. 
Reaction of 1c: Isocratic $40 \% \mathrm{~A}: 60 \% \mathrm{~B}, \mathrm{t}_{\mathrm{R}}$ ketone $=3.8 \mathrm{~min}$, $t_{R}$ anisaldehyde $=5.6 \mathrm{~min}, t_{R}$ aldol $1 \mathrm{c}=18.6 \mathrm{~min}$.

Reaction of 1d: Isocratic $30 \% \mathrm{~A}: 70 \% \mathrm{C}, \mathrm{t}_{\mathrm{R}}$ aldol $\mathbf{1 d}=9.9 \mathrm{~min}$.

Reaction of 1e: Isocratic $50 \% \mathrm{~A}: 50 \% \mathrm{~B}, \mathrm{t}_{\mathrm{R}}$ anisaldehyde $=3.7 \mathrm{~min}$, $\mathrm{t}_{\mathrm{R}}$ aldol $1 \mathrm{e}=12.8 \mathrm{~min}$.

Reaction of 1f: Isocratic $50 \% \mathrm{~A}: 50 \% \mathrm{~B}, \mathrm{t}_{\mathrm{R}}$ mesityl oxide $=4.0 \mathrm{~min}$, $\mathrm{t}_{\mathrm{R}}$ (4-methoxyphenyl)-acetaldehyde $=11.3 \mathrm{~min}, \mathrm{t}_{\mathrm{R}}$ aldol $\mathbf{1 f}=14.9 \mathrm{~min}$.

Reaction of 1g: Isocratic $30 \% \mathrm{~A}: 70 \% \mathrm{~B}, \mathrm{t}_{\mathrm{R}}$ mesityl oxide $=2.8 \mathrm{~min}$, $\mathrm{t}_{\mathrm{R}}$ 3-phenylpropionaldehyde $=4.7 \mathrm{~min}, \mathrm{t}_{\mathrm{R}}$ aldol $1 \mathrm{~g}=9.5 \mathrm{~min}$.

Reaction of $1 \mathbf{h}$ : Isocratic $50 \% \mathrm{~A}: 50 \% \mathrm{~B}, \mathrm{t}_{\mathrm{R}}$ mesityl oxide $=4.0 \mathrm{~min}$, $t_{R}$ 4-methoxycinnamaldehyde $=9.9 \mathrm{~min}, t_{R}$ aldol $\mathbf{1 h}=20.8 \mathrm{~min}$, $t_{R}$ dehydrated product $=62.7 \mathrm{~min}$.

Reaction of 1i: Isocratic $20 \% \mathrm{~A}: 80 \% \mathrm{~B}, \mathrm{t}_{\mathrm{R}}$ anisaldehyde $=8.4 \mathrm{~min}$, $\mathrm{t}_{\mathrm{R}}$ aldol $\mathbf{1 i}=5.4 \mathrm{~min}$.

Reaction of $\mathbf{1 j}$ : Isocratic $50 \% \mathrm{~A}: 50 \% \mathrm{~B}, \mathrm{t}_{\mathrm{R}}$ pent-3-en-2-one $=2.3 \mathrm{~min}$, $t_{R} 4$-methoxycinnamaldehyde $=9.9 \mathrm{~min}, \mathrm{t}_{\mathrm{R}}$ aldol $\mathbf{1} \mathbf{j}=14.1 \mathrm{~min}$.

Reaction of 1k: Isocratic $60 \% \mathrm{~A}: 40 \% \mathrm{~B}, \mathrm{t}_{\mathrm{R}}$ 4-methoxy-but-3-en-2-one $=4.3 \mathrm{~min}$, $\mathrm{t}_{\mathrm{R}}$ 4-methoxycinnamaldehyde $=16.0 \mathrm{~min}, \mathrm{t}_{\mathrm{R}}$ aldol $\mathbf{1} \mathbf{k}=19.0 \mathrm{~min}$.

Reaction of 11: Isocratic $62 \% \mathrm{~A}: 38 \% \mathrm{~B}, \mathrm{t}_{\mathrm{R}}$ methyl vinyl ketone $=2.1 \mathrm{~min}$, $t_{R}$ 4-methoxycinnamaldehyde $=19.5 \mathrm{~min}, t_{R}$ aldol $\mathbf{1 l}=22.9 \mathrm{~min}$.

\section{General procedure for $e e$ determination of antibody-catalyzed retro-aldol reactions:}

Antibody (32 nmol) was added to a stock solution of racemic aldol $(10 \mu \mathrm{lof} 80 \mathrm{mM}$ in acetonitrile, $800 \mathrm{nmol}$ ). The reactions were monitored by RP-HPLC using a Waters Nova-pak column, C18, $60 \AA$ pore size, $4 \mu \mathrm{m}$ particle size, $3.9 \times 150 \mathrm{~mm}$, flow rate 1.0 $\mathrm{ml} \mathrm{min}{ }^{-1}$, solvent $\mathrm{A}$ : water, solvent $\mathrm{B}$ : acetonitrile:water $(1: 1)$ as above. After reaching $50 \%$ conversion, the unreacted aldol was isolated by semi-preparative reversed-phase HPLC (Hypersil ODS column, $5 \mu \mathrm{m}$ particle size, $7 \times 250 \mathrm{~mm}$, flow rate $2.0 \mathrm{ml} \mathrm{min}^{-1}$ or Phenomenex Luna C18 column, $8.8 \mu \mathrm{m}$ particle size, $15 \times 250 \mathrm{~mm}$, flow rate $8.0 \mathrm{ml}$ $\mathrm{min}^{-1}$ ). The fractions were freeze-dried, the residue was redissolved in $200 \mu \mathrm{l}$ of dichloromethane:hexane (50:50) and the ee was determined by normal-phase HPLC using a Chiracel OD, Chiracel OJ, Chiracel OJ-H or a Chiracel AD column, $10 \mu \mathrm{m}$ particle size, $4.6 \times 250 \mathrm{~mm}$, flow rate $1 \mathrm{ml} \mathrm{min}^{-1}$. Solvent C: hexane, solvent D: isopropanol, solvent E: ethanol. 


\section{Chiral HPLC retention times for the aldol products in Table 1:}

Aldol 1a: on OJ-H column $\left(1 \mathrm{ml} \mathrm{min}{ }^{-1}\right)$, Isocratic $97 \% \mathrm{C}: 3 \% \mathrm{E}, \mathrm{t}_{\mathrm{R}}(R)-\mathbf{1 a}=56.6 \mathrm{~min}$, $\mathrm{t}_{\mathrm{R}}(S)-\mathbf{1 a}=62.2 \mathrm{~min}$.

Aldol 1b: on OD column $\left(1 \mathrm{ml} \mathrm{min} \mathrm{m}^{-1}\right)$, Isocratic $99 \% \mathrm{C}: 1 \% \mathrm{E}, \mathrm{t}_{\mathrm{R}}(R)-\mathbf{1 b}=37.0 \mathrm{~min}$, $\mathrm{t}_{\mathrm{R}}(S)-\mathbf{1 b}=39.0 \mathrm{~min}$.

Aldol 1c: on OD column $\left(1 \mathrm{ml} \mathrm{min}{ }^{-1}\right)$, Isocratic $99 \% \mathrm{C}: 1 \% \mathrm{E}, \mathrm{t}_{\mathrm{R}}(R)-\mathbf{1 c}=30.4 \mathrm{~min}$, $\mathrm{t}_{\mathrm{R}}(S)-\mathbf{1 c}=33.6 \mathrm{~min}$.

Aldol 1d: on OD column $\left(1 \mathrm{ml} \mathrm{min}{ }^{-1}\right)$, Isocratic $99 \% \mathrm{C}: 1 \% \mathrm{E}, \mathrm{t}_{\mathrm{R}}(R)-\mathbf{1 c}=25.4 \mathrm{~min}$, $\mathrm{t}_{\mathrm{R}}(S)-\mathbf{1 c}=27.5 \mathrm{~min}$.

Aldol 1f: on AD column $\left(1 \mathrm{ml} \mathrm{min}^{-1}\right)$, Isocratic $95 \% \mathrm{C}: 5 \% \mathrm{D}, \mathrm{t}_{\mathrm{R}}(R)-\mathbf{1 f}=19.8 \mathrm{~min}$, $\mathrm{t}_{\mathrm{R}}(S)-\mathbf{1 f}=28.4 \mathrm{~min}$.

Aldol 1g: on OJ column $\left(1 \mathrm{ml} \mathrm{min}{ }^{-1}\right)$, Isocratic $99 \% \mathrm{C}: 1 \% \mathrm{E}, \mathrm{t}_{\mathrm{R}}(S)-\mathbf{1 g}=18.4 \mathrm{~min}$, $\mathrm{t}_{\mathrm{R}}(R)-\mathbf{1 g}=20.5 \mathrm{~min}$.

Aldol 1h: on OJ column $\left(1 \mathrm{ml} \mathrm{m^{-1 }}\right)$, Isocratic $75 \% \mathrm{C}: 25 \% \mathrm{D}, \mathrm{t}_{\mathrm{R}}(S)-\mathbf{1 h}=13.9 \mathrm{~min}$, $\mathrm{t}_{\mathrm{R}}(R)-\mathbf{1 h}=17.2 \mathrm{~min}$.

Aldol 1i: on OJ-H column $\left(1 \mathrm{ml} \mathrm{min}^{-1}\right)$, Isocratic $80 \% \mathrm{C}: 20 \% \mathrm{E}, \mathrm{t}_{\mathrm{R}}(S)-\mathbf{1 i}=37.0 \mathrm{~min}$, $\mathrm{t}_{\mathrm{R}}(R)-\mathbf{1} \mathbf{i}=41.8 \mathrm{~min}$.

Aldol 1j: on AD column $\left(1 \mathrm{ml} \mathrm{min}{ }^{-1}\right)$, Isocratic $80 \% \mathrm{C}: 20 \% \mathrm{E}, \mathrm{t}_{\mathrm{R}}(R)-\mathbf{1 j}=18.3 \mathrm{~min}$, $\mathrm{t}_{\mathrm{R}}(S)-\mathbf{1} \mathbf{j}=21.8$ min.

Aldol 1k: on AD column $\left(1 \mathrm{ml} \mathrm{min}{ }^{-1}\right)$, Isocratic $70 \% \mathrm{C}: 30 \% \mathrm{E}, \mathrm{t}_{\mathrm{R}} \mathbf{1 k}=15.8$ and 19.3 min.

Aldol 11: on OJ-H column $\left(1 \mathrm{ml} \mathrm{min}^{-1}\right)$, Isocratic $80 \% \mathrm{C}: 20 \% \mathrm{E}, \mathrm{t}_{\mathrm{R}} \mathbf{1 l}=18.3$ and 19.3 $\min$.

\section{Chiral HPLC retention times for the HDA adducts}

2f: on OJ column $\left(1 \mathrm{ml} \mathrm{min}^{-1}\right)$, Isocratic $93 \% \mathrm{C}: 7 \% \mathrm{E}, \mathrm{t}_{\mathrm{R}}(R)-\mathbf{2 f}=10.2 \mathrm{~min}$, $\mathrm{t}_{\mathrm{R}}(S)-\mathbf{2 f}=11.8 \mathrm{~min}$.

2g: on OD column $\left(1 \mathrm{ml} \mathrm{min}^{-1}\right)$, Isocratic $96 \% \mathrm{C}: 4 \% \mathrm{E}, \mathrm{t}_{\mathrm{R}}(R)-\mathbf{2 g}=8.4 \mathrm{~min}$, $\mathrm{t}_{\mathrm{R}}(S)-\mathbf{2 g}=9.6 \mathrm{~min}$.

2h: on OJ-H column $\left(1 \mathrm{ml} \mathrm{min}{ }^{-1}\right)$, Isocratic $91 \% \mathrm{C}: 9 \% \mathrm{E}, \mathrm{t}_{\mathrm{R}}(S)-\mathbf{2 h}=12.7 \mathrm{~min}$, $\mathrm{t}_{\mathrm{R}}(\mathrm{R})-\mathbf{2 h}=13.7 \mathrm{~min}$.

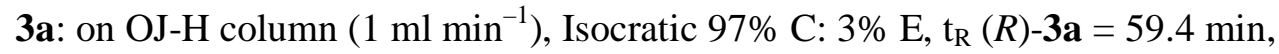
$\mathrm{t}_{\mathrm{R}}(S)-\mathbf{3 a}=66.2 \mathrm{~min}$. 


\section{Antibody-Catalyzed Kinetic Measurements}

Kinetic measurements were carried out using a constant concentration of antibody and varying the substrate concentration. Aliquots were periodically removed from the reactions and quenched with acetic acid.

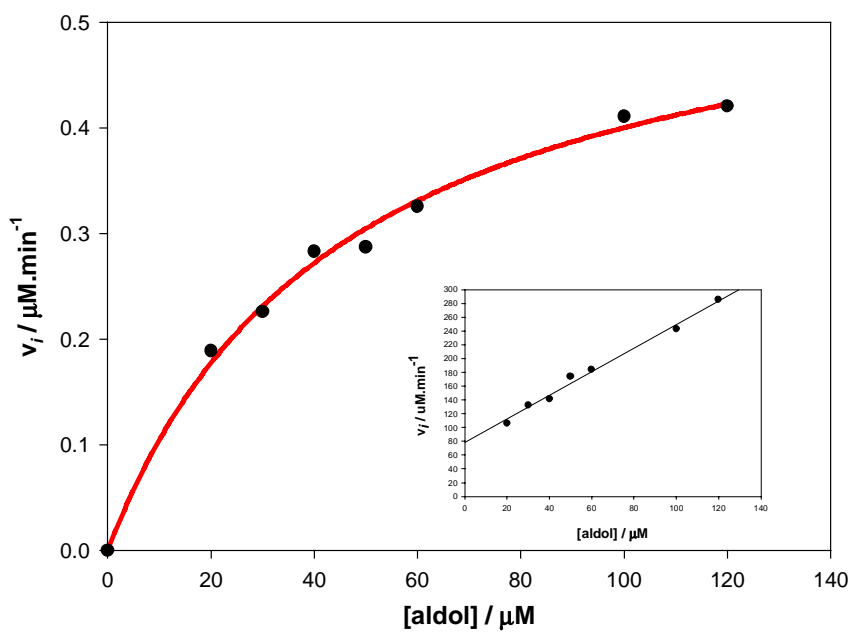

Figure 3. Demonstration of adherence to the Michaelis-Menten equation for the retroaldol reaction of $1 \mathbf{a}$ to give anisaldehyde and pent-3-en-2-one, catalyzed by Ab84G3.

All reactions were carried out at room temperature in PBS $(10 \mathrm{mM}$ phosphate, $16 \mathrm{mM}$ $\mathrm{NaCl}, \mathrm{pH} 7.4$ ) containing less than $3 \%$ of acetonitrile as the organic solvent. All catalyzed reactions were performed in the presence of $0.65 \mu \mathrm{M}$ of Ab84G3. The concentration of the aldol product was varied from 20 to $120 \mu \mathrm{M}$. Initial velocities were determined by following the formation of anisaldehyde by RP-HPLC within $<5 \%$ reaction completion. The points were determined experimentally and the best fit value of $V_{\max }$ and $K_{\mathrm{m}}$ were obtained by fitting the $v_{\mathrm{i}}$ versus $[\mathrm{S}]_{0}$ data to hyperbolic saturation curves by weighted non-linear regression using SigmaPlot 5.0 (from SPSS Inc). The data are reported per antibody active site. An IgG antibody possesses two active sites per MW of $\sim 150000 \mathrm{~g} \mathrm{~mol}^{-1}$.

\begin{tabular}{|c|c|c|}
\hline $\begin{array}{c}\text { Concentration } \\
\text { of } 1 \mathbf{a}(\mu \mathrm{M})\end{array}$ & $\begin{array}{c}v_{\mathrm{i}} \\
\left(\mu \mathrm{M} \min ^{-1}\right)\end{array}$ & Calculated \\
\hline 20 & 0.1891 & 0.1777 \\
\hline 30 & 0.2260 & 0.2313 \\
\hline 40 & 0.2832 & 0.2724 \\
\hline 50 & 0.2873 & 0.3049 \\
\hline 60 & 0.3258 & 0.3331 \\
\hline 100 & 0.4112 & 0.4006 \\
\hline 120 & 0.4209 & 0.4227 \\
\hline
\end{tabular}

\begin{tabular}{|ccc|}
\hline Variable & Value & $\begin{array}{c}\text { Std. } \\
\text { Error }\end{array}$ \\
\hline$V_{\max }\left(\mu \mathrm{M} \mathrm{min}{ }^{-1}\right)$ & 0.5838 & 0.0263 \\
$k_{\text {cat }}\left(\mathrm{min}^{-1}\right)$ & 0.452 & \\
$K_{\mathrm{m}}(\mu \mathrm{M})$ & 45.718 & 4.844 \\
\hline
\end{tabular}




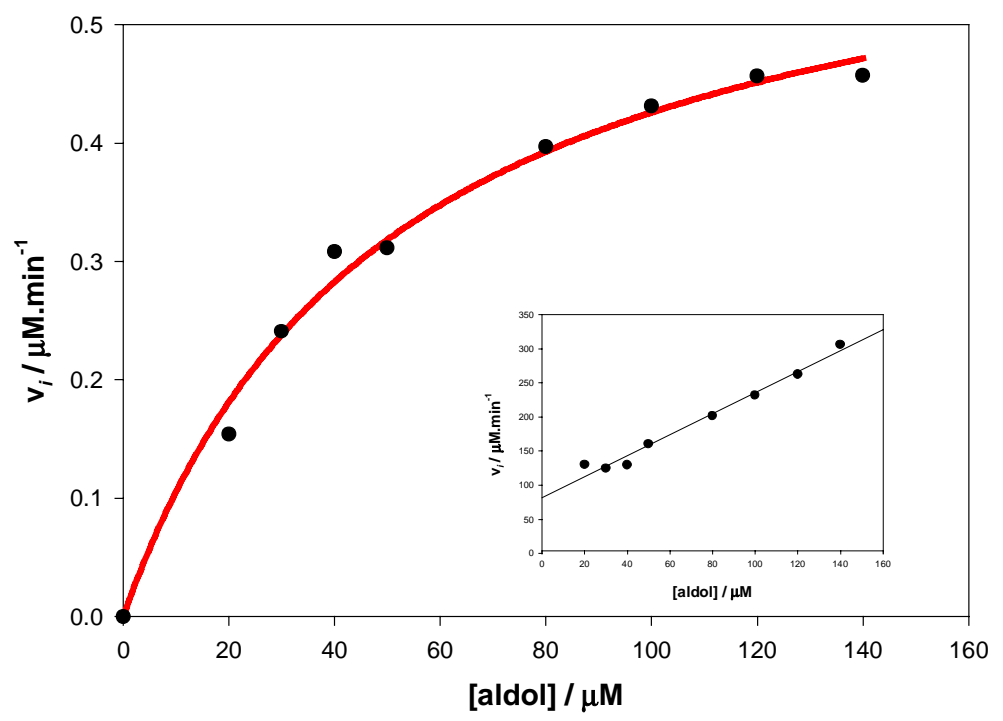

Figure 3. Demonstration of adherence to the Michaelis-Menten equation for the retroaldol reaction of 1a to give anisaldehyde and pent-3-en-2-one, catalyzed by Ab93F3.

All reactions were carried out at room temperature in PBS $(10 \mathrm{mM}$ phosphate, $16 \mathrm{mM}$ $\mathrm{NaCl}, \mathrm{pH} 7.4$ ) containing less than $3 \%$ of acetonitrile as the organic solvent. All catalyzed reactions were performed in the presence of $0.8 \mu \mathrm{M}$ of Ab93F3. The concentration of the aldol product was varied from 20 to $140 \mu \mathrm{M}$. Initial velocities were determined by following the formation of anisaldehyde by RP-HPLC within $<5 \%$ reaction completion. The points were determined experimentally and the best fit value of $V_{\max }$ and $K_{\mathrm{m}}$ were obtained by fitting the $v_{\mathrm{i}}$ versus $[\mathrm{S}]_{0}$ data to hyperbolic saturation curves by weighted non-linear regression using SigmaPlot 5.0 (from SPSS Inc). The data are reported per antibody active site. An IgG antibody possesses two active sites per MW of $\sim 150000 \mathrm{~g} \mathrm{~mol}^{-1}$.

\begin{tabular}{|c|c|c|}
\hline $\begin{array}{c}\text { Concentration } \\
\text { of } \mathbf{1 a}(\mu \mathrm{M})\end{array}$ & $\begin{array}{c}v_{\mathrm{i}} \\
\left(\mu \mathrm{M} \min ^{-1}\right)\end{array}$ & Calculated \\
\hline 20 & 0.1539 & 0.1812 \\
\hline 30 & 0.2409 & 0.2382 \\
\hline 40 & 0.3083 & 0.2827 \\
\hline 50 & 0.3113 & 0.3184 \\
\hline 80 & 0.3968 & 0.3928 \\
\hline 100 & 0.4310 & 0.4259 \\
\hline 120 & 0.4567 & 0.4513 \\
\hline 140 & 0.4570 & 0.4714 \\
\hline
\end{tabular}

\begin{tabular}{|ccc|}
\hline Variable & Value & $\begin{array}{c}\text { Std. } \\
\text { Error }\end{array}$ \\
\hline$V_{\max }\left(\mu \mathrm{M} \mathrm{min}{ }^{-1}\right)$ & 0.6431 & 0.0323 \\
$k_{\text {cat }}\left(\min ^{-1}\right)$ & 0.40 & \\
$K_{\mathrm{m}}(\mu \mathrm{M})$ & 50.984 & 6.351 \\
\hline
\end{tabular}




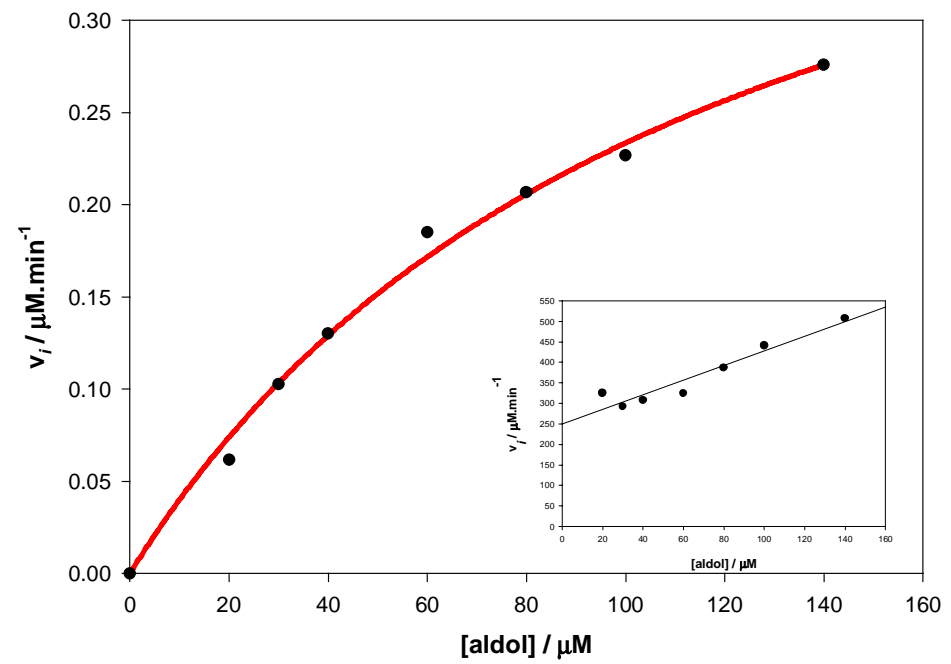

Figure 3. Demonstration of adherence to the Michaelis-Menten equation for the retroaldol reaction of $\mathbf{1 b}$ to give anisaldehyde and hex-3-en-2-one, catalyzed by Ab84G3.

All reactions were carried out at room temperature in PBS (10 mM phosphate, $16 \mathrm{mM}$ $\mathrm{NaCl}, \mathrm{pH}$ 7.4) containing less than $3 \%$ of acetonitrile as the organic solvent. All catalyzed reactions were performed in the presence of $10.34 \mu \mathrm{M}$ of Ab84G3. The concentration of the aldol product was varied from 20 to $140 \mu \mathrm{M}$. Initial velocities were determined by following the formation of anisaldehyde by RP-HPLC within $<5 \%$ reaction completion. The points were determined experimentally and the best fit value of $V_{\max }$ and $K_{\mathrm{m}}$ were obtained by fitting the $v_{\mathrm{i}}$ versus $[\mathrm{S}]_{0}$ data to hyperbolic saturation curves by weighted non-linear regression using SigmaPlot 5.0 (from SPSS Inc). The data are reported per antibody active site. An IgG antibody possesses two active sites per $\mathrm{MW}$ of $\sim 150000 \mathrm{~g} \mathrm{~mol}^{-1}$.

\begin{tabular}{|c|c|c|c|c|c|}
\hline $\begin{array}{c}\text { Concentration } \\
\text { of } \mathbf{1 b}(\mu \mathrm{M})\end{array}$ & $\begin{array}{c}v_{\mathrm{i}} \\
\left(\mu \mathrm{M} \min ^{-1}\right)\end{array}$ & Calculated & Variable & Value & $\begin{array}{l}\text { Std. } \\
\text { Error }\end{array}$ \\
\hline 20 & 0.0615 & 0.740 & $V_{\max }\left(\mu \mathrm{M} \min ^{-1}\right)$ & 0.5016 & 0.044 \\
\hline 30 & 0.1026 & 0.1035 & $k_{\text {cat }}\left(\min ^{-1}\right)$ & 0.025 & \\
\hline 40 & 0.1300 & 0.1291 & $K_{\mathrm{m}}(\mu \mathrm{M})$ & 116.76 & 17.51 \\
\hline 60 & 0.1851 & 0.1718 & & & \\
\hline 80 & 0.2068 & 0.2058 & & & \\
\hline 100 & 0.2267 & 0.2335 & & & \\
\hline 140 & 0.2759 & 0.2759 & & & \\
\hline
\end{tabular}




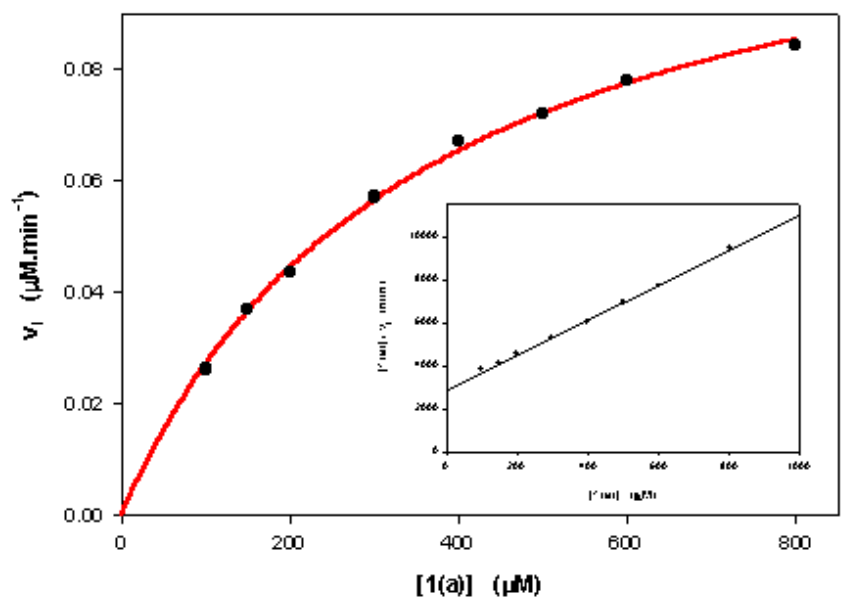

Figure 2. Demonstration of adherence to the Michaelis-Menten equation for the retroaldol reaction of $\mathbf{1 g}$ to give 3-phenylpropionaldehyde and mesityl oxide, catalyzed by Ab84G3.

All reactions were carried out at room temperature in PBS (10 mM phosphate, $16 \mathrm{mM}$ $\mathrm{NaCl}, \mathrm{pH}$ 7.4) containing less than $3 \%$ of acetonitrile as the organic solvent. All catalyzed reactions were performed in the presence of $9.9 \mu \mathrm{M}$ of Ab84G3. The concentration of the aldol product was varied from 100 to $800 \mu \mathrm{M}$. Initial velocities were determined by following the formation of mesityl oxide by RP-HPLC within $<5 \%$ reaction completion. The points were determined experimentally and the best fit value of $V_{\max }$ and $K_{\mathrm{m}}$ were obtained by fitting the $v_{\mathrm{i}}$ versus $[\mathrm{S}]_{0}$ data to hyperbolic saturation curves by weighted non-linear regression using SigmaPlot 5.0 (from SPSS Inc). The data are reported per antibody active site. An IgG antibody possesses two active sites per MW of $\sim 150000 \mathrm{~g} \mathrm{~mol}^{-1}$.

\begin{tabular}{|c|c|c|c|c|c|}
\hline $\begin{array}{c}\text { Concentration } \\
\text { of } 1 \mathrm{~g}(\mu \mathrm{M})\end{array}$ & $\begin{array}{c}v_{\mathrm{i}} \\
\left(\mu \mathrm{M} \min ^{-1}\right)\end{array}$ & Calculated & Variable & Value & $\begin{array}{l}\text { Std. } \\
\text { Error }\end{array}$ \\
\hline 100 & 0.0262 & 0.0272 & $V_{\max }\left(\mu \mathrm{M} \min ^{-1}\right)$ & 0.123 & 0.003 \\
\hline 150 & 0.0369 & 0.0367 & $k_{\text {cat }}\left(\min ^{-1}\right)$ & 0.006 & 0.00015 \\
\hline 200 & 0.0436 & 0.0445 & $K_{\mathrm{m}}(\mu \mathrm{M})$ & 352 & 16.8 \\
\hline 300 & 0.0571 & 0.0566 & & & \\
\hline 400 & 0.0670 & 0.0654 & & & \\
\hline 500 & 0.0720 & 0.0721 & & & \\
\hline 600 & 0.0780 & 0.0774 & & & \\
\hline 800 & 0.0843 & 0.0854 & & & \\
\hline
\end{tabular}




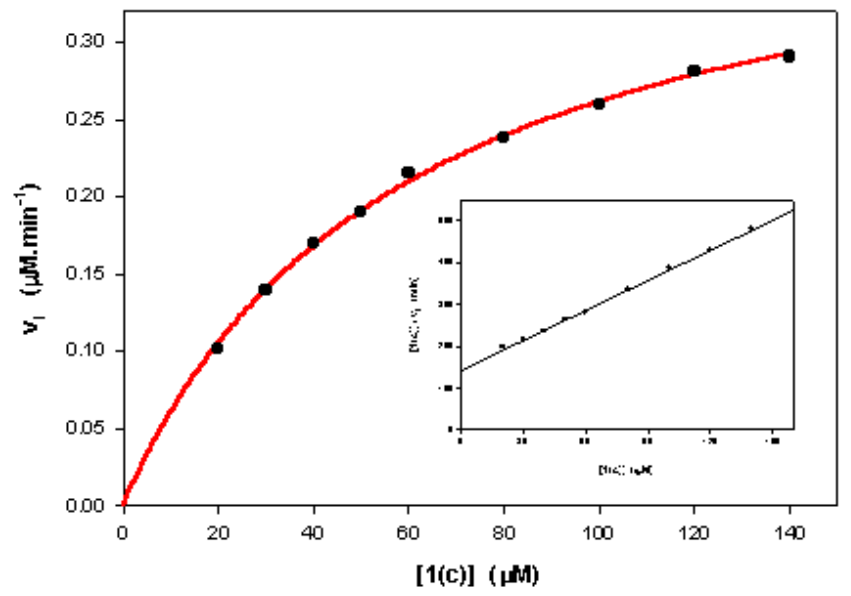

Figure 3. Demonstration of adherence to the Michaelis-Menten equation for the retroaldol reaction of $\mathbf{1 h}$ to give 4-methoxycinnamaldehyde and mesityl oxide, catalyzed by Ab84G3.

All reactions were carried out at room temperature in PBS $(10 \mathrm{mM}$ phosphate, $16 \mathrm{mM}$ $\mathrm{NaCl}, \mathrm{pH}$ 7.4) containing less than $3 \%$ of acetonitrile as the organic solvent. All catalyzed reactions were performed in the presence of $0.078 \mu \mathrm{M}$ of Ab84G3. The concentration of the aldol product was varied from 20 to $140 \mu \mathrm{M}$. Initial velocities were determined by following the formation of 4-methoxycinnamaldehyde by RPHPLC within $<5 \%$ reaction completion. The points were determined experimentally and the best fit value of $V_{\max }$ and $K_{\mathrm{m}}$ were obtained by fitting the $v_{\mathrm{i}}$ versus [S $]_{0}$ data to hyperbolic saturation curves by weighted non-linear regression using SigmaPlot 5.0 (from SPSS Inc). The data are reported per antibody active site. An IgG antibody possesses two active sites per MW of $\sim 150000 \mathrm{~g} \mathrm{~mol}^{-1}$.

\begin{tabular}{|c|c|c|c|c|c|}
\hline $\begin{array}{c}\text { Concentration } \\
\text { of } \mathbf{1 h}(\mu \mathrm{M})\end{array}$ & $\begin{array}{c}v_{\mathrm{i}} \\
\left(\mu \mathrm{M} \min ^{-1}\right)\end{array}$ & Calculated & Variable & Value & $\begin{array}{l}\text { Std. } \\
\text { Error }\end{array}$ \\
\hline 20 & 0.1010 & 0.1059 & $V_{\max }\left(\mu \mathrm{M} \min ^{-1}\right)$ & 0.416 & 0.007 \\
\hline 30 & 0.1392 & 0.1409 & $k_{\text {cat }}\left(\min ^{-1}\right)$ & 2.68 & 0.045 \\
\hline 40 & 0.1702 & 0.1688 & $K_{\mathrm{m}}(\mu \mathrm{M})$ & 59.0 & 2.28 \\
\hline 50 & 0.1901 & 0.1915 & & & \\
\hline 60 & 0.2148 & 0.2104 & & & \\
\hline 80 & 0.2379 & 0.2401 & & & \\
\hline 100 & 0.2594 & 0.2622 & & & \\
\hline 120 & 0.2807 & 0.2794 & & & \\
\hline 140 & 0.2905 & 0.2931 & & & \\
\hline
\end{tabular}




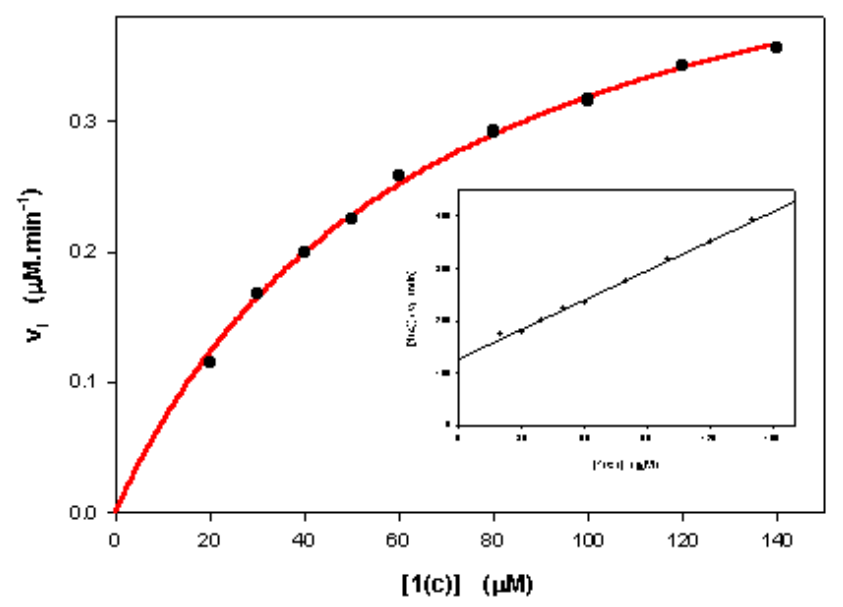

Figure 4. Demonstration of adherence to the Michaelis-Menten equation for the retroaldol reaction of $\mathbf{1 h}$ to give 4-methoxycinnamaldehyde and mesityl oxide, catalyzed by Ab93F3.

All reactions were carried out at room temperature in PBS $(10 \mathrm{mM}$ phosphate, $16 \mathrm{mM}$ $\mathrm{NaCl}, \mathrm{pH}$ 7.4) containing less than $3 \%$ of acetonitrile as the organic solvent. All catalyzed reactions were performed in the presence of $0.064 \mu \mathrm{M}$ of Ab93F3. The concentration of the aldol product was varied from 20 to $140 \mu \mathrm{M}$. Initial velocities were determined by following the formation of 4-methoxycinnamaldehyde by RPHPLC within $<5 \%$ reaction completion. The points were determined experimentally and the best fit value of $V_{\max }$ and $K_{\mathrm{m}}$ were obtained by fitting the $v_{\mathrm{i}}$ versus [S $]_{0}$ data to hyperbolic saturation curves by weighted non-linear regression using SigmaPlot 5.0 (from SPSS Inc). The data are reported per antibody active site. An IgG antibody possesses two active sites per MW of $\sim 150000 \mathrm{~g} \mathrm{~mol}^{-1}$.

\begin{tabular}{|c|c|c|c|c|c|}
\hline $\begin{array}{c}\text { Concentration } \\
\text { of } \mathbf{1 h}(\mu \mathrm{M})\end{array}$ & $\begin{array}{c}v_{\mathrm{i}} \\
\left(\mu \mathrm{M} \min ^{-1}\right)\end{array}$ & Calculated & Variable & Value & $\begin{array}{l}\text { Std. } \\
\text { Error }\end{array}$ \\
\hline 20 & 0.1155 & 0.1228 & $V_{\max }\left(\mu \mathrm{M} \min ^{-1}\right)$ & 0.529 & 0.012 \\
\hline 30 & 0.1682 & 0.1650 & $k_{\text {cat }}\left(\min ^{-1}\right)$ & 4.13 & 0.094 \\
\hline 40 & 0.1986 & 0.1993 & $K_{\mathrm{m}}(\mu \mathrm{M})$ & 66.1 & 3.19 \\
\hline 50 & 0.2247 & 0.2277 & & & \\
\hline 60 & 0.2583 & 0.2515 & & & \\
\hline 80 & 0.2919 & 0.2894 & & & \\
\hline 100 & 0.3160 & 0.3182 & & & \\
\hline 120 & 0.3426 & 0.3409 & & & \\
\hline 140 & 0.3557 & 0.3591 & & & \\
\hline
\end{tabular}




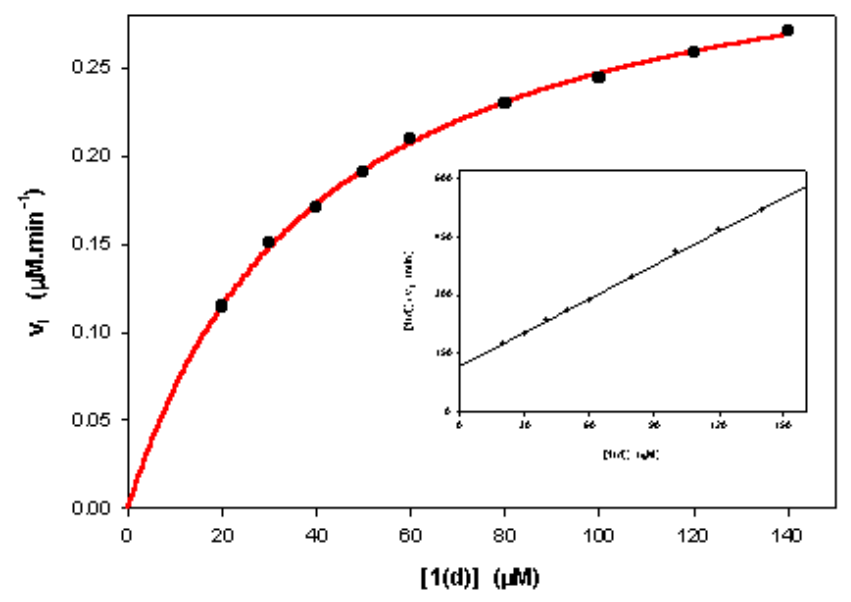

Figure 5. Demonstration of adherence to the Michaelis-Menten equation for the retroaldol reaction of $\mathbf{1} \mathbf{j}$ to give 4-methoxycinnamaldehyde and pent-3-en-2-one, catalyzed by Ab84G3.

All reactions were carried out at room temperature in PBS (10 mM phosphate, $16 \mathrm{mM}$ $\mathrm{NaCl}, \mathrm{pH}$ 7.4) containing less than $3 \%$ of acetonitrile as the organic solvent. All catalyzed reactions were performed in the presence of $0.078 \mu \mathrm{M}$ of Ab84G3. The concentration of the aldol product was varied from 20 to $140 \mu \mathrm{M}$. Initial velocities were determined by following the formation of 4-methoxycinnamaldehyde by RPHPLC within $<5 \%$ reaction completion. The points were determined experimentally and the best fit value of $V_{\max }$ and $K_{\mathrm{m}}$ were obtained by fitting the $v_{\mathrm{i}}$ versus $[\mathrm{S}]_{0}$ data to hyperbolic saturation curves by weighted non-linear regression using SigmaPlot 5.0 (from SPSS Inc). The data are reported per antibody active site. An IgG antibody possesses two active sites per MW of $\sim 150000 \mathrm{~g} \mathrm{~mol}^{-1}$.

\begin{tabular}{|c|c|c|}
\hline $\begin{array}{l}\text { Concentration } \\
\text { of } \mathbf{1} \mathbf{j}(\mu \mathrm{M})\end{array}$ & $\begin{array}{c}v_{\mathrm{i}} \\
\left(\mu \mathrm{Min}^{-1}\right)\end{array}$ & Calculated \\
\hline 20 & 0.1144 & 0.1151 \\
\hline 30 & 0.1509 & 0.1480 \\
\hline 40 & 0.1702 & 0.1726 \\
\hline 50 & 0.1909 & 0.1918 \\
\hline 60 & 0.2094 & 0.2071 \\
\hline 80 & 0.2300 & 0.2301 \\
\hline 100 & 0.2439 & 0.2465 \\
\hline 120 & 0.2581 & 0.2588 \\
\hline 140 & 0.2707 & 0.2684 \\
\hline
\end{tabular}

\begin{tabular}{|ccc|}
\hline Variable & Value & $\begin{array}{c}\text { Std. } \\
\text { Error }\end{array}$ \\
\hline$V_{\max }\left(\mu \mathrm{M} \mathrm{min} \min ^{-1}\right)$ & 0.345 & 0.004 \\
$k_{\text {cat }}\left(\mathrm{min}^{-1}\right)$ & 2.22 & 0.025 \\
$K_{\mathrm{m}}(\mu \mathrm{M})$ & 40.0 & 1.17 \\
\hline
\end{tabular}




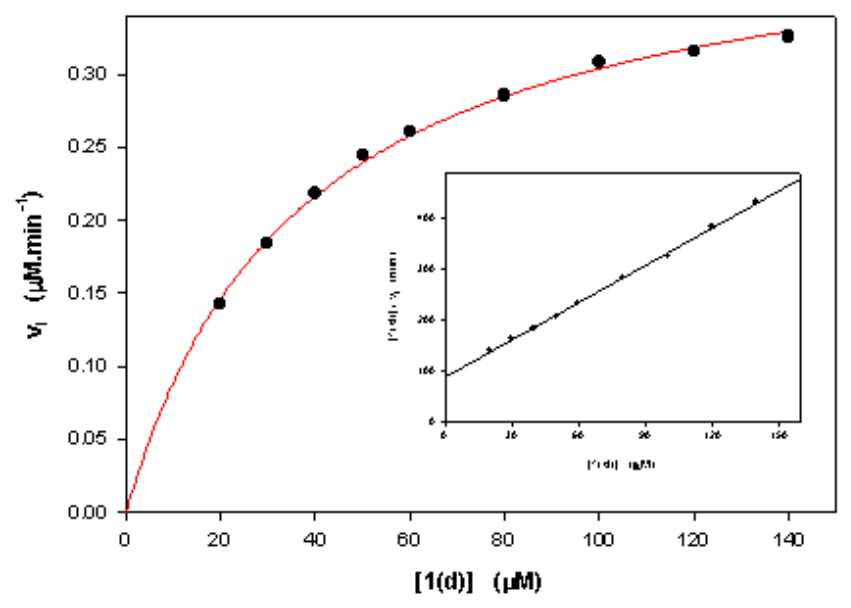

Figure 6. Demonstration of adherence to the Michaelis-Menten equation for the retroaldol reaction of $\mathbf{1} \mathbf{j}$ to give 4-methoxycinnamaldehyde and pent-3-en-2-one, catalyzed by Ab93F3.

All reactions were carried out at room temperature in PBS $(10 \mathrm{mM}$ phosphate, $16 \mathrm{mM}$ $\mathrm{NaCl}, \mathrm{pH}$ 7.4) containing less than $3 \%$ of acetonitrile as the organic solvent. All catalyzed reactions were performed in the presence of $0.064 \mu \mathrm{M}$ of $\mathrm{Ab} 93 \mathrm{~F} 3$. The concentration of the aldol product was varied from 20 to $140 \mu \mathrm{M}$. Initial velocities were determined by following the formation of para-methoxycinnamaldehyde by RPHPLC within $<5 \%$ reaction completion. The points were determined experimentally and the best fit value of $V_{\max }$ and $K_{\mathrm{m}}$ were obtained by fitting the $v_{\mathrm{i}}$ versus [S $]_{0}$ data to hyperbolic saturation curves by weighted non-linear regression using SigmaPlot 5.0 (from SPSS Inc). The data are reported per antibody active site. An IgG antibody possesses two active sites per MW of $\sim 150000 \mathrm{~g} \mathrm{~mol}^{-1}$.

\begin{tabular}{|c|c|c|c|c|c|}
\hline $\begin{array}{c}\text { Concentration } \\
\text { of } \mathbf{1} \mathbf{j}(\mu \mathrm{M})\end{array}$ & $\begin{array}{c}v_{\mathrm{i}} \\
\left(\mu \mathrm{M} \min ^{-1}\right)\end{array}$ & Calculated & Variable & Value & $\begin{array}{l}\text { Std. } \\
\text { Error }\end{array}$ \\
\hline 20 & 0.1422 & 0.1466 & $V_{\max }\left(\mu \mathrm{M} \min ^{-1}\right)$ & 0.415 & 0.006 \\
\hline 30 & 0.1836 & 0.1869 & $k_{\text {cat }}\left(\min ^{-1}\right)$ & 3.24 & 0.047 \\
\hline 40 & 0.2180 & 0.2167 & $K_{\mathrm{m}}(\mu \mathrm{M})$ & 36.6 & 1.42 \\
\hline 50 & 0.2443 & 0.2396 & & & \\
\hline 60 & 0.2605 & 0.2578 & & & \\
\hline 80 & 0.2851 & 0.2848 & & & \\
\hline 100 & 0.3080 & 0.3039 & & & \\
\hline 120 & 0.3150 & 0.3181 & & & \\
\hline 140 & 0.3255 & 0.3291 & & & \\
\hline
\end{tabular}

Uncatalyzed kinetics: All reactions were carried out at room temperature in PBS (10 $\mathrm{mM}$ phosphate, $16 \mathrm{mM} \mathrm{NaCl}, \mathrm{pH} 7.4$ ) containing $2.5 \%$ of acetonitrile as the organic solvent. The reactions were followed by RP-HPLC, and at a concentration of $4 \mathrm{mM}$ no formation of aldehyde or ketone was observed after 5 days. 


\section{Antibody-catalyzed route to enantioenriched HDA adducts}

\section{(R)-6-(4-Methoxybenzyl)-2,2-dimethyltetrahydropyran-4-one $(R)$-2f}<smiles>COc1ccc(C[C@@H]2CC(=O)CC(C)(C)O2)cc1</smiles>

Antibody 84G3 (1 ml, $32 \mathrm{nmol})$ was added to a stock solution of aldol $( \pm)-\mathbf{1 f}(10 \mu \mathrm{l}$ of $80 \mathrm{mM}$ in acetonitrile, $800 \mathrm{nmol}$ ). The reaction was monitored by RP-HPLC. After $216 \mathrm{~h}$ the reaction was observed to have reached $68 \%$ conversion and the unreacted aldol was isolated by semi-preparative reversed-phase HPLC. The fractions were freeze-dried, the residue was redissolved in dichloromethane $(3 \times 20 \mathrm{ml})$, filtered and the solvent removed in vacuo. The recovered aldol has an $e e$ of $83 \%$. The residue was dissolved in dichloromethane $(2.5 \mathrm{ml})$ and cooled to $-78{ }^{\circ} \mathrm{C}$. To this was added diisopropylethylamine $(2 \times 7.3 \mu \mathrm{l}$ of a solution made up as $0.1 \mathrm{ml}$ in $10 \mathrm{ml}$ dichloromethane, $0.85 \mu \mathrm{mol})$ and TMSOTf $(2 \times 8.3 \mu \mathrm{l}$ of a solution made up as $0.1 \mathrm{ml}$ in $10 \mathrm{ml}$ dichloromethane, $0.92 \mu \mathrm{mol})$. The mixture was stirred at $-78^{\circ} \mathrm{C}$ for $1 \mathrm{~h}$ then warmed to $-20{ }^{\circ} \mathrm{C}$ and stirred overnight. The mixture was then was allowed to warm to $10{ }^{\circ} \mathrm{C}$ for $6 \mathrm{~h}$. The crude mixture contained $(R)-2 \mathrm{f}$ with an $e e$ of $83 \%$.

\section{(R)-2,2-Dimethyl-6-phenylethyltetrahydropyran-4-one $(R)-2 \mathrm{~g}$}<smiles>CC1(C)CC(=O)C[C@@H](CCc2ccccc2)O1</smiles>

Antibody 84G3 (1 ml, $32 \mathrm{nmol})$ was added to a stock solution of aldol ( \pm )-1g (10 $\mu \mathrm{l}$ of $80 \mathrm{mM}$ in acetonitrile, $800 \mathrm{nmol}$ ). The reaction was monitored by RP-HPLC. After $216 \mathrm{~h}$ the reaction had reached $51 \%$ conversion and the unreacted aldol was isolated by semi-preparative reverse-phase HPLC. The fractions were freeze-dried, the residue was redissolved in dichloromethane $(3 \times 20 \mathrm{ml})$, filtered and the solvent removed in vacuo. The recovered aldol has an ee of $72 \%$. The residue was dissolved in dichloromethane $(2.5 \mathrm{ml})$ and cooled to $-78{ }^{\circ} \mathrm{C}$. To this was added DIPEA $(2 \times 7.3 \mu \mathrm{l}$ of a solution made up as $0.1 \mathrm{ml}$ in $10 \mathrm{ml}$ dichloromethane, $0.85 \mu \mathrm{mol}$ ) and TMSOTf ( $2 \times 8.3 \mu \mathrm{l}$ of a solution made up as $0.1 \mathrm{ml}$ in $10 \mathrm{ml}$ dichloromethane, $0.92 \mu \mathrm{mol}$ ). The mixture was stirred at $-78{ }^{\circ} \mathrm{C}$ for $1 \mathrm{~h}$ then allowed to warm to $-20{ }^{\circ} \mathrm{C}$ and stirred overnight. The mixture was then warmed to $10{ }^{\circ} \mathrm{C}$ for $6 \mathrm{~h}$. The crude mixture contained $(R)-\mathbf{2 g}$ with an $e e$ of $72 \%$. 


\section{(R)-6-[2-(4-Methoxyphenyl)-ethyl]-2,2-dimethyltetrahydropyran-4-one $(R)-2 h$}<smiles>COc1ccc(CCC2CC(=O)CC(C)(C)O2)cc1</smiles>

Aldol $( \pm)-1 \mathrm{~h}(2.5 \mathrm{mg}, 0.019 \mathrm{mmol})$ was dissolved in $\mathrm{MeCN}(200 \mu \mathrm{l})$. To this was added PBS $(1.8 \mathrm{ml})$ and Ab93F3 $(1 \mathrm{ml}, 164 \mathrm{nmol})$. The reaction was monitored by RP-HPLC. After $44 \mathrm{~h}$ the reaction had reached 52\% conversion and the unreacted aldol was isolated by semi-preparative reverse-phase HPLC. The fractions were freeze-dried, the residue was redissolved in dichloromethane $(3 \times 20 \mathrm{ml})$, filtered and the solvent removed in vacuo to yield the product $(1.1 \mathrm{mg}, 40 \%)$. The recovered aldol has an $e e$ of $>99 \%$. The residue was dissolved in toluene $(0.2 \mathrm{ml})$ and added to $\mathrm{RhCl}\left(\mathrm{PPh}_{3}\right)_{3}(0.83 \mathrm{mg}, \sim 075$ mass eq). The mixture was degassed and placed under $\mathrm{H}_{2}$ (3-layer balloon) and stirred for $24 \mathrm{~h}$. The solvent was removed in vacuo and the residue was taken up in dichloromethane $(1 \mathrm{ml})$, filtered through a silica plug and concentrated .The residue was redissolved in dichloromethane $(0.5 \mathrm{ml})$ and cooled to $-78^{\circ} \mathrm{C}$. To this was added DIPEA $(0.01 \mathrm{ml}$ of a $1 \%$ solution in dichloromethane, 0.8 $\mu \mathrm{mol})$ and TMSOTf $(0.02 \mathrm{ml}$ of a $1 \%$ solution in dichloromethane, $0.0011 \mathrm{mmol})$ and the mixture was stirred for $1 \mathrm{~h}$. The mixture was then allowed to warm to $-20^{\circ} \mathrm{C}$ and stirred for $3 \mathrm{~h}$ before standing in the freezer overnight. The reaction was quenched by addition of saturated $\mathrm{NaHCO}_{3(\mathrm{aq})}(0.5 \mathrm{ml})$ and extracted with dichloromethane $(3 \times 0.5$ $\mathrm{ml})$. The combined organic fractions were dried over $\mathrm{MgSO}_{4}$, filtered under suction

and the solvent removed in vacuo. The crude mixture contained $(R)-2 \mathbf{h}$ with an $e e$ of $>99 \%$.

\section{(S)-2-(4-Methoxyphenyl)-6-methyl-2,3-dihydro-4H-pyran-4-one $(S)$-3a}<smiles>COc1ccc([C@@H]2CC(=O)C=C(C)O2)cc1</smiles>

The racemic $\beta$-hydroxyenone $( \pm)-\mathbf{1 a}(5 \mathrm{mg}, 23 \mu \mathrm{mol})$ was added to a Teflon ${ }^{\circledR}$ tube and dissolved in either toluene or chlorobenzene $(275 \mu \mathrm{l})$. To this was added a $66.7 \mu \mathrm{M}$ solution of Ab84G3 (34 mg, $0.23 \mu \mathrm{mol})$ in PBS (3.4 ml, pH 7.4) and the tube sealed. The mixture was placed in a shaking bath (250 strokes/minute) at room temperature. The ee of the unreacted 1a was monitored periodically by HPLC on chiral stationary phase $(10 \mu \mathrm{l}$ aliquots were removed from the organic layer and diluted to $100 \mu \mathrm{l}$ with mobile phase before analysis). Once the desired substrate ee was attained, the mixture was placed in a freezer for several hours, after which time the organic layer was decanted and the aqueous layer was allowed to thaw. The aqueous layer was then extracted with 1:1 toluene-ethyl acetate $(2 \times 5 \mathrm{ml})$ and the combined organic phases were dried over sodium sulfate, filtered through a plug of silica gel and the solvent was removed under reduced pressure. The crude mixture contained $(S)-\mathbf{1 a}$ in $97 \%$ ee.

The crude reaction product was redissolved in toluene $(100 \mu \mathrm{l})$ and added to a Schlenk tube containing palladium(II) chloride (1 mg, $6 \mu \mathrm{mol})$ and copper(I) chloride $(0.5 \mathrm{mg}, 5 \mu \mathrm{mol})$. The vessel was purged with oxygen and the reaction was heated to $50{ }^{\circ} \mathrm{C}$ before adding PBS $(100 \mu \mathrm{l})$. The addition is accompanied by a gradual change 
in colour from amber to black. The biphasic mixture was stirred vigorously at $50{ }^{\circ} \mathrm{C}$ for a further $4 \mathrm{~h}$. After cooling to room temperature, toluene $(5 \mathrm{ml})$ and ethyl acetate $(5 \mathrm{ml})$ were added and the organic layer separated. The aqueous layer was further extracted with ethyl acetate $(3 \times 5 \mathrm{ml})$ and the organic layers were combined and evaporated under reduced pressure. The crude mixture was purified by passing through a short silica plug $(0.15 \times 150 \mathrm{~cm})$ using hexane-ethyl acetate $(2: 1)$ as eluent. Analysis by chiral phase HPLC revealed complete consumption of $(S)$-1a and cyclised product (S)-3a with $97 \%$ ee.

\section{(S)-1-Hydroxy-1-(4-methoxyphenyl)-pentadec-4-en-3-one (S)-1d}<smiles>COc1ccc([C@@H](O)CC(=O)/C=C/C(C)C)cc1</smiles>

The racemic $\beta$-hydroxyenone $( \pm)$-1a $(25 \mathrm{mg}, 0.11 \mathrm{mmol})$ was added to a Teflon ${ }^{\circledR}$ tube and dissolved in chlorobenzene $(1.3 \mathrm{ml})$. To this was added a $66.7 \mu \mathrm{M}$ solution of Ab84G3 (100 mg, $0.67 \mu \mathrm{mol})$ in PBS $(10.0 \mathrm{ml}, \mathrm{pH} 7.4)$ and the tube sealed. The mixture was placed in a shaking bath (250 strokes/minute) at room temperature. The ee of the unreacted 1a was monitored periodically by HPLC on chiral stationary phase (10 $\mu \mathrm{l}$ aliquots were removed from the organic layer and diluted to $100 \mu \mathrm{l}$ with mobile phase before analysis). After $7 \mathrm{~d}$ and $11 \mathrm{~d}$, further Ab84G3 solution was added (4.7 $\mathrm{ml}$ and $1 \mathrm{ml}$ of $66.7 \mu \mathrm{M}$ solution respectively) to the reaction. Once the desired substrate ee was attained, the mixture was placed in a freezer for several hours, after which time the organic layer was decanted and the aqueous layer was allowed to thaw. The aqueous layer was then extracted with ethyl acetate $(3 \times 10 \mathrm{ml})$ and the combined organic phases were dried over sodium sulfate, filtered through a plug of silica gel and the solvent was removed under reduced pressure. The crude mixture contained $(S)$-1a in $91 \%$ ee.

To a Schlenk tube containing a solution of (S)-1-hydroxy-1-(4-methoxyphenyl)-hex4-en-3-one $(S)-1 \mathrm{a}(6 \mathrm{mg}, 0.0272 \mathrm{mmol})$ and dodecene $(18 \mu 1,0.0817 \mathrm{mmol})$ in anhydrous dichloromethane $(1.5 \mathrm{ml})$ was added Hoveyda-Grubbs catalyst $(1.5 \mathrm{mg}$, $0.002 \mathrm{mmol}, 10 \mathrm{~mol} \%$ ). The reaction was stirred under an argon atmosphere for $24 \mathrm{~h}$ and then concentrated under reduced pressure to afford a dark brown oil. The reaction mixture was purified by column chromatography (eluent $4: 1$ cyclohexane-ethyl acetate) to yield $(S)$-1-hydroxy-1-(4-methoxyphenyl)-pentadec-4-en-3-one $(S)$-1d ( $8 \mathrm{mg}, 0.023 \mathrm{mmol}$ ) a pale brown oil in $85 \%$ yield.

Analysis by chiral phase HPLC revealed complete consumption of $(S)$-1a and crossmetathesis product (S)-1d with $90 \%$ ee. 
Assignment of absolute configurations: Independent asymmetric syntheses of 1f$h, 1 j$ and $2 f-h$

(4S)-Benzyl-3-((3S)-hydroxy-5-(4-methoxyphenyl)-pent-4-enoyl)-oxazolidin-2one (4a)

(4S)-Benzyl-3-((3R)-hydroxy-5-(4-methoxyphenyl)-pent-4-enoyl)-oxazolidin-2one (4b)<smiles>COc1ccc(/C=C/C(O)CC(=O)N2C(=O)OC[C@H]2Cc2ccccc2)cc1</smiles><smiles>COc1ccc(/C=C/C(O)CC(=O)N2C(=O)OC[C@H]2Cc2ccccc2)cc1</smiles>

Di-n-butylboron triflate $(5 \mathrm{ml}, 1 \mathrm{M}$ in dichloromethane, $5 \mathrm{mmol})$ and $\mathrm{Et}_{3} \mathrm{~N}(0.77 \mathrm{ml}$, $5.5 \mathrm{mmol})$ were added to a solution of oxazolidinone $(1 \mathrm{~g}, 4.56 \mathrm{mmol})$ in dichloromethane $(7 \mathrm{ml})$. The reaction mixture was stirred at $-78^{\circ} \mathrm{C}$ for $30 \mathrm{~min}$ and at $0{ }^{\circ} \mathrm{C}$ for $1 \mathrm{~h}$. After cooling the mixture to $-78^{\circ} \mathrm{C}$, a solution of 4-methoxycinnamaldehyde (740 $\mathrm{mg}, 4.56 \mathrm{mmol})$ in dichloromethane $(10 \mathrm{ml})$ was added dropwise. The reaction was stirred for $30 \mathrm{~min}$ at $-78{ }^{\circ} \mathrm{C}$ and then at $0{ }^{\circ} \mathrm{C}$ for $1 \mathrm{~h}$. The reaction was then quenched by addition of sat. $\mathrm{NH}_{4} \mathrm{Cl}(25 \mathrm{ml})$ and extracted with ethyl acetate $(3 \times 25$ $\mathrm{ml})$. The combined organic fractions were dried over $\mathrm{MgSO}_{4}$ and concentrated in vасио. Purification by column chromatography (dichloromethane:hexane:ethyl acetate, 7:2:1) afforded $\mathbf{4 a}$ and $\mathbf{4 b}(d e=54 \%)$ as colorless solids (971 $\mathrm{mg}, 56 \%)$. Analytical data for $\mathbf{4 a}$ (major diastereomer): $\mathrm{mp}$ 135-136 ${ }^{\circ} \mathrm{C} ; \quad \mathrm{R}_{\mathrm{f}}$ (dichloromethane:hexane:ethyl acetate, 7:2:1) $=0.23 ;[\alpha]^{25}{ }_{\mathrm{D}}+40.4^{\circ}\left(\mathrm{c}=0.1, \mathrm{CHCl}_{3}\right)$; $\delta_{1_{\mathrm{H}}}\left(\mathrm{CDCl}_{3}\right) 2.81(1 \mathrm{H}, \mathrm{dd}, J=13.6,9.6 \mathrm{~Hz}), 3.18-3.39(4 \mathrm{H}, \mathrm{m}), 4.18(1 \mathrm{H}, \mathrm{dd}, J=8.2$, $3.2 \mathrm{~Hz}), 4.21(1 \mathrm{H}, \mathrm{dd}, J=8.2,9.2 \mathrm{~Hz}), 4.68-4.75(1 \mathrm{H}, \mathrm{m}), 4.79-4.87(1 \mathrm{H}, \mathrm{m}), 6.18$ $(1 \mathrm{H}, \mathrm{dd}, J=16.0,6.4 \mathrm{~Hz}), 6.64(1 \mathrm{H}, \mathrm{d}, J=16.0 \mathrm{~Hz}), 6.86(2 \mathrm{H}, \mathrm{d}, J=8.6 \mathrm{~Hz}), 7.22$ $(2 \mathrm{H}, \mathrm{d}, J=8.4 \mathrm{~Hz}), 7.20-7.37(5 \mathrm{H}, \mathrm{m}) ; \delta_{{ }_{13} \mathrm{C}}\left(\mathrm{CDCl}_{3}\right) 37.7,42.8,55.1,55.3,66.3,68.9$, 114.0 (2C), 127.4, 127.8 (3C), 129.0 (2C), 129.1, 129.4 (2C), 130.3, 135.0, 153.4, 159.3, 172.0; $v_{\max }\left(\mathrm{CHCl}_{3}\right) 3553,1784,1692 ; \mathrm{m} / z$ (HRMS, FI) found $404.1485\left(\left[\mathrm{M}^{\circ}\right]\right)$ $\left[\mathrm{C}_{22} \mathrm{H}_{23} \mathrm{NO}_{5}+\mathrm{Na}\right]^{+}$requires 404.1474; Anal. Calcd for $\mathrm{C}_{22} \mathrm{H}_{23} \mathrm{NO}_{5}$ : C, 69.28; $\mathrm{H}, 6.08$; N, 3.67. Found: C, 69.26; H, 6.10; N, 3.71; Analytical data for 4b (minor diastereomer): $\mathrm{mp} 146{ }^{\circ} \mathrm{C} ; \mathrm{R}_{\mathrm{f}}$ (dichloromethane:hexane:ethyl acetate, 7:2:1) =0.15; $[\alpha]^{25}{ }_{\mathrm{D}}+62.1^{\circ}\left(\mathrm{c}=1, \mathrm{CHCl}_{3}\right) ; \delta_{{ }_{\mathrm{H}}}\left(\mathrm{CDCl}_{3}\right) 2.80(1 \mathrm{H}, \mathrm{dd}, J=12.6,9.6 \mathrm{~Hz}), 3.02(1 \mathrm{H}, \mathrm{d}$, $J=4.4 \mathrm{~Hz}), 3.27(1 \mathrm{H}, \mathrm{dd}, J=17.2,8.4 \mathrm{~Hz}), 3.33(1 \mathrm{H}, \mathrm{dd}, J=17.2,4.0 \mathrm{~Hz}), 3.33(1 \mathrm{H}$, $\mathrm{dd}, J=12.6,3.2 \mathrm{~Hz}), 6.18(1 \mathrm{H}, \mathrm{dd}, J=15.8,6.4 \mathrm{~Hz}), 6.65(1 \mathrm{H}, \mathrm{d}, J=15.6 \mathrm{~Hz}), 6.87$ $(2 \mathrm{H}, \mathrm{d}, J=8.6 \mathrm{~Hz}), 7.31(2 \mathrm{H}, \mathrm{d}, J=8.4 \mathrm{~Hz}), 7.21-7.38(5 \mathrm{H}, \mathrm{m}) ; \delta_{13 \mathrm{C}}\left(\mathrm{CDCl}_{3}\right) 37.9$, $42.7,55.1,55.3,66.4,68.9,114.0$ (2C), 127.4, 127.6, 127.8 (2C), 129.0 (2C), 129.1, 129.4 (2C), 130.4, 135.1, 153.4, 159.4, 171.9; $v_{\max }\left(\mathrm{CHCl}_{3}\right) 3607,1784,1692 ; \mathrm{m} / \mathrm{z}$ (HRMS, FI) found $404.1469\left(\left[\mathrm{M}^{\circ}\right]\right)\left[\mathrm{C}_{22} \mathrm{H}_{23} \mathrm{NO}_{5}+\mathrm{Na}\right]^{+}$requires 404.1474; Anal. Calcd for $\mathrm{C}_{22} \mathrm{H}_{23} \mathrm{NO}_{5}$ : C, 69.28; H, 6.08; N, 3.67. Found: C, 68.95; H, 6.08; N, 3.75. 
<smiles>COc1ccc(/C=C/[C@@H](O)CC(=O)N(C)OC)cc1</smiles>

Trimethylaluminium ( $2 \mathrm{ml}, 2 \mathrm{M}$ in dichloromethane, $4 \mathrm{mmol}$ ) in toluene was added to a solution of N,O-dimethylhydroxylamine hydrochloride (397 $\mathrm{mg}, 4 \mathrm{mmol}$ ) in THF $(13 \mathrm{ml})$ at $0{ }^{\circ} \mathrm{C}$. After stirring $30 \mathrm{~min}$ at $0{ }^{\circ} \mathrm{C}$ and $20 \mathrm{~min}$ at $\mathrm{RT}$, the reaction mixture was cooled to $-15^{\circ} \mathrm{C}$ and a solution of aldol $4 \mathbf{a}(500 \mathrm{mg}, 1.3 \mathrm{mmol})$ in THF (10 ml) was added dropwise. The cloudy mixture was warmed to $0{ }^{\circ} \mathrm{C}$ and stirred for further 4 $\mathrm{h}$. The reaction was then quenched with $0.5 \mathrm{M} \mathrm{HCl}$ and the aqueous layer was extracted with ethyl acetate $(3 \times 25 \mathrm{ml})$. The organic layer was washed with water, dried over $\mathrm{MgSO}_{4}$ and concentrated in vacuo. Purification by column chromatography (100\% ethyl acetate) afforded $(S)-5(258 \mathrm{mg}, 75 \%)$ as a colorless oil; $\mathrm{R}_{\mathrm{f}}$ (ethyl acetate $)=0.35 ;$ ee $>99 \% ;[\alpha]_{D}^{25}-27.3^{\circ}\left(\mathrm{c}=0.6, \mathrm{CHCl}_{3}\right) ; \delta_{{ }_{\mathrm{H}}}\left(\mathrm{CDCl}_{3}\right) 2.69(1 \mathrm{H}, \mathrm{dd}, J$ $=16.6,9.1 \mathrm{~Hz}), 2.80(1 \mathrm{H}, \mathrm{d}, J=16.6 \mathrm{~Hz}), 3.22(3 \mathrm{H}, \mathrm{s}), 3.70(3 \mathrm{H}, \mathrm{s}), 3.81(3 \mathrm{H}, \mathrm{s})$, $4.00(1 \mathrm{H}, \mathrm{br} \mathrm{s}), 4.70-4.78(1 \mathrm{H}, \mathrm{m}), 6.12(1 \mathrm{H}, \mathrm{dd}, J=6.2,15.9 \mathrm{~Hz}), 6.62(1 \mathrm{H}, \mathrm{d}, J=$ $15.9 \mathrm{~Hz}), 6.85(2 \mathrm{H}, \mathrm{d}, J=8.6 \mathrm{~Hz}), 7.33(2 \mathrm{H}, \mathrm{d}, J=8.6 \mathrm{~Hz}) ; \delta_{13 \mathrm{C}}\left(\mathrm{CDCl}_{3}\right) 31.8,38.6$, $55.2,61.2,68.8,113.9$ (2C), $127.6(2 \mathrm{C}), 128.5,129.4,129.6,159.1,172.9 ; v_{\max }$ (neat) $3427.5,1644.9 ; \mathrm{m} / \mathrm{z}$ (HRMS, GCT, FI) $265.1314\left(\left[\mathrm{M}^{\circ}\right]\right), \mathrm{C}_{14} \mathrm{H}_{19} \mathrm{NO}_{4}$ requires 265.1314.

\section{(S)-6-Hydroxy-8-(4-methoxy-phenyl)-2-methyl-octa-2,7-dien-4-one (S)-1h}<smiles>COc1ccc(/C=C/[C@@H](O)CC(=O)C=C(C)C)cc1</smiles>

2-Methyl-1-prop-1-enyl-magnesium bromide $(9.6 \mathrm{ml}, 4.8 \mathrm{mmol})$ was added to a solution of Weinreb amide $(S)-5(240 \mathrm{mg}, 0.85 \mathrm{mmol})$ in THF $(8 \mathrm{ml})$ at $-40{ }^{\circ} \mathrm{C}$. The mixture was allowed to warm to $0{ }^{\circ} \mathrm{C}$ over $30 \mathrm{~min}$ and stirred for further $48 \mathrm{~h}$. Sat. $\mathrm{NH}_{4} \mathrm{Cl}$ was added $(30 \mathrm{ml})$ and the mixture allowed to warm up to RT. The reaction was extracted with dichloromethane $(3 \times 30 \mathrm{ml})$, dried over $\mathrm{MgSO}_{4}$ and concentrated in vacuo. Purification by column chromatography (hexane:ethyl acetate, 7:3) afforded $(S)-\mathbf{1 h}(70 \mathrm{mg}, 32 \%$, ee $=40 \%)$ as a yellow oil; $\mathrm{R}_{\mathrm{f}}$ (hexane:ethyl acetate, $\left.7: 3\right)=0.66$; $[\alpha]^{25}-5.8^{\circ}\left(\mathrm{c}=1, \mathrm{CHCl}_{3}\right)$ 
<smiles>COc1ccc(CC[C@@H]2CC(=O)CC(C)(C)O2)cc1</smiles>

Aldol $(S)$-1h $(6 \mathrm{mg}, 0.023 \mathrm{mmol})$ in toluene $(1 \mathrm{ml})$ was added to $\mathrm{RhCl}\left(\mathrm{PPh}_{3}\right)_{3}(4.5$ $\mathrm{mg}, 0.75$ mass eq). The mixture was degassed and placed under $\mathrm{H}_{2}$. The mixture was allowed to stir for $24 \mathrm{~h}$. The solvent was removed in vacuo. The residue was taken up in dichloromethane $(1 \mathrm{ml})$ and filtered through a plug of silica which was washed with dichloromethane. The solvent was removed in vacuo to yield a yellow oil. The residue was dissolved in dichloromethane $(0.5 \mathrm{ml})$ and cooled to $-78^{\circ} \mathrm{C}$. To this was added diisopropylethylamine $(0.01 \mathrm{ml}$ of a $10 \%$ solution in dichloromethane, $0.008 \mathrm{mmol})$ and TMSOTf $(0.02 \mathrm{ml}$ of a $10 \%$ solution in dichloromethane, $0.011 \mathrm{mmol})$ and the mixture allowed to stir for $1 \mathrm{~h}$. The mixture was then allowed to warm to $-20^{\circ} \mathrm{C}$ and allowed to stir for $3 \mathrm{~h}$. The mixture was then placed in the freezer overnight. The mixture was quenched by addition of saturated $\mathrm{NaHCO}_{3(\mathrm{aq})}(2.5 \mathrm{ml})$. The mixture was extracted with dichloromethane $(3 \times 2.5 \mathrm{ml})$, the combined organic fractions dried over $\mathrm{MgSO}_{4}$, filtered under suction and the solvent removed in vacuo. The residue was purified by column chromatography (cyclohexane:diethyl ether, 2:1) to yield the $(R)$ 2h $(3.5 \mathrm{mg}, 58 \%$ over 2 steps $)$ as an oil; ee $=40 \%$; $[\alpha]^{25}{ }_{\mathrm{D}}+16.4^{\circ}\left(\mathrm{c}=0.25, \mathrm{CHCl}_{3}\right)$.

\section{(S)-6-Hydroxy-8-(4-methoxyphenyl)-2-methyl-octa-2,7-dien-4-one (S)-1j}<smiles>C/C=C/C(=O)C[C@@H](O)/C=C/c1ccc(OC)cc1</smiles>

1-Prop-1-enyl magnesium bromide $(12 \mathrm{ml}, 6 \mathrm{mmol})$ was added to a solution of Weinreb amide $(S)-5(280 \mathrm{mg}, 0.99 \mathrm{mmol})$ in $\mathrm{THF}(6 \mathrm{ml})$ at $-40{ }^{\circ} \mathrm{C}$. The mixture was allowed to warm to $0{ }^{\circ} \mathrm{C}$ over $30 \mathrm{~min}$ and stirred for further $6 \mathrm{~h}$. Sat. $\mathrm{NH}_{4} \mathrm{Cl}$ was added $(20 \mathrm{ml})$ and the mixture allowed to warm up to RT. The reaction was extracted with dichloromethane $(3 \times 30 \mathrm{ml})$, dried over $\mathrm{MgSO}_{4}$ and concentrated in vacuo. Purification by column chromatography (hexane:ethyl acetate, 6:4) afforded $(S)$-1j $\left(140 \mathrm{mg}, 58 \%\right.$, ee>99\%) as a yellow oil; $\mathrm{R}_{\mathrm{f}}($ hexane:ethyl acetate, $6: 4)=0.34 ;[\alpha]^{25}{ }_{\mathrm{D}}^{-}$ $16.5^{\circ}\left(\mathrm{c}=0.6, \mathrm{CHCl}_{3}\right)$.

\section{(S)-3-Hydroxy-5-phenyl-pentanoic acid ethyl ester $(S)-6^{\dagger}$}<smiles>CCOC(=O)C[C@@H](O)CCc1ccccc1</smiles>

In a $1 \mathrm{~L}$ round bottom flask was placed 3-oxo-5-phenyl-pentanoic acid ethyl ester (2.4 $\mathrm{g}, 10.8 \mathrm{mmol}$ ) , $376 \mathrm{ml}$ of petroleum ether (boiling range $\left.40-60^{\circ} \mathrm{C}\right), 112 \mathrm{~g}$ of yeast $(10$ $\mathrm{g} / \mathrm{mmol}$ of substrate), $90 \mathrm{ml}$ of water $(0.8 \mathrm{ml} / \mathrm{g}$ of yeast $)$, and the reaction stirred at room temperature. After $24 \mathrm{~h}$ the reaction mixture was filtered through cotton wool and the yeast washed with ethyl acetate $(4 \times 50 \mathrm{ml})$, filtered and the solvent removed

\footnotetext{
${ }^{\dagger}$ Reference: N. Athanasiou, A.J. Smallridge; M.A. Trewhella Journal of Molecular Catalysis B. Enzymatic 2001, 11 (4-6), 2003.
} 
under reduced pressure. Purification by column chromatography on silica (hexane:ethyl acetate, 8:2) afforded $(S)-6(1.4 \mathrm{~g}, 56 \%)$ as a colorless oil; $\mathrm{R}_{\mathrm{f}}$ (hexane:ethyl acetate, 7:3) $=0.27$; ee>99\%; $[\alpha]^{25}{ }^{-2.6^{\circ}}\left(\mathrm{c}=0.5, \mathrm{CHCl}_{3}\right)$.

\section{(S)-3-Hydroxy-5-phenyl-pentanoic acid methoxymethylamide (S)-7}<smiles>CON(C)C(=O)C[C@@H](O)CCc1ccccc1</smiles>

Trimethylaluminium $(1.4 \mathrm{ml}, 2 \mathrm{M}$ in dichloromethane, $2.8 \mathrm{mmol})$ in toluene was added to a solution of N,O-dimethylhydroxylamine hydrochloride (266 mg, 2.7 mmol) in THF $(8 \mathrm{ml})$ at $0{ }^{\circ} \mathrm{C}$. After stirring $30 \mathrm{~min}$ at $0{ }^{\circ} \mathrm{C}$ and $20 \mathrm{~min}$ at $\mathrm{RT}$, the reaction mixture was cooled to $-15^{\circ} \mathrm{C}$ and a solution of aldol $(S)-6(200 \mathrm{mg}, 0.9$ $\mathrm{mmol})$ in THF $(5 \mathrm{ml})$ was added dropwise. The cloudy mixture was warmed to $0{ }^{\circ} \mathrm{C}$ and stirred for further $4 \mathrm{~h}$. The reaction was then quenched with $0.5 \mathrm{M} \mathrm{HCl}(2 \mathrm{ml})$ and the aqueous layer was extracted with ethyl acetate $(3 \times 10 \mathrm{ml})$. The organic layer was washed with water, dried over $\mathrm{MgSO}_{4}$ and concentrated in vacuo. Purification by column chromatography (hexane:ethyl acetate, 4:6) afforded $(S)-7(180 \mathrm{mg}, 85 \%)$ as a colorless oil; $\mathrm{R}_{\mathrm{f}}(\mathrm{c}$-hexane:ethyl acetate, $4: 6)=0.20$; ee $>99 \% ;[\alpha]^{25}+28.6^{\circ}(\mathrm{c}=1.08$, $\left.\mathrm{CHCl}_{3}\right) ; \delta_{1_{\mathrm{H}}}\left(\mathrm{CDCl}_{3}\right) 1.73-1.82(1 \mathrm{H}, \mathrm{m}), 1.85-1.95(1 \mathrm{H}, \mathrm{m}), 2.54(1 \mathrm{H}, \mathrm{dd}, J=16.4$, $9.2 \mathrm{~Hz}), 2.65(1 \mathrm{H}$, app. d, $J=16.4 \mathrm{~Hz}), 2.74(1 \mathrm{H}, \mathrm{ddd}, J=14.1,6.8,9.6 \mathrm{~Hz}), 2.88$ $(1 \mathrm{H}, \mathrm{ddd}, J=14.1,5.2,9.4 \mathrm{~Hz}), 3.18(3 \mathrm{H}, \mathrm{s}), 3.65(3 \mathrm{H}, \mathrm{s}), 4.04-4.15(2 \mathrm{H}, \mathrm{m}), 7.16-$ $7.32(5 \mathrm{H}, \mathrm{m}) ; \delta_{13 \mathrm{C}}\left(\mathrm{CDCl}_{3}\right): 32.2,32.3,38.8(2 \mathrm{C}), 61.6,67.6,126.2,128.8(2 \mathrm{C}), 128.9$ (2C), 142.5, 174.1; $v_{\max }$ (neat) 3437, 1647; $\mathrm{m} / \mathrm{z}$ (HRMS, FI) found $237.1366\left(\left[\mathrm{M}^{\circ}\right]\right)$ $\mathrm{C}_{13} \mathrm{H}_{19} \mathrm{NO}_{3}$ requires 237.1365.

\section{(S)-6-Hydroxy-2-methyl-8-phenyl-oct-2-en-4-one (S)-1g}<smiles>CC(C)=CC(=O)C[C@@H](O)CCc1ccccc1</smiles>

2-Methyl-1-prop-1-enyl-magnesium bromide (17 $\mathrm{ml}, 8.5 \mathrm{mmol})$ was added to a solution of Weinreb amide $(S)-7(380 \mathrm{mg}, 1.6 \mathrm{mmol})$ in $\mathrm{THF}(15 \mathrm{ml})$ at $-40{ }^{\circ} \mathrm{C}$. The mixture was allowed to warm to $0{ }^{\circ} \mathrm{C}$ over $30 \mathrm{~min}$ and stirred for further $48 \mathrm{~h}$. Sat. $\mathrm{NH}_{4} \mathrm{Cl}$ was added $(30 \mathrm{ml})$ and the mixture allowed to warm up to RT. The reaction was extracted with dichloromethane, dried over $\mathrm{MgSO}_{4}$ and concentrated in vacuo. Purification by column chromatography (hexane:ethyl acetate, 7:3) afforded $(S)$-1g $\left(120 \mathrm{mg}, 32 \%\right.$, ee>99\%) as a yellow oil; $\mathrm{R}_{\mathrm{f}}$ (c-hexane:ethyl acetate, $\left.4: 6\right)=0.75$; $[\alpha]^{25}+15^{\circ}\left(\mathrm{c}=0.21, \mathrm{CHCl}_{3}\right)$.

\section{2,2-Dimethyl-(6S)-phenylethyl-tetrahydro-pyran-4-one $(S)-2 \mathrm{~g}$}<smiles>CC1(C)CC(=O)C[C@@H](CCc2ccccc2)O1</smiles>

Diisopropylethylamine $(12.8 \mu \mathrm{l}, 0.075 \mathrm{mmol})$ and TMSOTf $(24.5 \mu \mathrm{l}, 0.13 \mathrm{mmol})$ were added to a solution of aldol $(S)-1 \mathrm{~g}(116 \mathrm{mg}, 0.5 \mathrm{mmol})$ in dichloromethane $(2.5$ $\mathrm{ml})$ at $-78{ }^{\circ} \mathrm{C}$. The reaction was stirred $1 \mathrm{~h}$ at $-78{ }^{\circ} \mathrm{C}$ and then at $-20^{\circ} \mathrm{C}$ overnight. After $24 \mathrm{~h}$ the reaction mixture was quenched with $\mathrm{NaHCO}_{3}$ and the aqueous layer was extracted with ethyl acetate. The organic layer was washed with water, dried over $\mathrm{MgSO}_{4}$ and concentrated in vacuo. Purification by column chromatography 
(hexane:ethyl acetate, 8:2) afforded $(S)-\mathbf{2 g}(80 \mathrm{mg}, 69 \%$, ee>99\%) as a colorless oil; $\mathrm{R}_{\mathrm{f}}\left(\mathrm{c}\right.$-hexane:ethyl acetate, 8:2) $=0.34 ;[\alpha]^{25}{ }^{-44.8^{\circ}}\left(\mathrm{c}=0.62, \mathrm{CHCl}_{3}\right)$.

(4R)-Benzyl-3-((3R)-hydroxy-4-(4-methoxy-phenyl)-butyryl)-oxazolidin-2-one 8 (4R)-Benzyl-3-((3S)-hydroxy-4-(4-methoxy-phenyl)-butyryl)-oxazolidin-2-one 9
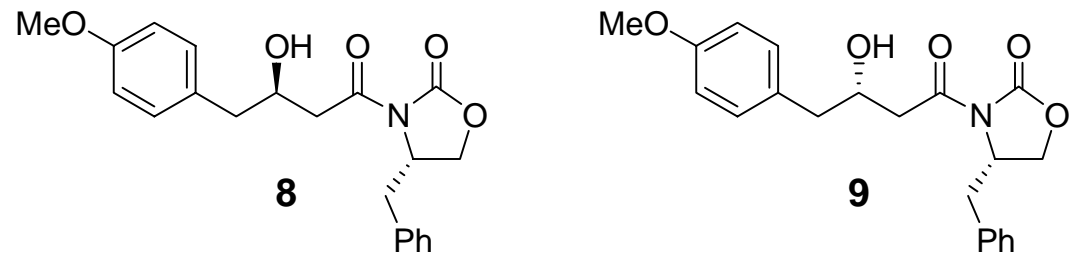

Di-n-butylboron triflate $(5 \mathrm{ml}, 1 \mathrm{M}$ in dichloromethane, $5 \mathrm{mmol}$ ) and triethylamine $(0.77 \mathrm{ml}, 5.5 \mathrm{mmol})$ were added to a solution of oxazolidinone $(1 \mathrm{~g}, 4.56 \mathrm{mmol})$ in dichloromethane $(7 \mathrm{ml})$. The reaction mixture was stirred at $-78^{\circ} \mathrm{C}$ for $30 \mathrm{~min}$ and at $0{ }^{\circ} \mathrm{C}$ for $1 \mathrm{~h}$. After cooling the mixture to $-78{ }^{\circ} \mathrm{C}$, a solution of (4-methoxyphenyl)acetaldehyde $(684 \mathrm{mg}, 4.56 \mathrm{mmol})$ in dichloromethane $(10 \mathrm{ml})$ was added dropwise. The reaction was allowed to stir at $-78{ }^{\circ} \mathrm{C}$ for $30 \mathrm{~min}$ and then $0{ }^{\circ} \mathrm{C}$ for $1 \mathrm{~h}$. The reaction was then quenched by addition of sat. $\mathrm{NH}_{4} \mathrm{Cl}(25 \mathrm{ml})$ and extracted with ethyl acetate $(3 \times 25 \mathrm{ml})$. The combined organic fractions were dried over $\mathrm{MgSO}_{4}$ and concentrated in vacuo. Purification by column chromatography (dichloromethane:ethyl acetate, 9:1) afforded the two diastereomers 8 and 9 (de= $19 \%$ ) as white solids (897 mg, 53\%); Analysis for 8: $\mathrm{mp} 88^{\circ} \mathrm{C} ; \mathrm{R}_{\mathrm{f}}$ (dichloromethane: ethyl acetate, 9:1) =0.36; $[\alpha]^{25}{ }_{\mathrm{D}}+22.9\left(\mathrm{c}=0.95, \mathrm{CHCl}_{3}\right) ; \delta_{{ }_{\mathrm{H}}}\left(\mathrm{CDCl}_{3}\right) 2.79(1 \mathrm{H}$, app. $\mathrm{d}, J=13.4 \mathrm{~Hz}), 2.82(1 \mathrm{H}, \mathrm{dd}, J=13.8,4.8 \mathrm{~Hz}), 2.88(1 \mathrm{H}, \mathrm{dd}, J=13.8,7.2 \mathrm{~Hz}), 3.12$ $(1 \mathrm{H}, \mathrm{dd}, J=17.4,8.0 \mathrm{~Hz}), 3.14(1 \mathrm{H}, \mathrm{dd}, J=17.4,4.4 \mathrm{~Hz}), 3.29(1 \mathrm{H}, \mathrm{dd}, J=13.4,3.6$ $\mathrm{Hz}), 3.81(3 \mathrm{H}, \mathrm{s}), 4.19(1 \mathrm{H}, \mathrm{dd}, J=8.8,4.0 \mathrm{~Hz}), 4.21(1 \mathrm{H}, \mathrm{dd}, J=8.8,9.2 \mathrm{~Hz}), 4.30$ $5.38(1 \mathrm{H}, \mathrm{m}), 4.65-4.72(1 \mathrm{H}, \mathrm{m}), 6.88(2 \mathrm{H}, \mathrm{d}, J=8.4 \mathrm{~Hz}), 7.19(2 \mathrm{H}, \mathrm{d}, J=8.4 \mathrm{~Hz})$, 7.17-7.38 $(5 \mathrm{H}, \mathrm{m}) ; v_{\max }\left(\mathrm{CHCl}_{3}\right) 3567,1784,1692 ; \mathrm{m} / z\left(\mathrm{HRMS}, \mathrm{ESI}^{+}\right)$found $392.1479\left([\mathrm{M}+\mathrm{Na}]^{+}\right) \quad \mathrm{C}_{21} \mathrm{H}_{24} \mathrm{NO}_{5}$ requires 392.1474; Analysis for 9: $\mathrm{R}_{\mathrm{f}}$ (dichloromethane:ethyl acetate, 9:1) $=0.30 ;[\alpha]_{\mathrm{D}}^{25} 74.8\left(\mathrm{c}=1, \mathrm{CHCl}_{3}\right) ; \delta_{\mathrm{H}_{\mathrm{H}}}\left(\mathrm{CDCl}_{3}\right)$ $2.76(1 \mathrm{H}, \mathrm{dd}, J=13.5,9.6 \mathrm{~Hz}), 2.82(1 \mathrm{H}, \mathrm{dd}, J=13.6,6.0 \mathrm{~Hz}), 2.86(1 \mathrm{H}, \mathrm{dd}, J=$ $13.6,6.8 \mathrm{~Hz}), 2.91(1 \mathrm{H}$, br s), $3.07(1 \mathrm{H}, \mathrm{dd}, J=17.4,8.8 \mathrm{~Hz}), 3.19(1 \mathrm{H}, \mathrm{dd}, J=17.4$, $2.4 \mathrm{~Hz}), 3.30(1 \mathrm{H}, \mathrm{dd}, J=13.5,3.2 \mathrm{~Hz}) 3.81(3 \mathrm{H}, \mathrm{s}), 4.17(1 \mathrm{H}, \mathrm{dd}, J=8.7,3.2 \mathrm{~Hz})$, $4.20(1 \mathrm{H}, \mathrm{dd}, J=8.7,9.2 \mathrm{~Hz}), 4.35-4.43(1 \mathrm{H}, \mathrm{m}), 4.64-4.72(1 \mathrm{H}, \mathrm{m}), 6.89(2 \mathrm{H}, \mathrm{d}, J=$ $8.6 \mathrm{~Hz}), 7.21(2 \mathrm{H}, \mathrm{d}, J=8.4 \mathrm{~Hz}), 7.18-7.37(5 \mathrm{H}, \mathrm{m}) ; \delta_{13 \mathrm{C}}\left(\mathrm{CDCl}_{3}\right) 37.9,42.0,42.1$, 55.1, 55.2, 66.3, 69.0, 114.0 (2C), 127.4, 129.0 (2C), 129.4 (2C), 129.8, 130.5 (2C), 135.1, 153.4, 158.4, 172.4; $v_{\max }\left(\mathrm{CHCl}_{3}\right) 3572,1784,1693 ; \mathrm{m} / z\left(\mathrm{HRMS}, \mathrm{ESI}^{+}\right)$found $392.1471\left([\mathrm{M}+\mathrm{Na}]^{+}\right) \mathrm{C}_{21} \mathrm{H}_{24} \mathrm{NO}_{5}$ requires 392.1474.

\section{(R)-3-Hydroxy- $N$-methoxy-4-(4-methoxyphenyl)- $N$-methylbutyramide $(R)-10$}<smiles>COc1ccc(C[C@@H](O)CC(=O)N(C)OC)cc1</smiles>

Trimethyaluminium ( $1.4 \mathrm{ml}, 2 \mathrm{M}$ in dichloromethane, $2.8 \mathrm{mmol})$ in toluene was added to a solution of N,O-dimethylhydroxylamine hydrochloride $(278 \mathrm{mg}, 2.8 \mathrm{mmol})$ in THF $(5 \mathrm{ml})$ at $0{ }^{\circ} \mathrm{C}$. After stirring $30 \mathrm{~min}$ at $0{ }^{\circ} \mathrm{C}$ and $20 \mathrm{~min}$ at $\mathrm{RT}$, the reaction mixture was cooled to $-15{ }^{\circ} \mathrm{C}$ and a solution of aldol 8 (349 mg, $\left.0.94 \mathrm{mmol}\right)$ in THF $(5 \mathrm{ml})$ was added dropwise. The mixture was warmed to $0^{\circ} \mathrm{C}$ and stirred for further 4 
h. The reaction was then quenched with $0.5 \mathrm{M} \mathrm{HCl}(2 \mathrm{ml})$ and the aqueous layer was extracted with ethyl acetate $(3 \times 10 \mathrm{ml})$. The organic layer was washed with water, dried over $\mathrm{MgSO}_{4}$ and concentrated in vacuo. Purification by column chromatography (hexane:ethyl acetate, 4:6) afforded $(R)-\mathbf{1 0}(200 \mathrm{mg}, 88 \%)$ as a colorless oil; $\mathrm{R}_{\mathrm{f}}(\mathrm{c}-$ hexane:ethyl acetate, 8:2) $=0.13$; ee>99\%; $[\alpha]^{25}-46.96^{\circ}\left(\mathrm{c}=1.08, \mathrm{CHCl}_{3}\right) ; \delta_{{ }_{\mathrm{H}}}$ $\left(\mathrm{CDCl}_{3}\right) 2.49(1 \mathrm{H}, \mathrm{dd}, J=16.3,9.2 \mathrm{~Hz}), 2.67(1 \mathrm{H}$, app. d, $J=16.3 \mathrm{~Hz}), 2.73(1 \mathrm{H}, \mathrm{dd}$, $J=13.6,6.4 \mathrm{~Hz}), 2.87(1 \mathrm{H}, \mathrm{dd}, J=13.6,7.2 \mathrm{~Hz}), 3.19(3 \mathrm{H}, \mathrm{s}), 3.64(3 \mathrm{H}, \mathrm{s}), 3.80(3 \mathrm{H}$, s), $4.22-4.29(1 \mathrm{H}, \mathrm{m}), 6.86(2 \mathrm{H}, \mathrm{d}, J=8.8 \mathrm{~Hz}), 7.17(2 \mathrm{H}, \mathrm{d}, J=8.8 \mathrm{~Hz}) ; \delta_{{ }^{3} \mathrm{C}}\left(\mathrm{CDCl}_{3}\right)$ $31.8,37.3,42.055 .2,61.2,69.2,113.8(2 \mathrm{C}), 130.2,130.3(2 \mathrm{C}), 158.2 ; v_{\max }$ (neat) 3434,$1759 ; \mathrm{m} / \mathrm{z}$ (HRMS, $\left.\mathrm{CI}^{+}\right)$found $254.1391\left(\left[\mathrm{M}+\mathrm{H}^{+}\right]\right) \mathrm{C}_{13} \mathrm{H}_{20} \mathrm{NO}_{4}$ requires 254.1392 .

\section{(R)-6-Hydroxy-7-(4-methoxyphenyl)-2-methylhept-2-en-4-one $(R)-1 f$}<smiles>COc1ccc(CC(O)CC(=O)C=C(C)C)cc1</smiles>

2-Methyl-1-prop-1-enyl magnesium bromide $(6.4 \mathrm{ml}, 3.2 \mathrm{mmol})$ was added to a solution of Weinreb amide $(R)-\mathbf{1 0}(134 \mathrm{mg}, 0.53 \mathrm{mmol})$ in THF $(5 \mathrm{ml})$ at $-40{ }^{\circ} \mathrm{C}$. The mixture was allowed to warm to $0{ }^{\circ} \mathrm{C}$ over $30 \mathrm{~min}$ and stirred for further $48 \mathrm{~h}$. Sat. $\mathrm{NH}_{4} \mathrm{Cl}$ was added $(10 \mathrm{ml})$ and the mixture allowed to warm up to RT. The reaction was extracted with dichloromethane $(3 \times 15 \mathrm{ml})$, dried over $\mathrm{MgSO}_{4}$ and concentrated in vacuo. Purification by column chromatography (c-hexane:ethyl acetate, 8:2) afforded $(R)-\mathbf{1 f}\left(40 \mathrm{mg}, 30 \%\right.$, ee>99\%) as a yellow oil; $[\alpha]^{25} \mathrm{D}^{-15.3^{\circ}}\left(\mathrm{c}=1, \mathrm{CHCl}_{3}\right)$.

\section{(6R)-4-Methoxybenzyl-2,2-dimethyltetrahydropyran-4-one $(R)-2 f$}<smiles>COc1ccc(C[C@@H]2CC(=O)CC(C)(C)O2)cc1</smiles>

Diisopropylethylamine $(6 \mu \mathrm{l}, 0.023 \mathrm{mmol})$ and trimethylsilyl triflate $(12 \mu \mathrm{l}, 0.063$ mmol) were added to a solution of aldol $(R)-\mathbf{1 f}(39 \mathrm{mg}, 0.16 \mathrm{mmol})$ in dichloromethane $(2 \mathrm{ml})$ at $-78{ }^{\circ} \mathrm{C}$. The reaction was stirred $1 \mathrm{~h}$ at $-78{ }^{\circ} \mathrm{C}, 4 \mathrm{~h}$ at -10 ${ }^{\circ} \mathrm{C}$ and then overnight at $0{ }^{\circ} \mathrm{C}$. After $24 \mathrm{~h}$ the reaction mixture was quenched with $\mathrm{NaHCO}_{3}(2 \mathrm{ml})$ and the aqueous layer was extracted with ethyl acetate $(3 \times 10 \mathrm{ml})$. The organic layer was washed with water, dried over $\mathrm{MgSO}_{4}$ and concentrated in vacuo. Purification by column chromatography (c-hexane:ethyl acetate, 9:1) afforded $(R)$-2f as a colorless oil $(80 \mathrm{mg}, 70 \%$, ee $>99 \%) . \mathrm{R}_{\mathrm{f}}(\mathrm{c}$-hexane:ethyl acetate, $8: 2)=0.34$; $[\alpha]^{25}+22.17^{\circ}\left(\mathrm{c}=0.62, \mathrm{CHCl}_{3}\right)$. 


\section{Inhibition Experiments}

Control experiment 1: Racemization of $\beta$-hydroxyenone $\mathbf{1 b}$<smiles>CC/C=C/C(=O)CC(O)c1ccc(OC)cc1</smiles><smiles>CC/C=C/C(=O)C[C@H](O)c1ccc(OC)cc1</smiles>

\begin{tabular}{|c|c|c|c|}
\hline Entry & Time (days) & Conversion (\%) & ee (\%) \\
\hline $\mathbf{1}$ & $81 / \mathbf{2}$ & 52 & 40 \\
\hline $\mathbf{2}$ & 10 & 52 & 26 \\
\hline
\end{tabular}

Control experiment 2: Inhibition by $\beta$-hydroxyenones $\mathbf{1 l}$ and $\mathbf{1 k}$.<smiles>CC/C=C/C(=O)CC(O)c1ccc(OC)cc1</smiles>
ab 84G3 (10 mol\%)

PBS (10\% MeCN), rt 50 to $200 \%$ mol of $\mathbf{1 k}$<smiles>CC/C=C/C(=O)C[C@@H](O)c1ccc(OC)cc1</smiles>

\begin{tabular}{|c|c|c|c|c|c|}
\hline Entry & $\begin{array}{c}\text { Time } \\
\text { (min) }\end{array}$ & $\begin{array}{c}\mathbf{0} \text { mol\% 1k/ } \\
\text { Conv. (\%) }\end{array}$ & $\begin{array}{c}\text { 50 mol\% 1k/ } \\
\text { Conv. (\%) }\end{array}$ & $\begin{array}{c}\text { 100 mol \% 1k/ } \\
\text { Conv. (\%) }\end{array}$ & $\begin{array}{c}\text { 200 mol\% 1k/ } \\
\text { Conv. (\%) }\end{array}$ \\
\hline $\mathbf{1}$ & 40 & 33 & 56 & 51 & 47 \\
\hline $\mathbf{2}$ & 80 & 50 & 53 & 48 & 44 \\
\hline $\mathbf{3}$ & 200 & 50 & 50 & 33 & 28 \\
\hline
\end{tabular}<smiles>CC/C=C/C(=O)CC(O)c1ccc(OC)cc1</smiles>
ab 84G3 (10 mol\%) PBS (10\% MeCN), rt 50 to $100 \% \mathrm{~mol}$ of $\mathbf{1 l}$<smiles>CC/C=C/C(=O)C[C@@H](O)c1ccc(OC)cc1</smiles>

\begin{tabular}{|c|c|c|c|c|}
\hline Entry & $\begin{array}{c}\text { Time } \\
\text { (min) }\end{array}$ & $\begin{array}{c}\text { 0 mol \% 1l/ } \\
\text { Conv. }(\boldsymbol{\%})\end{array}$ & $\begin{array}{c}\mathbf{5 0} \text { mol \% 1l/ } \\
\text { Conv. (\%) }\end{array}$ & $\begin{array}{c}\text { 100 mol \% 1l/ } \\
\text { Conv. (\%) }\end{array}$ \\
\hline $\mathbf{1}$ & 40 & 33 & 22 & 22 \\
\hline $\mathbf{2}$ & 80 & 50 & 18 & 16 \\
\hline $\mathbf{3}$ & 200 & 50 & 11 & 4 \\
\hline
\end{tabular}




\title{
Inorganic Chemistry Crystallography Service
}

\author{
Single-crystal X-ray diffraction report for $4 a \mathrm{C}_{22} \mathrm{H}_{23} \mathrm{NO}_{5}$ (ARC331) \\ Andrew R. Cowley
}

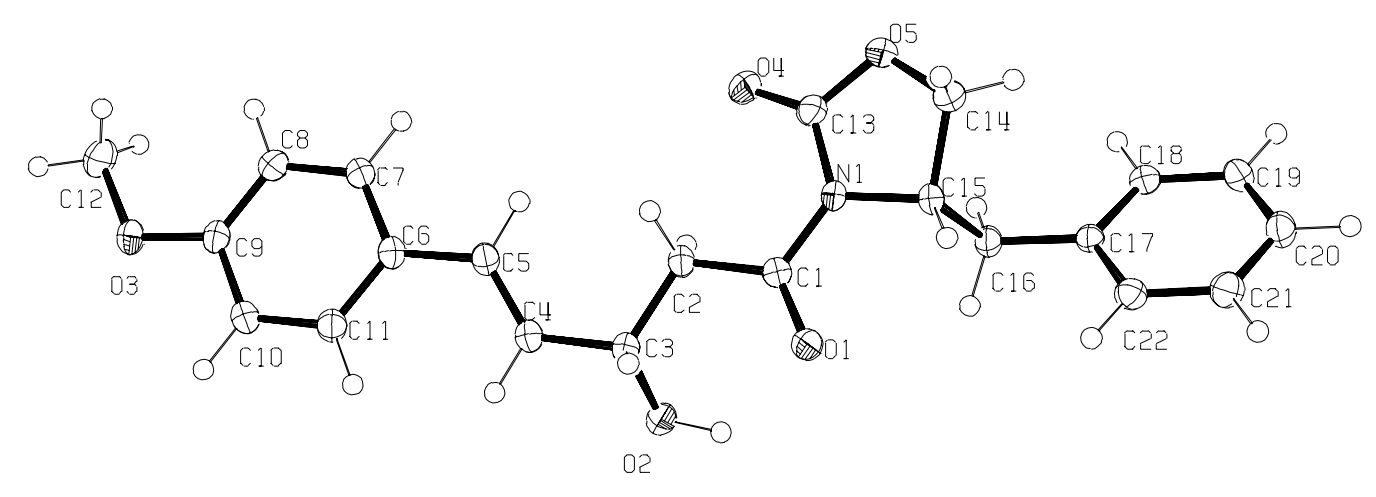

Crystals of ARC331 were grown by recrystallisation from methylene chloride. A large single crystal was cut to give a fragment having dimensions approximately $0.12 \times 0.32 \times 0.34$ $\mathrm{mm}$. This was mounted on a glass fibre using perfluoropolyether oil and cooled rapidly to $150 \mathrm{~K}$ in a stream of cold $\mathrm{N}_{2}$ using an Oxford Cryosystems CRYOSTREAM unit. Diffraction data were measured using an Enraf-Nonius KappaCCD diffractometer (graphite-monochromated $\mathrm{MoK}_{\alpha}$ radiation, $\lambda=0.71073 \AA$ ). Intensity data were processed using the DENZO-SMN package ${ }^{1}$. to be either

Examination of the systematic absences of the intensity data showed the space group

$P 2_{1}$ or $P 2_{1} / m$. The structure was solved in the space group $P 2_{1}$ using the direct-methods program SIR92 ${ }^{2}$, which located all non-hydrogen atoms. Examination of the resulting model cklearly showed no mirror plane to be present, confirming the assignment of symmetry. Subsequent full-matrix least-squares refinement was carried out using the CRYSTALS program suite $^{3}$. Coordinates and anisotropic thermal parameters of all non-hydrogen atoms were refined. The hydrxyl $\mathrm{H}$ atom was located in a difference Fourier map and its coordiantes and isotropic thermal parameter subsequently refined. Other hydrogen atoms were positioned geometrically after each cycle of refinement. A 3-term Chebychev polynomial weighting scheme was applied. Refinement converged satisfactorily to give $R=0.0278, w R=0.0363$.

Attached is a thermal ellipsoid plot (ORTEP- $3^{4}$ ) at $40 \%$ probability. A summary of crystallographic data is given below, as are full lists of atomic coordinates, anisotropic thermal parameters and those bond lengths and angles not concerning $\mathrm{H}$ atoms.

\section{Comment:}

The hydroxyl hydrogen atom forms a bifurcated hydrogen bond with the amide $\mathrm{O}$ atom of the same molecule $(\mathrm{O}(2) \cdots \mathrm{O}(1) 2.9319(17) \AA)$ and with the carbamate carbonyl O atom of a second molecule related by a translation along the $b$ axis $\left(O(!) \cdots O(4)^{\prime} 2.8874(18) \AA\right)$. The Corresponding $\mathrm{O}-\mathrm{H} \cdots \mathrm{O}$ angles are $127(3)$ and $136(3)^{\circ}$ respectively.

\section{References:}

1 Z. Otwinowski and W. Minor, Processing of X-ray Diffraction Data Collected in Oscillation Mode, Methods Enzymol., 1997, 276, Eds C. W. Carter and R. M. Sweet, Academic Press.

2 A. Altomare, G. Cascarano, G. Giacovazzo, A. Guagliardi ,M. C. Burla, G. Polidori and M. Camalli, J. Appl. Cryst. 1994, 27, 435.

3 D. J. Watkin, C. K. Prout, J. R. Carruthers, P. W. Betteridge and R. I. Cooper, 4 CRYSTALS issue 11, Chemical Crystallography Laboratory, 
Table 1: Crystal data and refinement details

\begin{tabular}{|c|c|}
\hline Crystal identification & ARC331 \\
\hline Chemical formula & $\mathrm{C}_{22} \mathrm{H}_{23} \mathrm{NO}_{5}$ \\
\hline Formula weight & 381.43 \\
\hline Temperature $(\mathrm{K})$ & 150 \\
\hline Wavelength $(\AA)$ & 0.71073 \\
\hline Crystal system & Monoclinic \\
\hline Space group & $P 2_{1}$ \\
\hline$a(\AA)$ & $6.9822(1)$ \\
\hline 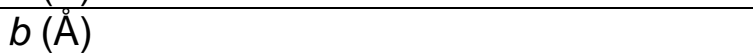 & $6.4712(1)$ \\
\hline$c(\AA)$ & 20.9553(4) \\
\hline$\alpha\left(^{\circ}\right)$ & 90 \\
\hline$\beta\left(^{\circ}\right)$ & 94.6879(8) \\
\hline$\gamma\left({ }^{\circ}\right)$ & 90 \\
\hline Cell volume $\left(\AA^{3}\right)$ & 943.7 \\
\hline Z & 2 \\
\hline Calculated density $\left(\mathrm{Mg} / \mathrm{m}^{3}\right)$ & 1.342 \\
\hline Absorption coefficient $\left(\mathrm{mm}^{-1}\right)$ & 0.095 \\
\hline $\mathrm{F}_{000}$ & 404.122 \\
\hline Crystal size $(\mathrm{mm})$ & $0.12 \times 0.32 \times 0.34$ \\
\hline Description of crystal & Colourless fragment \\
\hline Absorption correction & Semi-empirical from equivalent reflections \\
\hline Transmission coefficients (min,max) & $0.97,0.99$ \\
\hline$\theta$ range for data collection $\left({ }^{\circ}\right)$ & $5.0 \leq \theta \leq 27.5$ \\
\hline Index ranges & $-9 \leq h \leq 9,0 \leq k \leq 8,0 \leq I \leq 27$ \\
\hline Reflections measured & 10862 \\
\hline Unique reflections & 2311 \\
\hline $\mathrm{R}_{\text {int }}$ & 0.028 \\
\hline Observed reflections $(\mathrm{I}>3 \sigma(\mathrm{I}))$ & 1998 \\
\hline Refinement method & Full-matrix least-squares on $F$ \\
\hline Parameters refined & 257 \\
\hline Weighting scheme & Chebychev 3-term polynomial \\
\hline Goodness of fit & 0.9632 \\
\hline $\mathrm{R}$ & 0.0278 \\
\hline$w R$ & 0.0363 \\
\hline Residual electron density $(\min , \max )\left(\mathrm{e} \AA^{-3}\right)$ & $-0.13,0.16$ \\
\hline
\end{tabular}


Table 2: Atomic coordinates and equivalent isotropic thermal parameters $\left(\AA^{2}\right)$ of non-hydrogen atoms

\begin{tabular}{|c|c|c|c|c|}
\hline Atom & $\mathrm{X}$ & $\mathrm{y}$ & $\mathrm{Z}$ & $\mathrm{U}_{\text {equiv }}$ \\
\hline & & & & \\
\hline $\mathrm{N}(1)$ & $0.39243(19)$ & $0.0912(2)$ & $0.21000(6)$ & 0.0211 \\
\hline $\mathrm{C}(1)$ & $0.5030(2)$ & $0.2360(3)$ & $0.24622(7)$ & 0.0200 \\
\hline $\mathrm{O}(1)$ & $0.43238(16)$ & $0.4025(2)$ & $0.25742(6)$ & 0.0268 \\
\hline $\mathrm{C}(2)$ & $0.7052(2)$ & $0.1742(3)$ & $0.26953(8)$ & 0.0225 \\
\hline $\mathrm{C}(3)$ & $0.8059(2)$ & $0.3405(3)$ & $0.31106(7)$ & 0.0220 \\
\hline $\mathrm{O}(2)$ & $0.83698(18)$ & $0.5264(2)$ & $0.27620(6)$ & 0.0277 \\
\hline $\mathrm{C}(4)$ & $1.0014(2)$ & $0.2758(3)$ & $0.33984(8)$ & 0.0233 \\
\hline $\mathrm{C}(5)$ & $1.0735(2)$ & $0.0854(3)$ & $0.34366(7)$ & 0.0220 \\
\hline $\mathrm{C}(6)$ & $1.2653(2)$ & $0.0311(3)$ & $0.37375(7)$ & 0.0220 \\
\hline $\mathrm{C}(7)$ & $1.3459(2)$ & $-0.1598(3)$ & $0.36223(8)$ & 0.0241 \\
\hline $\mathrm{C}(8)$ & $1.5276(2)$ & $-0.2165(3)$ & $0.38971(8)$ & 0.0252 \\
\hline $\mathrm{C}(9)$ & $1.6293(2)$ & $-0.0794(3)$ & $0.43046(7)$ & 0.0222 \\
\hline $\mathrm{C}(11)$ & $1.5507(2)$ & $0.1130(3)$ & $0.44304(8)$ & 0.0256 \\
\hline $\mathrm{O}(3)$ & $1.3719(2)$ & $0.1678(3)$ & $0.41491(8)$ & 0.0250 \\
\hline $\mathrm{C}(12)$ & $1.80689(16)$ & $-0.1168(2)$ & $0.46128(6)$ & 0.0282 \\
\hline $\mathrm{C}(13)$ & $1.8939(3)$ & $-0.3112(3)$ & $0.4491(1)$ & 0.0353 \\
\hline $\mathrm{O}(4)$ & $0.4484(2)$ & $-0.1047(3)$ & $0.19230(7)$ & 0.0250 \\
\hline $\mathrm{O}(5)$ & $0.60527(18)$ & $-0.1833(2)$ & $0.19898(6)$ & 0.0325 \\
\hline $\mathrm{C}(14)$ & $0.29478(18)$ & $-0.2032(2)$ & $0.16346(6)$ & 0.0301 \\
\hline $\mathrm{C}(15)$ & $0.1225(3)$ & $-0.0820(3)$ & $0.17009(8)$ & 0.0267 \\
\hline $\mathrm{C}(16)$ & $0.1967(2)$ & $0.1376(3)$ & $0.18240(7)$ & 0.0207 \\
\hline $\mathrm{C}(17)$ & $0.2033(2)$ & $0.2680(3)$ & $0.12150(7)$ & 0.0218 \\
\hline $\mathrm{C}(18)$ & $0.0054(2)$ & $0.3018(3)$ & $0.08831(7)$ & 0.0188 \\
\hline $\mathrm{C}(19)$ & $-0.0480(2)$ & $0.2034(3)$ & $0.03037(7)$ & 0.0220 \\
\hline $\mathrm{C}(20)$ & $-0.2307(2)$ & $0.2317(3)$ & $-0.00010(8)$ & 0.0246 \\
\hline $\mathrm{C}(21)$ & $-0.3623(2)$ & $0.3589(3)$ & $0.02670(8)$ & 0.0268 \\
\hline $\mathrm{C}(22)$ & $-0.3102(2)$ & $0.4585(3)$ & $0.08421(8)$ & 0.0273 \\
\hline & $-0.1279(2)$ & $0.4303(3)$ & $0.11502(7)$ & 0.0235 \\
\hline
\end{tabular}


Table 3: Atomic coordinates and isotropic thermal parameters $\left(\AA^{2}\right)$ of hydrogen atoms

\begin{tabular}{|c|c|c|c|c|}
\hline Atom & $\mathrm{x}$ & $\mathrm{y}$ & $\mathrm{z}$ & $\mathrm{U}_{\text {iso }}$ \\
\hline & & & & \\
\hline $\mathrm{H}(1)$ & $0.712(5)$ & $0.578(6)$ & $0.2617(16)$ & $0.077(11)$ \\
\hline $\mathrm{H}(21)$ & 0.7001 & 0.0442 & 0.2952 & 0.0267 \\
\hline $\mathrm{H}(22)$ & 0.7803 & 0.1489 & 0.2316 & 0.0267 \\
\hline $\mathrm{H}(31)$ & 0.7164 & 0.3644 & 0.3452 & 0.0261 \\
\hline $\mathrm{H}(41)$ & 1.0868 & 0.3888 & 0.3582 & 0.0276 \\
\hline $\mathrm{H}(51)$ & 0.9916 & -0.0294 & 0.3247 & 0.0262 \\
\hline $\mathrm{H}(71)$ & 1.2719 & -0.2599 & 0.3334 & 0.0286 \\
\hline $\mathrm{H}(81)$ & 1.5835 & -0.3542 & 0.3801 & 0.0300 \\
\hline $\mathrm{H}(101)$ & 1.6239 & 0.2118 & 0.4725 & 0.0302 \\
\hline $\mathrm{H}(111)$ & 1.3176 & 0.3067 & 0.4240 & 0.0297 \\
\hline $\mathrm{H}(122)$ & 2.0219 & -0.3202 & 0.4741 & 0.0419 \\
\hline $\mathrm{H}(123)$ & 1.8094 & -0.4256 & 0.4624 & 0.0419 \\
\hline $\mathrm{H}(141)$ & 1.9113 & -0.3237 & 0.4024 & 0.0419 \\
\hline $\mathrm{H}(142)$ & 0.0531 & -0.1327 & 0.2069 & 0.0316 \\
\hline $\mathrm{H}(151)$ & 0.0347 & -0.0880 & 0.1300 & 0.0316 \\
\hline $\mathrm{H}(161)$ & 0.1141 & 0.2216 & 0.2094 & 0.0245 \\
\hline $\mathrm{H}(162)$ & 0.2615 & 0.4053 & 0.1333 & 0.0259 \\
\hline $\mathrm{H}(181)$ & 0.2846 & 0.1953 & 0.0914 & 0.0259 \\
\hline $\mathrm{H}(191)$ & 0.0459 & 0.1115 & 0.0106 & 0.0264 \\
\hline $\mathrm{H}(201)$ & -0.2673 & 0.1599 & -0.0416 & 0.0291 \\
\hline $\mathrm{H}(211)$ & -0.4937 & 0.3788 & 0.0048 & 0.0319 \\
\hline $\mathrm{H}(221)$ & -0.4043 & 0.5511 & 0.1036 & 0.0329 \\
\hline & -0.0919 & 0.5023 & 0.1565 & 0.0281 \\
\hline
\end{tabular}


Table 4: Anisotropic thermal parameters $\left(\AA^{2}\right)$

\begin{tabular}{|c|c|c|c|c|c|c|}
\hline Atom & $U_{11}$ & $U_{22}$ & $U_{33}$ & $U_{23}$ & $U_{13}$ & $U_{12}$ \\
\hline $\mathrm{N}(1)$ & $0.0200(6)$ & $0.0202(6)$ & $0.0222(6)$ & $0.0003(5)$ & $-0.0050(5)$ & $0.0025(5)$ \\
\hline$C(1)$ & $0.0196(7)$ & $0.0204(7)$ & $0.0199(6)$ & $-0.0002(6)$ & $0.0006(5)$ & $-0.0000(6)$ \\
\hline $\mathrm{O}(1)$ & $0.0220(5)$ & $0.0235(6)$ & $0.0339(6)$ & $-0.0059(5)$ & $-0.0035(4)$ & $0.0036(5)$ \\
\hline $\mathrm{C}(2)$ & $0.0204(7)$ & $0.0239(8)$ & $0.0225(7)$ & $-0.0009(6)$ & $-0.0038(6)$ & $0.0023(6)$ \\
\hline $\mathrm{C}(3)$ & $0.0205(7)$ & $0.0215(8)$ & $0.0232(7)$ & $-0.0004(6)$ & $-0.0027(5)$ & $0.0023(6)$ \\
\hline $\mathrm{O}(2)$ & $0.0244(6)$ & $0.0222(6)$ & $0.0354(6)$ & $0.0039(5)$ & $-0.0049(5)$ & $0.0002(5)$ \\
\hline$C(4)$ & $0.0198(7)$ & $0.0242(8)$ & $0.0251(7)$ & $-0.0007(7)$ & $-0.0027(6)$ & $0.0004(6)$ \\
\hline$C(5)$ & $0.0201(7)$ & $0.0253(8)$ & $0.0202(7)$ & $-0.0007(6)$ & $-0.0014(5)$ & $0.0007(6)$ \\
\hline $\mathrm{C}(6)$ & $0.0215(7)$ & $0.0248(8)$ & $0.0193(7)$ & $0.0013(7)$ & $-0.0009(6)$ & $0.0006(7)$ \\
\hline $\mathrm{C}(7)$ & $0.0246(7)$ & $0.0228(8)$ & $0.0240(7)$ & $-0.0023(6)$ & $-0.0031(6)$ & $0.0018(7)$ \\
\hline $\mathrm{C}(8)$ & $0.0241(7)$ & $0.0223(8)$ & $0.0288(7)$ & $-0.0002(7)$ & $-0.0008(6)$ & $0.0028(7)$ \\
\hline $\mathrm{C}(9)$ & $0.0189(7)$ & $0.0251(8)$ & $0.0221(7)$ & $0.0034(7)$ & $-0.0005(5)$ & $0.0015(7)$ \\
\hline$C(10)$ & $0.0244(7)$ & $0.0264(8)$ & $0.0249(7)$ & $-0.0018(7)$ & $-0.0048(6)$ & $0.0001(7)$ \\
\hline $\mathrm{C}(11)$ & $0.0251(8)$ & $0.0260(8)$ & $0.0232(7)$ & $-0.0025(7)$ & $-0.0017(6)$ & $0.0042(7)$ \\
\hline $\mathrm{O}(3)$ & $0.0201(5)$ & $0.0295(7)$ & $0.0337(6)$ & $0.0001(5)$ & $-0.0068(4)$ & $0.0041(5)$ \\
\hline $\mathrm{C}(12)$ & $0.0250(8)$ & $0.033(1)$ & $0.047(1)$ & $0.0017(9)$ & $-0.0041(7)$ & $0.0108(8)$ \\
\hline$C(13)$ & $0.0311(8)$ & $0.0209(8)$ & $0.0220(7)$ & $0.0009(6)$ & $-0.0037(6)$ & $0.0021(7)$ \\
\hline $\mathrm{O}(4)$ & $0.0329(6)$ & $0.0244(6)$ & $0.0386(6)$ & $-0.0051(6)$ & $-0.0074(5)$ & $0.0100(6)$ \\
\hline $\mathrm{O}(5)$ & $0.0341(6)$ & $0.0199(6)$ & $0.0341(6)$ & $-0.0035(5)$ & $-0.0097(5)$ & $0.0009(5)$ \\
\hline $\mathrm{C}(14)$ & $0.0276(8)$ & $0.0224(8)$ & $0.0292(8)$ & $0.0038(7)$ & $-0.0031(6)$ & $-0.0023(7)$ \\
\hline $\mathrm{C}(15)$ & $0.0169(7)$ & $0.0216(8)$ & $0.0228(7)$ & $-0.0002(6)$ & $-0.0033(5)$ & $0.0007(6)$ \\
\hline $\mathrm{C}(16)$ & $0.0184(7)$ & $0.0223(8)$ & $0.0241(7)$ & $0.0023(6)$ & $-0.0020(5)$ & $-0.0004(6)$ \\
\hline $\mathrm{C}(17)$ & $0.0179(6)$ & $0.0171(7)$ & $0.0212(6)$ & $0.0027(6)$ & $0.0003(5)$ & $-0.0013(6)$ \\
\hline $\mathrm{C}(18)$ & $0.0227(7)$ & $0.0193(8)$ & $0.0240(7)$ & $-0.0013(6)$ & $0.0013(6)$ & $0.0010(6)$ \\
\hline$C(19)$ & $0.0242(7)$ & $0.0253(8)$ & $0.0235(7)$ & $-0.0014(6)$ & $-0.0032(6)$ & $-0.0022(7)$ \\
\hline $\mathrm{C}(20)$ & $0.0202(7)$ & $0.0295(9)$ & $0.0301(8)$ & $0.0023(7)$ & $-0.0026(6)$ & $-0.0007(7)$ \\
\hline $\mathrm{C}(21)$ & $0.0203(7)$ & $0.0280(9)$ & $0.0340(9)$ & $-0.0029(7)$ & $0.0050(6)$ & $0.0029(7)$ \\
\hline $\mathrm{C}(22)$ & $0.0261(8)$ & $0.0221(8)$ & $0.0221(7)$ & $-0.0014(6)$ & $0.0011(6)$ & $0.0003(7)$ \\
\hline
\end{tabular}


Table 5: Bond lengths (Å)

\begin{tabular}{|c|c|}
\hline$N(1)-C(1)$ & $1.398(2)$ \\
\hline $\mathrm{N}(1)-\mathrm{C}(13)$ & $1.386(2)$ \\
\hline $\mathrm{N}(1)-\mathrm{C}(15)$ & $1.4708(18)$ \\
\hline$C(1)-O(1)$ & $1.216(2)$ \\
\hline$C(1)-C(2)$ & $1.510(2)$ \\
\hline$C(2)-C(3)$ & $1.520(2)$ \\
\hline $\mathrm{C}(3)-\mathrm{O}(2)$ & $1.433(2)$ \\
\hline$C(3)-C(4)$ & $1.506(2)$ \\
\hline $\mathrm{O}(2)-\mathrm{H}(1)$ & $0.96(4)$ \\
\hline$C(4)-C(5)$ & $1.331(2)$ \\
\hline$C(5)-C(6)$ & $1.475(2)$ \\
\hline$C(6)-C(7)$ & $1.387(2)$ \\
\hline$C(6)-C(11)$ & $1.405(2)$ \\
\hline$C(7)-C(8)$ & $1.399(2)$ \\
\hline$C(8)-C(9)$ & $1.386(2)$ \\
\hline$C(9)-C(10)$ & $1.395(2)$ \\
\hline $\mathrm{C}(9)-\mathrm{O}(3)$ & $1.3723(18)$ \\
\hline$C(10)-C(11)$ & $1.382(2)$ \\
\hline $\mathrm{O}(3)-\mathrm{C}(12)$ & $1.429(2)$ \\
\hline $\mathrm{C}(13)-\mathrm{O}(4)$ & $1.205(2)$ \\
\hline $\mathrm{C}(13)-\mathrm{O}(5)$ & $1.347(2)$ \\
\hline $\mathrm{O}(5)-\mathrm{C}(14)$ & $1.452(2)$ \\
\hline$C(14)-C(15)$ & $1.527(2)$ \\
\hline$C(15)-C(16)$ & $1.534(2)$ \\
\hline$C(16)-C(17)$ & $1.5110(19)$ \\
\hline$C(17)-C(18)$ & $1.395(2)$ \\
\hline$C(17)-C(22)$ & $1.398(2)$ \\
\hline$C(18)-C(19)$ & $1.391(2)$ \\
\hline$C(19)-C(20)$ & $1.386(2)$ \\
\hline$C(20)-C(21)$ & $1.389(2)$ \\
\hline$C(21)-C(22)$ & $1.392(2)$ \\
\hline
\end{tabular}

Note - geometrically-positioned $\mathrm{H}$ atoms have been excluded 
Table 6: Bond angles $\left(^{\circ}\right)$

\begin{tabular}{|c|c|}
\hline$C(1)-N(1)-C(13)$ & $127.09(14)$ \\
\hline$C(1)-N(1)-C(15)$ & $122.06(14)$ \\
\hline$C(13)-N(1)-C(15)$ & $110.77(13)$ \\
\hline $\mathrm{N}(1)-\mathrm{C}(1)-\mathrm{O}(1)$ & 118.96(14) \\
\hline$N(1)-C(1)-C(2)$ & $117.28(14)$ \\
\hline $\mathrm{O}(1)-\mathrm{C}(1)-\mathrm{C}(2)$ & 123.76(15) \\
\hline$C(1)-C(2)-C(3)$ & $111.96(14)$ \\
\hline $\mathrm{C}(2)-\mathrm{C}(3)-\mathrm{O}(2)$ & $112.63(12)$ \\
\hline$C(2)-C(3)-C(4)$ & $113.20(14)$ \\
\hline $\mathrm{O}(2)-\mathrm{C}(3)-\mathrm{C}(4)$ & 105.53(13) \\
\hline $\mathrm{C}(3)-\mathrm{O}(2)-\mathrm{H}(1)$ & $106.3(23)$ \\
\hline$C(3)-C(4)-C(5)$ & 127.42(15) \\
\hline$C(4)-C(5)-C(6)$ & $124.88(15)$ \\
\hline$C(5)-C(6)-C(7)$ & 120.31(15) \\
\hline$C(5)-C(6)-C(11)$ & 121.94(16) \\
\hline$C(7)-C(6)-C(11)$ & 117.74(14) \\
\hline$C(6)-C(7)-C(8)$ & $121.95(16)$ \\
\hline$C(7)-C(8)-C(9)$ & $119.17(16)$ \\
\hline$C(8)-C(9)-C(10)$ & 119.91(14) \\
\hline$C(8)-C(9)-O(3)$ & 125.07(15) \\
\hline $\mathrm{C}(10)-\mathrm{C}(9)-\mathrm{O}(3)$ & $115.02(14)$ \\
\hline$C(9)-C(10)-C(11)$ & $120.25(16)$ \\
\hline$C(6)-C(11)-C(10)$ & $120.98(17)$ \\
\hline$C(9)-O(3)-C(12)$ & $116.92(13)$ \\
\hline$N(1)-C(13)-O(4)$ & $128.89(17)$ \\
\hline $\mathrm{N}(1)-\mathrm{C}(13)-\mathrm{O}(5)$ & $108.72(14)$ \\
\hline $\mathrm{O}(4)-\mathrm{C}(13)-\mathrm{O}(5)$ & $122.38(17)$ \\
\hline $\mathrm{C}(13)-\mathrm{O}(5)-\mathrm{C}(14)$ & $109.69(13)$ \\
\hline$O(5)-C(14)-C(15)$ & 104.29(13) \\
\hline $\mathrm{N}(1)-\mathrm{C}(15)-\mathrm{C}(14)$ & $99.65(13)$ \\
\hline $\mathrm{N}(1)-\mathrm{C}(15)-\mathrm{C}(16)$ & $110.45(13)$ \\
\hline$C(14)-C(15)-C(16)$ & $113.84(13)$ \\
\hline$C(15)-C(16)-C(17)$ & $111.98(12)$ \\
\hline$C(16)-C(17)-C(18)$ & $120.26(13)$ \\
\hline$C(16)-C(17)-C(22)$ & $121.02(13)$ \\
\hline$C(18)-C(17)-C(22)$ & 118.72(13) \\
\hline$C(17)-C(18)-C(19)$ & $120.62(14)$ \\
\hline$C(18)-C(19)-C(20)$ & 120.36(15) \\
\hline$C(19)-C(20)-C(21)$ & $119.46(14)$ \\
\hline$C(20)-C(21)-C(22)$ & $120.43(15)$ \\
\hline$C(17)-C(22)-C(21)$ & 120.39(14) \\
\hline
\end{tabular}

Note - geometrically-positioned $\mathrm{H}$ atoms have been excluded 


\section{Inorganic Chemistry Crystallography Service}

\section{Single-crystal X-ray diffraction report for $\mathrm{C}_{21} \mathrm{H}_{23} \mathrm{NO}_{5} 8$ (ARC667)}

Andrew R. Cowley

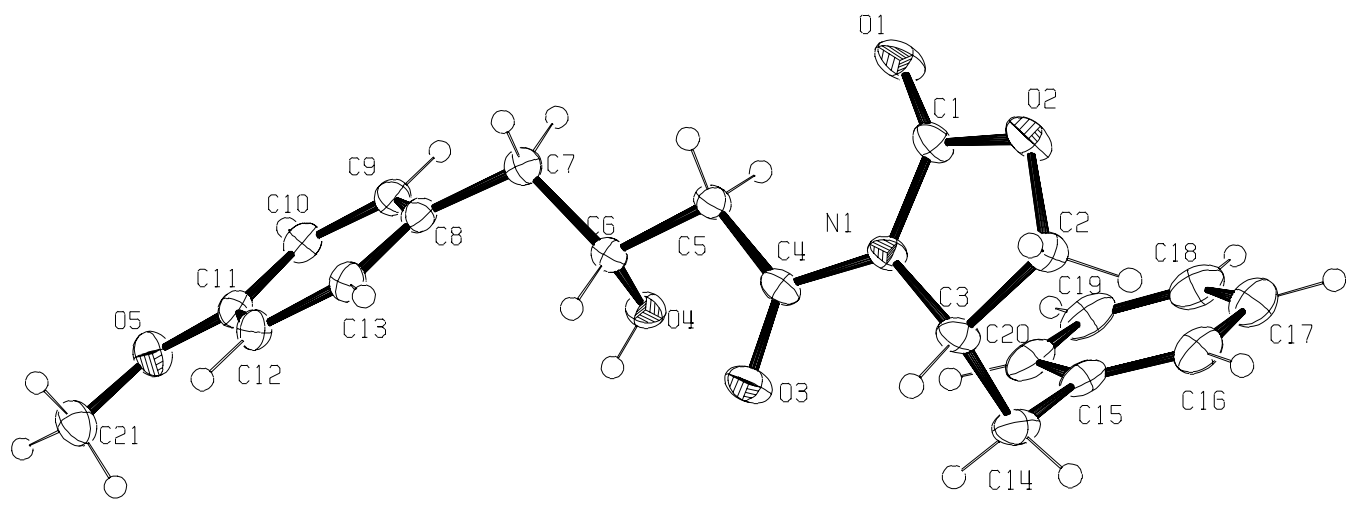

Crystals of ARC667 were grown by were grown by recrystallisation from methylene chloride/hexane. A single crystal having dimensions approximately $0.08 \times 0.10 \times 0.32 \mathrm{~mm}$ was mounted on a glass fibre using perfluoropolyether oil and cooled rapidly to $150 \mathrm{~K}$ in a stream of cold $\mathrm{N}_{2}$ using an Oxford Cryosystems CRYOSTREAM unit. Diffraction data were measured using an Enraf-Nonius KappaCCD diffractometer (graphite-monochromated $\mathrm{MoK}_{\alpha}$ radiation, $\lambda=0.71073 \AA$ ) . Intensity data were processed using the DENZO-SMN package ${ }^{1}$. Examination of the systematic absences of the intensity data showed the space group to be

$P 2_{1} 2_{1} 2_{1}$. The structure was solved using the direct-methods program SIR92 ${ }^{2}$, which located all non-hydrogen atoms. Subsequent full-matrix leastsquares refinement was carried out using the CRYSTALS program suite ${ }^{3}$. Coordinates and anisotropic thermal parameters of all non-hydrogen atoms were refined. The hydroxyl hydrogen atom was located in a difference Fourier map and its coordinates and isotropic thermal parameter subsequently refined. Other hydrogen atoms were positioned geometrically after each cycle of refinement. A 3-term Chebychev polynomial weighting scheme was applied. Refinement converged satisfactorily to give $R=0.0302, w R=$ 0.0334 .

Attached is a thermal ellipsoid plot (ORTEP- $3^{4}$ ) at $40 \%$ probability. A summary of crystallographic data is given below, as are full lists of atomic coordinates, anisotropic thermal parameters and those bond lengths and angles not concerning geometrically-positioned $\mathrm{H}$ atoms.

\section{Comment:}

The $\mathrm{OH}$ group forms a hydrogen bond to the ether $\mathrm{O}$ atom of a neighbouring molecule $(\mathrm{O}(4) \cdots O(5) ' 2.821$ (2) $\AA$, symmetry operator $1 / 2+x, 3 / 2$ $y, 1-z)$. The hydrogen bonds link the molecules to form helical chains running parallel to the crystallographic a axis. 


\section{References:}

1 Z. Otwinowski and W. Minor, Processing of X-ray Diffraction Data Collected in Oscillation Mode, Methods Enzymol., 1997, 276, Eds C. W. Carter and R. M. Sweet, Academic Press.

2 A. Altomare, G. Cascarano, G. Giacovazzo, A. Guagliardi ,M. C. Burla, G. Polidori and M. Camalli, J. Appl. Cryst. 1994, $27,435$.

3 D. J. Watkin, C. K. Prout, J. R. Carruthers, P. W. Betteridge and R. I. Cooper, CRYSTALS issue 11, Chemical Crystallography Laboratory, Oxford, UK, 2001.

4 ORTEP-3 v. 1.0.2, C. K. Johnson and M. K. Burnett, 1998.

Table 1: Crystal data and refinement details

\begin{tabular}{|c|c|}
\hline Crystal identification & ARC667 \\
\hline Chemical formula & $\mathrm{C}_{21} \mathrm{H}_{23} \mathrm{NO}_{5}$ \\
\hline Formula weight & 369.42 \\
\hline Temperature $(\mathrm{K})$ & 150 \\
\hline Wavelength $(\AA)$ & 0.71073 \\
\hline Crystal system & Orthorhombic \\
\hline Space group & $P 2_{1} 2_{1} 2_{1}$ \\
\hline$a(\AA)$ & $6.1113(2)$ \\
\hline$b(\AA)$ & $10.0071(2)$ \\
\hline$c(\AA)$ & $30.1100(5)$ \\
\hline$\alpha\left(^{\circ}\right)$ & 90 \\
\hline$\beta\left(^{\circ}\right)$ & 90 \\
\hline$\gamma\left({ }^{\circ}\right)$ & 90 \\
\hline Cell volume $\left(\AA^{3}\right)$ & 1841.42(8) \\
\hline$Z$ & 4 \\
\hline Calculated density $\left(\mathrm{Mg} / \mathrm{m}^{3}\right)$ & 1.332 \\
\hline Absorption coefficient $\left(\mathrm{mm}^{-1}\right)$ & 0.095 \\
\hline$F_{000}$ & 784 \\
\hline Crystal size $(\mathrm{mm})$ & $0.08 \times 0.10 \times 0.32$ \\
\hline Description of crystal & Colourless prism \\
\hline Absorption correction & Semi-empirical from equivalent reflections \\
\hline Transmission coefficients (min,max) & $0.97,0.99$ \\
\hline$\theta$ range for data collection $\left({ }^{\circ}\right)$ & $5.0 \leq \theta \leq 27.5$ \\
\hline Index ranges & $0 \leq h \leq 7,0 \leq k \leq 12,0 \leq I \leq 38$ \\
\hline Reflections measured & 12925 \\
\hline Unique reflections & 2408 \\
\hline $\mathrm{R}_{\text {int }}$ & 0.035 \\
\hline Observed reflections $(\mathrm{I}>3 \sigma(\mathrm{I}))$ & 1839 \\
\hline Refinement method & Full-matrix least-squares on $F$ \\
\hline Parameters refined & 248 \\
\hline Weighting scheme & Chebychev 3-term polynomial \\
\hline Goodness of fit & 1.0680 \\
\hline $\mathrm{R}$ & 0.0302 \\
\hline $\mathrm{wR}$ & 0.0334 \\
\hline Residual electron density (min,max) $\left(e \AA^{-3}\right)$ & $-0.15,0.16$ \\
\hline
\end{tabular}


Table 2: Atomic coordinates and equivalent isotropic thermal parameters $\left(\AA^{2}\right)$ of non-hydrogen atoms

\begin{tabular}{|c|c|c|c|c|}
\hline Atom & $\mathbf{X}$ & $\mathbf{y}$ & $\mathbf{z}$ & $\mathrm{U}_{\text {equiv }}$ \\
\hline & & & & \\
\hline $\mathrm{N}(1)$ & $0.3068(3)$ & $0.11734(16)$ & $0.63745(5)$ & 0.0230 \\
\hline $\mathrm{C}(1)$ & $0.1744(3)$ & $0.0074(2)$ & $0.64418(7)$ & 0.0272 \\
\hline $\mathrm{O}(1)$ & $-0.0131(2)$ & $-0.00808(15)$ & $0.63326(5)$ & 0.0372 \\
\hline $\mathrm{O}(2)$ & $0.2875(2)$ & $-0.08719(14)$ & $0.66628(5)$ & 0.0338 \\
\hline $\mathrm{C}(2)$ & $0.5128(3)$ & $-0.0455(2)$ & $0.67259(7)$ & 0.0279 \\
\hline $\mathrm{C}(3)$ & $0.5224(3)$ & $0.10103(19)$ & $0.65832(7)$ & 0.0268 \\
\hline $\mathrm{C}(4)$ & $0.2681(3)$ & $0.22546(19)$ & $0.60896(6)$ & 0.0250 \\
\hline $\mathrm{C}(5)$ & $0.0492(3)$ & $0.23623(18)$ & $0.58654(6)$ & 0.0255 \\
\hline $\mathrm{C}(6)$ & $0.0273(3)$ & $0.36555(18)$ & $0.56016(6)$ & 0.0247 \\
\hline $\mathrm{C}(7)$ & $-0.1509(3)$ & $0.3533(2)$ & $0.52461(6)$ & 0.0286 \\
\hline $\mathrm{C}(8)$ & $-0.1670(3)$ & $0.4759(2)$ & $0.49525(6)$ & 0.0254 \\
\hline $\mathrm{C}(9)$ & $-0.3523(3)$ & $0.5568(2)$ & $0.49558(6)$ & 0.0282 \\
\hline $\mathrm{C}(10)$ & $-0.3650(3)$ & $0.6713(2)$ & $0.4694996)$ & 0.0291 \\
\hline $\mathrm{C}(11)$ & $-0.1896(3)$ & $0.7070(2)$ & $0.44295(6)$ & 0.0265 \\
\hline $\mathrm{C}(12)$ & $-0.0042(3)$ & $0.6277(2)$ & $0.44124(6)$ & 0.0271 \\
\hline $\mathrm{C}(14)$ & $0.0046(3)$ & $0.5123(2)$ & $0.46747(6)$ & 0.0276 \\
\hline $\mathrm{C}(15)$ & $0.5622(4)$ & $0.1983(2)$ & $0.69667(7)$ & 0.0337 \\
\hline $\mathrm{C}(16)$ & $0.3862(4)$ & $0.1977(2)$ & $0.73178(7)$ & 0.0327 \\
\hline $\mathrm{C}(17)$ & $0.3952(4)$ & $0.1100(2)$ & $0.76777(7)$ & 0.0381 \\
\hline $\mathrm{C}(19)$ & $0.2263(5)$ & $0.1062(3)$ & $0.79885(7)$ & 0.0429 \\
\hline $\mathrm{C}(20)$ & $0.0507(4)$ & $0.1935(3)$ & $0.79521(8)$ & 0.0447 \\
\hline $\mathrm{O}(3)$ & $0.0440(4)$ & $0.2834(3)$ & $0.76017(8)$ & 0.0438 \\
\hline $\mathrm{O}(4)$ & $0.2084(4)$ & $0.2844(2)$ & $0.72846(7)$ & 0.0383 \\
\hline $\mathrm{O}(5)$ & $0.4162(3)$ & $0.30451(15)$ & $0.60299(5)$ & 0.0352 \\
\hline $\mathrm{C}(21)$ & $-0.0257(3)$ & $0.46969(15)$ & $0.59087(5)$ & 0.0291 \\
\hline & $-0.2126(3)$ & $0.82583(14)$ & $0.42006(4)$ & 0.0338 \\
\hline & $-0.0390(4)$ & $0.8667(2)$ & $0.39126(7)$ & 0.0377 \\
\hline
\end{tabular}


Table 3: Atomic coordinates and isotropic thermal parameters $\left(\AA^{2}\right)$ of hydrogen atoms

\begin{tabular}{|c|c|c|c|c|}
\hline Atom & $\mathbf{X}$ & $\mathrm{y}$ & $\mathrm{Z}$ & $\mathrm{U}_{\text {iso }}$ \\
\hline & & & & \\
\hline $\mathrm{H}(1)$ & $0.042(6)$ & $0.537(3)$ & $0.5839(9)$ & $0.06(1)$ \\
\hline $\mathrm{H}(21)$ & 0.5556 & -0.0547 & 0.7045 & 0.0335 \\
\hline $\mathrm{H}(22)$ & 0.6130 & -0.1008 & 0.6538 & 0.0335 \\
\hline $\mathrm{H}(31)$ & 0.6484 & 0.1220 & 0.6383 & 0.0321 \\
\hline $\mathrm{H}(51)$ & -0.0681 & 0.2335 & 0.6097 & 0.0307 \\
\hline $\mathrm{H}(52)$ & 0.0311 & 0.1588 & 0.5659 & 0.0307 \\
\hline $\mathrm{H}(61)$ & 0.1676 & 0.3857 & 0.5444 & 0.0296 \\
\hline $\mathrm{H}(71)$ & -0.2949 & 0.3396 & 0.5397 & 0.0343 \\
\hline $\mathrm{H}(72)$ & -0.1173 & 0.2742 & 0.5055 & 0.0343 \\
\hline $\mathrm{H}(101)$ & -0.4789 & 0.5321 & 0.5150 & 0.0338 \\
\hline $\mathrm{H}(121)$ & -0.5003 & 0.7275 & 0.4699 & 0.0349 \\
\hline $\mathrm{H}(131)$ & 0.1214 & 0.6523 & 0.4216 & 0.0325 \\
\hline $\mathrm{H}(141)$ & 0.1379 & 0.4545 & 0.4662 & 0.0331 \\
\hline $\mathrm{H}(142)$ & 0.7041 & 0.1743 & 0.7111 & 0.0405 \\
\hline $\mathrm{H}(161)$ & 0.5723 & 0.2907 & 0.6841 & 0.0405 \\
\hline $\mathrm{H}(171)$ & 0.5241 & 0.0494 & 0.7713 & 0.0457 \\
\hline $\mathrm{H}(181)$ & 0.2316 & 0.0404 & 0.8238 & 0.0514 \\
\hline $\mathrm{H}(191)$ & -0.0698 & 0.1917 & 0.8177 & 0.0537 \\
\hline $\mathrm{H}(201)$ & 0.0804 & 0.3479 & 0.7578 & 0.0525 \\
\hline $\mathrm{H}(211)$ & -0.0778 & 0.3480 & 0.7029 & 0.0459 \\
\hline $\mathrm{H}(212)$ & 0.0986 & 0.9538 & 0.3770 & 0.0453 \\
\hline $\mathrm{H}(213)$ & -0.0164 & 0.8774 & 0.4089 & 0.0453 \\
\hline & & 0.7974 & 0.3678 & 0.0453 \\
\hline
\end{tabular}


Table 4: Anisotropic thermal parameters $\left(\AA^{2}\right)$

\begin{tabular}{|c|l|l|l|l|l|c|}
\hline Atom & $\mathrm{U}_{11}$ & $\mathrm{U}_{22}$ & $\mathrm{U}_{33}$ & $\mathrm{U}_{23}$ & $\mathrm{U}_{13}$ & $\mathrm{U}_{12}$ \\
\hline & & & & & & \\
\hline $\mathrm{N}(1)$ & $0.0173(8)$ & $0.0215(7)$ & $0.0303(8)$ & $0.0015(6)$ & $0.0022(7)$ & $0.0000(7)$ \\
\hline $\mathrm{C}(1)$ & $0.021(1)$ & $0.025(1)$ & $0.035(1)$ & $0.0062(8)$ & $0.0062(8)$ & $0.0023(9)$ \\
\hline $\mathrm{O}(1)$ & $0.0214(8)$ & $0.0303(8)$ & $0.0599(9)$ & $0.0113(7)$ & $0.0032(7)$ & $-0.0021(7)$ \\
\hline $\mathrm{O}(2)$ & $0.0236(7)$ & $0.0270(7)$ & $0.0507(8)$ & $0.0141(7)$ & $0.0057(7)$ & $0.0015(6)$ \\
\hline $\mathrm{C}(2)$ & $0.022(1)$ & $0.0263(9)$ & $0.035(1)$ & $0.0013(8)$ & $0.0002(8)$ & $0.0023(9)$ \\
\hline $\mathrm{C}(3)$ & $0.0183(9)$ & $0.0238(9)$ & $0.038(1)$ & $0.0024(8)$ & $0.0011(8)$ & $-0.0002(8)$ \\
\hline $\mathrm{C}(4)$ & $0.024(1)$ & $0.0211(9)$ & $0.0299(9)$ & $0.0011(8)$ & $0.0079(8)$ & $-0.0014(9)$ \\
\hline $\mathrm{C}(5)$ & $0.0256(11)$ & $0.0217(9)$ & $0.029(1)$ & $0.0027(8)$ & $-0.0001(8)$ & $-0.0027(8)$ \\
\hline $\mathrm{C}(6)$ & $0.025(1)$ & $0.0224(9)$ & $0.0263(8)$ & $0.0001(7)$ & $0.0018(8)$ & $-0.0015(9)$ \\
\hline $\mathrm{C}(7)$ & $0.029(1)$ & $0.028(1)$ & $0.0288(9)$ & $0.0009(8)$ & $-0.0014(8)$ & $-0.0009(9)$ \\
\hline $\mathrm{C}(8)$ & $0.028(1)$ & $0.0253(9)$ & $0.0235(8)$ & $-0.0027(8)$ & $-0.0030(8)$ & $-0.0007(9)$ \\
\hline $\mathrm{C}(9)$ & $0.024(1)$ & $0.0346(11)$ & $0.0258(9)$ & $-0.0016(8)$ & $0.0012(8)$ & $-0.0014(9)$ \\
\hline $\mathrm{C}(10)$ & $0.027(1)$ & $0.0325(11)$ & $0.0282(9)$ & $-0.0048(8)$ & $-0.0018(8)$ & $0.0062(9)$ \\
\hline $\mathrm{C}(11)$ & $0.031(1)$ & $0.0247(9)$ & $0.0239(8)$ & $-0.0017(8)$ & $-0.0039(8)$ & $0.0026(9)$ \\
\hline $\mathrm{C}(12)$ & $0.028(1)$ & $0.0294(9)$ & $0.0234(8)$ & $0.0001(8)$ & $0.0016(8)$ & $0.003(1)$ \\
\hline $\mathrm{C}(13)$ & $0.027(1)$ & $0.030(1)$ & $0.0256(8)$ & $0.0001(8)$ & $-0.0011(8)$ & $0.0027(9)$ \\
\hline $\mathrm{C}(14)$ & $0.026(1)$ & $0.030(1)$ & $0.0452(11)$ & $-0.0020(9)$ & $-0.0078(9)$ & $-0.003(1)$ \\
\hline $\mathrm{C}(15)$ & $0.0305(11)$ & $0.032(1)$ & $0.035(1)$ & $-0.0122(9)$ & $-0.0097(9)$ & $-0.000(1)$ \\
\hline $\mathrm{C}(16)$ & $0.0380(12)$ & $0.0374(12)$ & $0.0388(11)$ & $-0.011(1)$ & $-0.007(1)$ & $0.0087(11)$ \\
\hline $\mathrm{C}(17)$ & $0.0489(14)$ & $0.0451(13)$ & $0.035(1)$ & $-0.012(1)$ & $-0.0022(11)$ & $0.0041(13)$ \\
\hline $\mathrm{C}(18)$ & $0.0365(13)$ & $0.0545(14)$ & $0.0432(12)$ & $-0.0215(12)$ & $-0.0014(11)$ & $0.0013(13)$ \\
\hline $\mathrm{C}(19)$ & $0.0351(13)$ & $0.0487(13)$ & $0.0475(12)$ & $-0.0238(11)$ & $-0.0103(11)$ & $0.0125(12)$ \\
\hline $\mathrm{C}(20)$ & $0.0363(12)$ & $0.0347(11)$ & $0.0437(11)$ & $-0.014(1)$ & $-0.0147(11)$ & $0.0064(11)$ \\
\hline $\mathrm{O}(3)$ & $0.0256(7)$ & $0.0290(7)$ & $0.0510(8)$ & $0.0093(7)$ & $-0.0000(7)$ & $-0.0055(7)$ \\
\hline $\mathrm{O}(4)$ & $0.0319(8)$ & $0.0239(7)$ & $0.0315(7)$ & $-0.0028(6)$ & $0.0012(6)$ & $-0.0013(7)$ \\
\hline $\mathrm{O}(5)$ & $0.0391(9)$ & $0.0264(7)$ & $0.0360(7)$ & $0.0045(6)$ & $0.0022(7)$ & $0.0078(7)$ \\
\hline $\mathrm{C}(21)$ & $0.0490(14)$ & $0.028(1)$ & $0.036(1)$ & $0.0021(9)$ & $0.0074(11)$ & $0.0007(11)$ \\
\hline
\end{tabular}


Table 5: Bond lengths (Å)

\begin{tabular}{|c|c|c|c|}
\hline $\mathrm{N}(1)-\mathrm{C}(1)$ & $1.381(3)$ & $\mathrm{C}(8)-\mathrm{C}(13)$ & $1.390(3)$ \\
\hline $\mathrm{N}(1)-\mathrm{C}(3)$ & $1.469(2)$ & $\mathrm{C}(9)-\mathrm{C}(10)$ & $1.391(3)$ \\
\hline $\mathrm{N}(1)-\mathrm{C}(4)$ & $1.401(2)$ & $\mathrm{C}(10)-\mathrm{C}(11)$ & $1.384(3)$ \\
\hline $\mathrm{C}(1)-\mathrm{O}(1)$ & $1.202(3)$ & $\mathrm{C}(11)-\mathrm{C}(12)$ & $1.384(3)$ \\
\hline $\mathrm{C}(1)-\mathrm{O}(2)$ & $1.348(2)$ & $\mathrm{C}(11)-\mathrm{O}(5)$ & $1.381(2)$ \\
\hline $\mathrm{O}(2)-\mathrm{C}(2)$ & $1.451(3)$ & $\mathrm{C}(12)-\mathrm{C}(13)$ & $1.400(3)$ \\
\hline $\mathrm{C}(2)-\mathrm{C}(3)$ & $1.529(3)$ & $\mathrm{C}(14)-\mathrm{C}(15)$ & $1.508(3)$ \\
\hline $\mathrm{C}(3)-\mathrm{C}(14)$ & $1.530(3)$ & $\mathrm{C}(15)-\mathrm{C}(16)$ & $1.395(3)$ \\
\hline $\mathrm{C}(4)-\mathrm{C}(5)$ & $1.502(3)$ & $\mathrm{C}(15)-\mathrm{C}(20)$ & $1.394(3)$ \\
\hline $\mathrm{C}(4)-\mathrm{O}(3)$ & $1.215(2)$ & $\mathrm{C}(16)-\mathrm{C}(17)$ & $1.394(3)$ \\
\hline $\mathrm{C}(5)-\mathrm{C}(6)$ & $1.524(3)$ & $\mathrm{C}(17)-\mathrm{C}(18)$ & $1.388(4)$ \\
\hline $\mathrm{C}(6)-\mathrm{C}(7)$ & $1.532(3)$ & $\mathrm{C}(18)-\mathrm{C}(19)$ & $1.387(4)$ \\
\hline $\mathrm{C}(6)-\mathrm{O}(4)$ & $1.430(2)$ & $\mathrm{C}(19)-\mathrm{C}(20)$ & $1.386(3)$ \\
\hline $\mathrm{C}(7)-\mathrm{C}(8)$ & $1.516(3)$ & $\mathrm{O}(4)-\mathrm{H}(1)$ & $0.82(3)$ \\
\hline $\mathrm{C}(8)-\mathrm{C}(9)$ & $1.391(3)$ & $\mathrm{O}(5)-\mathrm{C}(21)$ & $1.430(3)$ \\
\hline
\end{tabular}

Note - geometrically-positioned $\mathrm{H}$ atoms have been excluded

Table 6: Bond angles $\left({ }^{\circ}\right)$

\begin{tabular}{|c|c|r|c|}
\hline $\mathrm{C}(1)-\mathrm{N}(1)-\mathrm{C}(3)$ & $111.97(15)$ & $\mathrm{C}(7)-\mathrm{C}(8)-\mathrm{C}(13)$ & $120.92(18)$ \\
\hline $\mathrm{C}(1)-\mathrm{N}(1)-\mathrm{C}(4)$ & $127.35(16)$ & $\mathrm{C}(9)-\mathrm{C}(8)-\mathrm{C}(13)$ & $117.77(17)$ \\
\hline $\mathrm{C}(3)-\mathrm{N}(1)-\mathrm{C}(4)$ & $119.94(16)$ & $\mathrm{C}(8)-\mathrm{C}(9)-\mathrm{C}(10)$ & $121.34(18)$ \\
\hline $\mathrm{N}(1)-\mathrm{C}(1)-\mathrm{O}(1)$ & $128.38(19)$ & $\mathrm{C}(9)-\mathrm{C}(10)-\mathrm{C}(11)$ & $119.71(18)$ \\
\hline $\mathrm{N}(1)-\mathrm{C}(1)-\mathrm{O}(2)$ & $109.37(16)$ & $\mathrm{C}(10)-\mathrm{C}(11)-\mathrm{C}(12)$ & $120.46(18)$ \\
\hline $\mathrm{O}(1)-\mathrm{C}(1)-\mathrm{O}(2)$ & $122.25(19)$ & $\mathrm{C}(10)-\mathrm{C}(11)-\mathrm{O}(5)$ & $115.56(18)$ \\
\hline $\mathrm{C}(1)-\mathrm{O}(2)-\mathrm{C}(2)$ & $110.47(15)$ & $\mathrm{C}(12)-\mathrm{C}(11)-\mathrm{O}(5)$ & $123.96(18)$ \\
\hline $\mathrm{O}(2)-\mathrm{C}(2)-\mathrm{C}(3)$ & $105.96(16)$ & $\mathrm{C}(11)-\mathrm{C}(12)-\mathrm{C}(13)$ & $118.92(18)$ \\
\hline $\mathrm{N}(1)-\mathrm{C}(3)-\mathrm{C}(2)$ & $101.09(16)$ & $\mathrm{C}(8)-\mathrm{C}(13)-\mathrm{C}(12)$ & $121.78(19)$ \\
\hline $\mathrm{N}(1)-\mathrm{C}(3)-\mathrm{C}(14)$ & $113.24(17)$ & $\mathrm{C}(3)-\mathrm{C}(14)-\mathrm{C}(15)$ & $114.41(17)$ \\
\hline $\mathrm{C}(2)-\mathrm{C}(3)-\mathrm{C}(14)$ & $113.85(17)$ & $\mathrm{C}(14)-\mathrm{C}(15)-\mathrm{C}(16)$ & $121.3(2)$ \\
\hline $\mathrm{N}(1)-\mathrm{C}(4)-\mathrm{C}(5)$ & $118.74(16)$ & $\mathrm{C}(14)-\mathrm{C}(15)-\mathrm{C}(20)$ & $120.2(2)$ \\
\hline $\mathrm{N}(1)-\mathrm{C}(4)-\mathrm{O}(3)$ & $117.89(18)$ & $\mathrm{C}(16)-\mathrm{C}(15)-\mathrm{C}(20)$ & $118.5(2)$ \\
\hline $\mathrm{C}(5)-\mathrm{C}(4)-\mathrm{O}(3)$ & $123.36(17)$ & $\mathrm{C}(15)-\mathrm{C}(16)-\mathrm{C}(17)$ & $120.6(2)$ \\
\hline $\mathrm{C}(4)-\mathrm{C}(5)-\mathrm{C}(6)$ & $111.92(16)$ & $\mathrm{C}(16)-\mathrm{C}(17)-\mathrm{C}(18)$ & $120.1(2)$ \\
\hline $\mathrm{C}(5)-\mathrm{C}(6)-\mathrm{C}(7)$ & $111.02(16)$ & $\mathrm{C}(17)-\mathrm{C}(18)-\mathrm{C}(19)$ & $119.4(2)$ \\
\hline $\mathrm{C}(5)-\mathrm{C}(6)-\mathrm{O}(4)$ & $107.55(14)$ & $\mathrm{C}(18)-\mathrm{C}(19)-\mathrm{C}(20)$ & $120.5(2)$ \\
\hline $\mathrm{C}(7)-\mathrm{C}(6)-\mathrm{O}(4)$ & $110.41(16)$ & $\mathrm{C}(15)-\mathrm{C}(20)-\mathrm{C}(19)$ & $120.7(2)$ \\
\hline $\mathrm{C}(6)-\mathrm{C}(7)-\mathrm{C}(8)$ & $112.90(16)$ & $\mathrm{C}(6)-\mathrm{O}(4)-\mathrm{H}(1)$ & $109 .(2)$ \\
\hline $\mathrm{C}(7)-\mathrm{C}(8)-\mathrm{C}(9)$ & $121.30(18)$ & $\mathrm{C}(11)-\mathrm{O}(5)-\mathrm{C}(21)$ & $118.22(17)$ \\
\hline
\end{tabular}

Note - geometrically-positioned $\mathrm{H}$ atoms have been excluded 